LA-14296-T

Thesis

Approved for public release;

distribution is unlimited

\title{
Improvement of Photon Buildup Factors for
}

Radiological Assessment 
This thesis was accepted by the Department of Nuclear Engineering, North Carolina State University, Raleigh, North Carolina, in partial fulfillment of the requirements for the degree of Master of Science. The text and illustrations are the independent work of the author, and only the front matter has been edited by the IMR-CAS Writing and Editing Staff to conform with Department of Energy and Los Alamos National Laboratory publication policies.

Los Alamos National Laboratory, an affirmative action/ equal opportunity employer, is operated by Los Alamos National Security, LLC, for the National Nuclear Security Administration of the U.S. Department of Energy under contract DE-AC52-06NA25396.

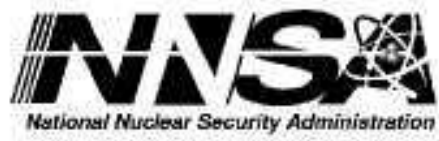

This report was prepared as an account of work sponsored by an agency of the U.S. Government. Neither Los Alamos National Securty, LLC, the U.S. Government nor any agency thereof, nor any of their employees make any warranty, express or implied, or assume any legal liability or responsibility for the accuracy, completeness, or usefulness of any information, apparatus, product, or process disclosed, or represent that its use would not infringe privately owned rights. Reference herein to any specific commercial product, process, or service by trade name, trademark, manufacturer, or otherwise does not necessarily constitute or imply its endorsement, recommendation, or favoring by Los Alamos National, LLC, the U.S. Government, or any agency thereof. The views and opinions of authors expressed herein do not necessarily state or reflect those of Los Alamos National Security, LLC, the U.S. Government, or any agency thereof. Los Alamos National Laboratory strongly supports academic freedom and a researcher's right to publish; as an institution, however, the Laboratory does not endorse the viewpoint of a publication or guarantee its technical correctness. 
LA-14296-T

Thesis

Issued. July 2006

Improvement of Photon Buildup Factors for

Radiological Assessment

Fritz Gordon Schimers

- Los Alamos NATIONAL LABORATORY 



\section{ABSTRACT}

SCHIRMERS, FRITZ GORDON. Improvement of Photon Buildup Factors for Radiological Assessment. (Under the direction of Man-Sung Yim.)

Slant-path buildup factors for photons between $\mathrm{l} \mathrm{keV}$ and $10 \mathrm{MeV}$ for nine radiation shielding materials (air, aluminum, concrete, iron, lead, leaded glass, polyethylene, stainless steel, and water) are calculated with the most recent cross-section data available using Monte Carlo and discrete ordinates methods. Discrete ordinates calculations use a 244-group energy structure that is based on previous research at Los Alamos National Laboratory (LANL), but extended with the results of this thesis, and its focused studies on low-energy photon transport and the effects of group widths in multigroup calculations. Buildup factor calculations in discrete ordinates benefit from coupled photon/electron cross sections to account for secondary photon effects. Also, ambient dose equivalent (herein referred to as dose) buildup factors were analyzed at lower energies where corresponding response functions do not exist in literature. The results of these studies are directly applicable to radiation safety at LANL, where the dose modeling tool Pandemonium is used to estimate worker dose in plutonium handling facilities. Buildup factors determined in this thesis will be used to enhance the code's modeling capabilities, but should be of interest to the radiation shielding community. 


\title{
Improvement of Photon Buildup Factors for Radiological Assessment
}

\author{
by
}

FRITZ GORDON SCHIRMERS

\author{
A thesis submitted to the Graduate Faculty of \\ North Carolina State University \\ in partial fulfillment of the \\ requirements for the Degree of \\ Master of Science
}

\section{NUCLEAR ENGINEERING}

\author{
Raleigh, North Carolina
}

2006

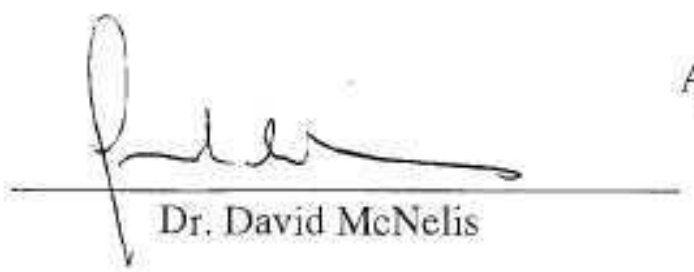

Approved by:
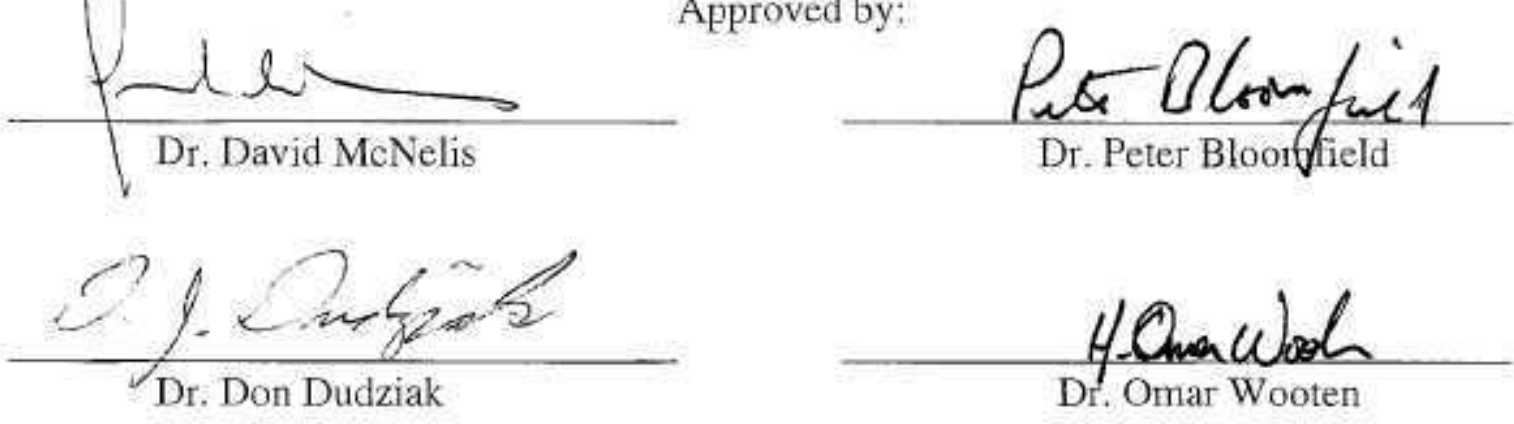

Dr. Omar Wooten

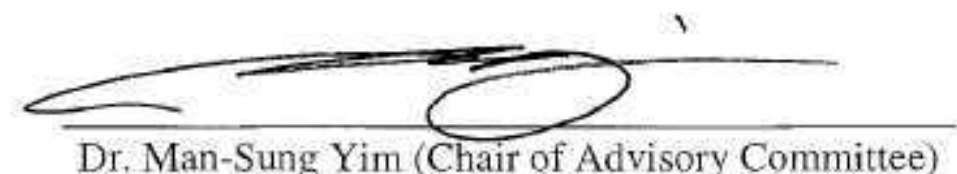




\section{BIOGRAPHY}

1 was born in St. Cloud, Minnesota in 1982 and moved to Ramona, Califomia in 1986. After graduating from Ramona High School in 2000 , I went to the University of California. Los Angeles to obtain a Bachelors of Science in Mechanical Engineering in 2004. Immediately afterwards, I furthered my education by attending North Carolina State University to obtain a Masters of Science in Nuclear Engineering, which included a seven-month stay at Los Alamos National Laboratory in Los Alamos, New Mexico to work on this research on slantpath photon buildup factors. 


\section{ACKNOWLEDGEMENTS}

1 would like to thank my academic advisor Dr. Man-Sung Yim for the opportunity to work with him. I also appreciate his support to help me with obtaining the graduate research assistant poșition at Los Alamos National Laboratory. I would alșo like to thank Drs. David McNelis and Peter Bloomfield for their interest in this research and participating on my thesis committee.

While working at Los Alamos National Laboratory on this research, there are some individuals that made it memorable. I would like to thank the Drs. Donald Dudziak, Drew Kornreich, and Tom Farish for their interest and support to continue the work on the PANDEMONIUM code that were also instrumental in bringing me to Los Alamos. I am also extremely appreciative of everyone in the Stockpile Complex Modeling \& Analysis Group (D-2) at Los Alamos that made me teel as if 1 was a fellow member of the group and not a student.

I would like to acknowledge and thank my two mentors, Drs. Donald Dudziak and Omar Wooten, which became good friends over my tenure in Los Alamos. I extremely enjoyed their company that evolved into numerous different discussions on research, life, politics, fishing and humting.

I al so would like to thank my close set of friends at North Carolina State University that have made my graduate school experience enjoyable.

Lastly, I would like to thank my mom, dad, and sister for their love and support in my dreams and aspirations. 


\section{TABLE OF CONTENTS}

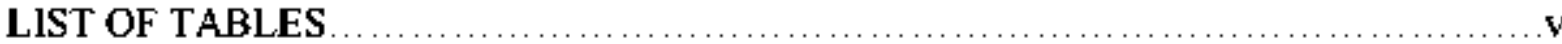

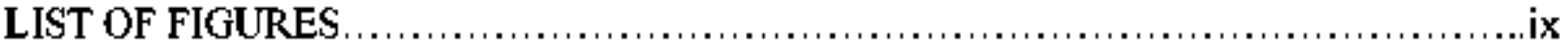

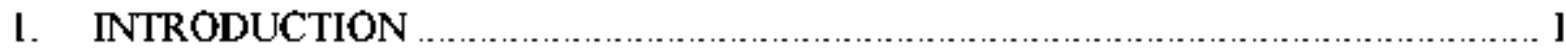

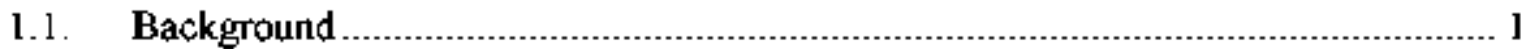

1.2. Pandemonium models................................................................................... ]

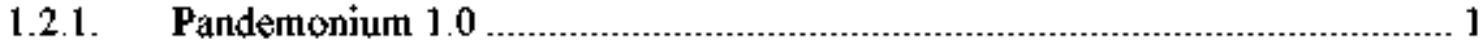

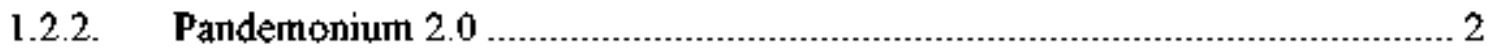

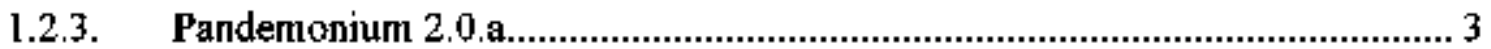

2. The PANDEMONIUM PHOTON MODEL ….................................................. 4

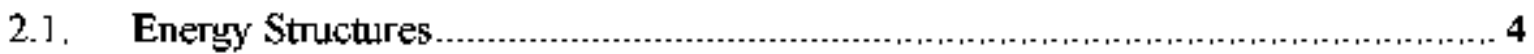

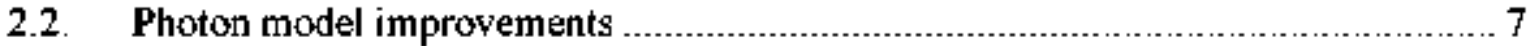

2.2.1. Energy range extension.................................................................................. 7

3. METHODOLOGY TO CALCULATE PHOTON BULDUP FACTORS

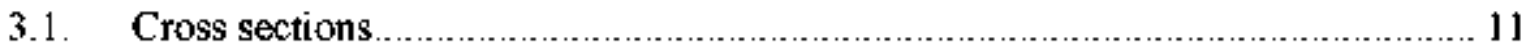

3.1.1. Cross-section libraries............................................................................ 13

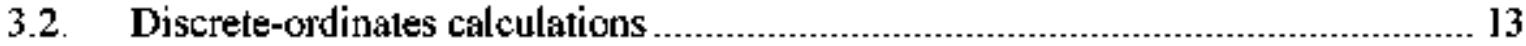

3.2.1. Group structure and cross sections ..................................................... 14

3.2.2. Quadrature details ...................................................................................... 26

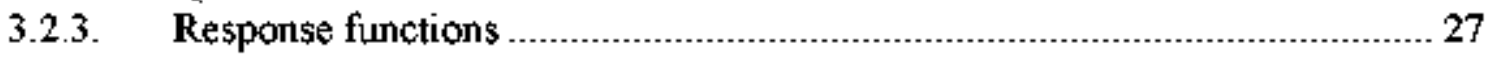

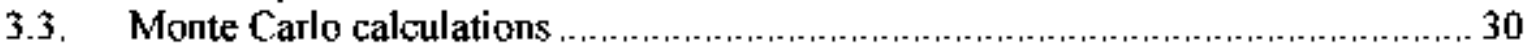

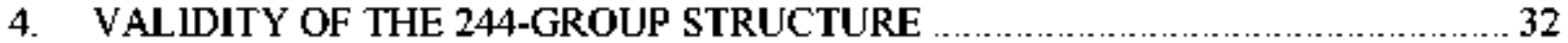

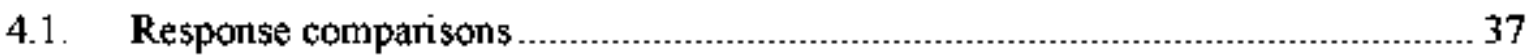

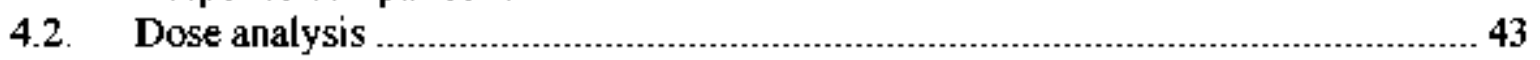

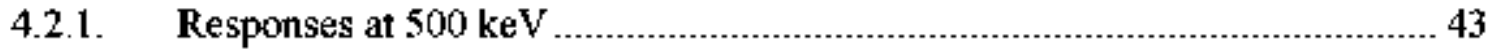

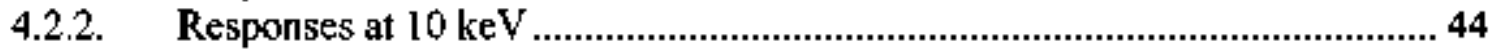

5. COMPARISONS OF RESULTS

5.1. Referenced buildup factor comparison ....................................................... 58

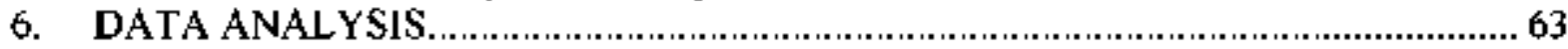

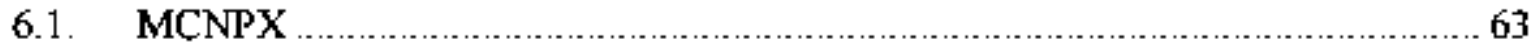

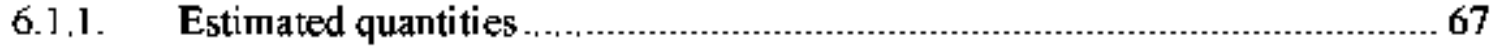

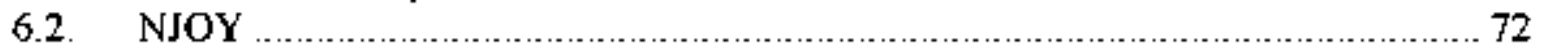

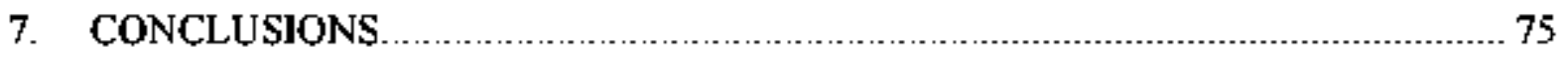

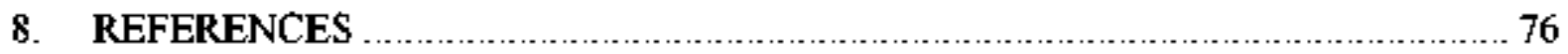

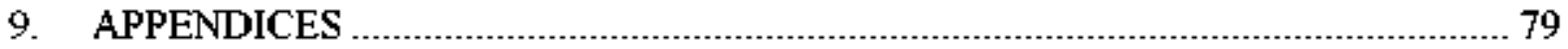

APPENDIX A: PARTISN BUILDUP FACTORS TABLES ........................................ 80

APPENDIX B: MCNPX BUILDUP FACTORS TABLES …................................ 333

APPENDIX C: EXPOSURE BULDUP FACTOR COMPARISONS .......................... 36]

APPENDIX D: SAMPLE INPUT FILES FOR CODES ............................................. 377

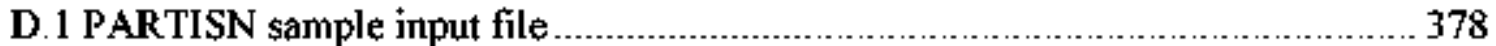

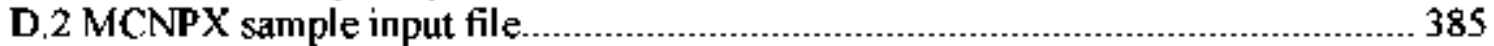

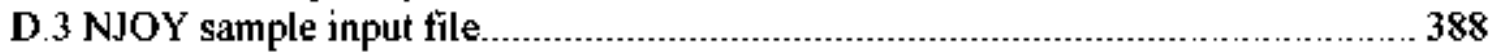

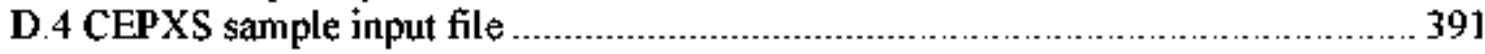




\section{LIST OF TABLES}

Table 2. 1: $\quad$ Energy group structure for photon model in PANDEMONIUM 2.0 _.......... 5

Table 3. 1: 220-group structure for discrete-ordinates photon buildup calculations of Wooten which includes the group index number, the energy of the group's upper limit, and the group width in keV............................................ Is

Table 3.2: Energy interval of group 75 and 76 in the original 220-group structure. ...... 18

Table 3.3: Linearly and logarithmically spaced intervals between group 75 (500 keV) and $76(450 \mathrm{keV})$.......................................................................... 18

Table 3.4: Total exit flux for linearly spaced intervals between modified groups 75 and

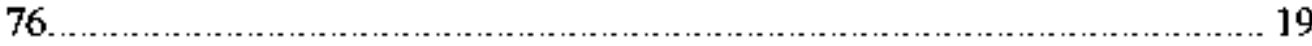

Table 3.5: Total exit flux for logarithmically spaced intervals between modified groups

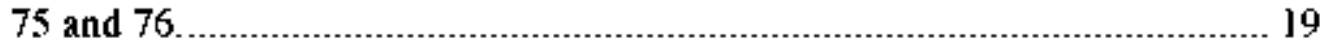

Table 3.6: MCNPX total flux for 500-keV photons incident on lead .......................... 19

Table 3.7: Percent difference for different group structures when compared to MCNPX for $500-\mathrm{keV}$ photons incident on lead................................................. 20

Table 3.8: $\quad$ PARTISN total flux for $50-\mathrm{keV}$ source group on lead................................ 2]

Table 3.9: MCNPX total flux for 50-keV photons incident on lead ......................... 2 ]

Table 3. 10: Percent difference for different group structures when compared to MCNPX for $50-\mathrm{keV}$ photons incident on lead.....................................................2]

Table 3.11: Lead thickness for the different mean-free-path thicknesses for both group structures at an energy of $50 \mathrm{keV}$.

Table 3. 12: 244-group structure for discrete-ordinates photon buildup calculations (for Pandemonium 2.0.a) which includes the group index number, the energy of the group's upper limit, and the group width in $\mathrm{keV}$.

Table 3.13: CEPXS particle interactions and physical phenomena accounted for in coupled cross section tables.................................................................25

Table 3. 14: First 50 guadratures and weights of the $S_{100}$ set used in PARTISN; the remaining 50 are negative values of these listed.

Table 3.15: Mass-energy absorption for air $\left(\mathrm{cm}^{2} / \mathrm{g}\right)$ and dose $\left(\mathrm{pSv}-\mathrm{cm}^{2}\right)$ response functions coefficients used for the PARTISN and MCNPX response functions. 28

Table 3. 16: $\quad$ arameters used in the discrete-ordinates calculations. ...............................30

Table 3.17: Different Response Names for the Type 2 Tally in the Monte Carlo code. ... 31

Table 4. 1 : Corresponding Attenuation Coefficient Values at the Group's Lower Energy for lead 33

Table 4.2: ENDF Cross-Section Values for CEPXS and MCNPX at the Group's Lower Energy for Lead. .................................................................. 36

Table 4.3: Responses for 500-keV photons nomally incident on a lead slab at $1 \mathrm{mfp}$... 38

Table 4.4: Responses for 10 -ke $V$ photons nomally incident on a lead slab at $1 \mathrm{mfp}$..... 38

Table 4.5: Percent difference between the MCNPX value and the different group

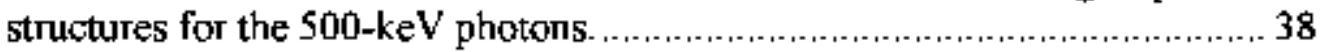

Table 4.6: $\quad$ Percent difference between the MCNPX value and the different group structures for the 10-keV photons........................................................ 38

Table 4.7: Lead slab thickness differences for different group structures. .................... 39 
Table 4.8: Checks for the $10-\mathrm{keV}$ and $500-\mathrm{keV}$ incidem photons for both energy group structures.

Table 4.9: Responses of the different CEPXS files for $500-\mathrm{keV}$ photons normally incident on a lead slab at $1 \mathrm{mfp}$ with the 220 -group structure.

Table 4. 10: Responses of the different CEPXS files for $500-\mathrm{keV}$ photons normally incident on a lead slab at $1 \mathrm{mfp}$ with the 244 -group structure.

Table 4.1 1: Percent difference between the MCNPX value and the different group structures with the different CEPXS files for $500-\mathrm{keV}$ photons......

Table 4.12: Responses of the different CEPXS files for 10-keV photons normally incident on a lead slab at $\mathrm{m}$ mp with the 220-group structure....................... 42

Table 4.13: Responses of the different CEPXS files for 10-keV photons normally incident on a lead slab at $\mathrm{l} \mathrm{mfp}$ with the 244-group structure....................... 42

Table 4. 14: Percent difference between the MCNPX value and the different group structures with the different CEPXS files for the 10-keV photons................ 42

Table 4. 15: Responses for $500-\mathrm{keV}$ photons nomally incident on a I-mfp lead slab with both dose response function coefficient $\mathrm{H}^{*}(10)$ schemes

Table 4. 16: Comparison of MCNPX and PARTISN codes' responses for $500-\mathrm{keV}$ photons normally incident on a l-mfp lead slab with two dose response function coefficient $H^{*}(10)$ schemes. .................................................. 44

Table 4. 17: Buildup factors for $500-\mathrm{keV}$ photons normally incident on a $1-\mathrm{mfp}$ lead slab with both dose response function coefficient $\mathrm{H}^{*}(10)$ schemes............. 44

Table 4. 18: Percent difference between the MCNPX and PARTISN buildup factors at $500 \mathrm{keV}$ with two dose response function coefficient $\mathrm{H}^{*}(\mathrm{I} 0)$ schemes.

Table 4. 19: Responses for $10-\mathrm{keV}$ photons normally incident on a 1 -mfp lead slab with both dose response function coefficient $\mathrm{H}^{*}(10)$ schemes.

Table 4.20: Comparison of MCNPX and PARTISN codes' responses for $10-\mathrm{keV}$ photons normally incident on a l-mfp lead slab with two dose response function coefficient $\mathrm{H}^{*}(10)$ schemes. .................................................. 45

Table 4.21: Buildup factors for $10-\mathrm{keV}$ photons normally incident on a 1-mfp lead slab with both dose response function coefficient $\mathrm{H}^{*}(10)$ schemes. ................... 45

Table 4.22: Percent difference between MCNPX and PARTISN Buildup factors at $10 \mathrm{keV}$ with two dose response function coefficient $\mathrm{H}^{*}(10)$ schemes. 45

Table 5.1: Glovebox materials and physical properties used for discrete-ordinates and Monte Carlo buildup-factor calculations. ............................................... 48

Table 5.2: Angles (relative to normal) at which the incident photons are implemented for the buildup factor calculations.

Table 5.3: Properties of buildup factor calculations by previous authors, including geometries, methods, and cross-section specifics [7] ............................... 60

Table 5.4: Exposure buildup factor comparison for iron for normally-incident photons .............................................................6l

Table 5.5: Exposure buildup factor comparison for water for normally-incident photons ............................................................. 62

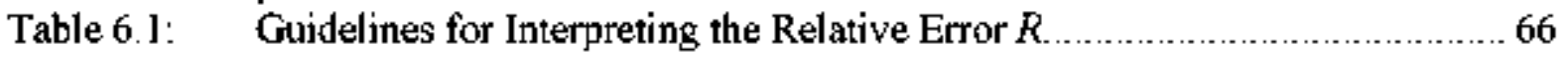

Table 6.2: Statistics for the three different MCNPX input decks ..................................67

Table 6.3: Figure of Merit for the three different MCNPX input decks ........................ 69

Table 6.4: Computer Time to nu the different MCNPX input decks ............................ 69 
Table 6.5: Mean and relative error for the uncollided and total radiation based on the different MCNPX input decks. ......................................................70

Table 6.6: $\quad 68 \%$ Confidence Interval for the three MCNPX Input Decks Uncollided and Total Radiation values........................................................................ 71

Table 6.7: Buildup Factor Percent Difference when varying the MCNPX NPS values.. 7]

Table 6.8: A comparison of the cross sections for lead with different NJOY files. ....... 73

Table A.l : $\quad$ Exit flux photon buildup factors for air. ............................................... 8 ]

Table A.2: Exposure photon buildup factors for air. ................................................ 88

Table A.3: Dose [extrapolation scheme] buildup factors for air. .................................. 95

Table A.4: Dose [constant scheme] photon buildup factors for air. .............................. 102

Table A.5: $\quad$ Exit flux photon buildup factors for aluminum. .................................... 109

Table A.6: Exposure photon buildup factors for aluminum. ................................... 116

Table A.7: Dose [extrapolation scheme] buildup factors for aluminum. .................. 123

Table A.8: Dose [constant scheme] photon buildup factors for aluminum. ................. 130

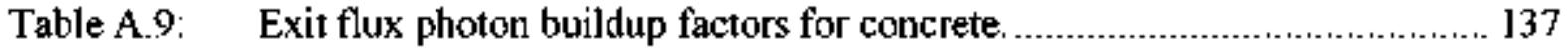

Table A. 10: Exposure photon buildup factors for concrete …................................. 144

Table A.l : $\quad$ Dose [extrapolation scheme] buildup factors for concrete. ........................ 15]

Table A. 12: Dose [constant scheme] photon buildup factors for concrete .................... 158

Table A.13: Exit flux photon buildup factors for iron. ........................................... 165

Table A.14: Exposure photon buildup factors for iron. ................................................ 172

Table A.15: Dose [extrapolation scheme] buildup factors for iton. ........................... 179

Table A. 16: Dose [constant scheme] photon buildup factors for iron. ........................... 186

Table A. 17: Exit flux photon buildup factors for lead ......................................... 193

Table A.18: Exposure photon buildup factors for lead ............................................. 200

Table A. 19: Dose [extrapolation scheme] buildup factors for lead. .......................... 207

Table A.20: Dose [constant scheme] photon buildup factors for lead ............................ 2 ]4

Table A.21 : Exit flux photon buildup factors for leaded glass................................... 22]

Table A.22: Exposure photon buildup factors for leaded glass . ................................ 228

Table A.23: Dose [extrapolation scheme] buildup factors for leaded glass................... 235

Table A.24: Dose [constant scheme] photon buildup factors for leaded glass................ 242

Table A.25: Exit flux photen buildup factors for polyethylene ................................. 249

Table A.26: Exposure photon buildup factors for polyethylene. .............................. 256

Table A.27: Dose [extrapolation scheme] buildup factors for polyethylene ................ 263

Table A.28: Dose [constant scheme] photon buildup factors for polyethylene ............. 270

Table A.29: Exit flux photon buildup factors for stainless steel............................... 277

Table A.30: Exposure photon buildup factors for stainless steel ................................ 284

Table A.31: Dose [extrapolation scheme] buildup factors for stainless steel................ 29]

Table A.32: Dose [constant scheme] photon buildup factors for stainless steel. ........... 298

Table A.33: Exit flux photon buildup factors for water............................................... 305

Table A.34: Exposure photon buildup factors for water............................................... 3 12

Table A.35: Dose [extrapolation scheme] buildup facters for water............................. 319

Table A.36: Dose [constant scheme] photon buildup factors for water. ...................... 326

Table B.l: $\quad$ Exit flux photon buildup facters for air. .......................................... 334

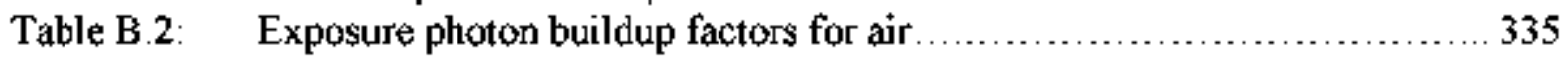

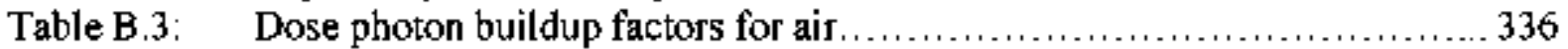

Table B 4: Exit flux photon buildup factors for aluminum....................... 337 
Table B.5:

Table B.6:

Table B.7:

Table B .8:

Table B.9:

Table B. I0:

Table B.ll:

Table B. 12 :

Table B. 13 :

Table B.14:

Table B.15:

Table B. 16

Table B. 17:

Table B. 18

Table B:19:

Table B.20:

Table B.21:

Table B. 22:

Table B.23:

Table B.24:

Table B.25:

Table B.26

Table B.27:

Table C.1:

Table C.2:

Table C.3:

Table C.4:

Table C.5:

Table C.6:

Table C. 7

Table C.8:

Table C.9.

Table C.10:

Table C.II :

Table C. 12
Exposure photon buildup factors for aluminum 338

Dose photon buildup factors for aluminum.............................. 339

Exit flux photon buildup factors for concrete ........................ 340

Exposure photon buildup factors for concrete .......................... 341

Dose photon buildup factors for concrete ............................ 342

Exit flux photon buildup factors for iron ................................... 343

Exposure photon buildup factors for iron ................................ $\$ 44$

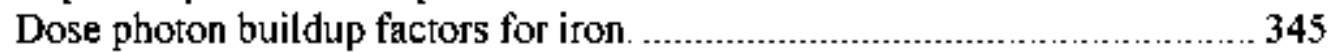

Exit flux photon buildup factors for lead ..................................346

Exposure photon buildup factors for lead ...............................347

Dose photon buildup factors for lead ................................ 348

Exit flux photon buildup factors for leaded . ............................... 349

Exposure photon buildup factors for leaded glass ........................350

Dose photon buildup factors for leaded glass ............................351

Exit flux photon buildup factors for polyethylene ..................... 352

Exposure photon buildup factors for polyethylene. ……......................... 353

Dose photon buildup factors for polyethylene.........................................354

Exit flux photon buildup factors for stainless steel................................. 355

Exposure photon buildup factors for stainless steel...................................356

Dose photon buildup factors for stainless steel..................................... 357

Exit flux photon buildup factors for water .............................................358

Exposure photon buildup factors for water..............................................359

Dose photon buildup factors for water …..............................................360

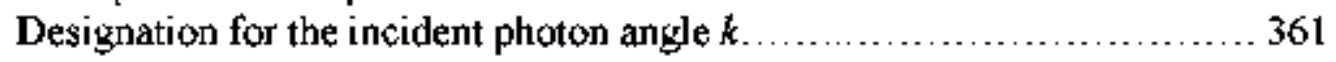

Exposure photon buildup factor comparisons for air ............................ 362

Exposure photon buildup factor comparisons for al uminum...................364

Exposure photon buildup factor comparisons for concrete.................. 366

Exposure photon buildup factor comparisons for iron ......................368

Exposure photon buildup factor comparisons for lead ..................... 370

Exposure photon buildup factor comparisons for water................... 372

Cosine values for the different author's buildup factor angles performed ....373

Corresponding optical thickness based on the different geomettries of

calculating exposure buildup factors .................................... 374

Comparable exposure buildup factors for the material concrete based on the

geometry implemented

375

Comparable exposure buildup factors for the material iron based on the geometry implemented.

Comparable exposure buildup factors for the material lead based on the

geometry implemented. 


\section{LIST OF FIGURES}

Figure 2.1: Geometry for previous angular buildup factors keeping (a) nomal slab thickness constant; and geometry for identifying (b) purely angular effect on buildup

Figure 2.2: $\quad$ Purely-angular effect of photon buildup is evident by comparing the results from (a) the slant-path and (b) the normal-incident case.

Figure 3.1: Modification of the PARTISN slab thickness to correspond to the MCNPX thickness

Figure 3.2: Extrapolation and constant scheme for the ICRP dose conversion coefficients (pSv-cm ${ }^{2}$ ) and the exposure response function of Berger, Hubbell, and Seltzer (MeV-cming).

Figure 4.1: Values of the mass attenuation coefficient ( $\mu / \rho)$ and mass energyabsorption coefficient $\left(\mu_{\text {el1 }} / \rho\right)$ of lead as a function of photon energy [23] .... 34

Figure 4.2: Macroscopic cross section at a given energy level in (a) a larger energy group compared to (b) a smaller energy group.

Figure 5.1: Optical escape path differences for normal, moderate, and oblique incident angles.

Figure 5.2: $\quad$ Purely-angular photon buildup factors for 10-MeV photons incident on

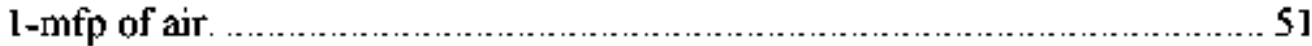

Figure 5.3: $\quad$ Purely-angular photon buildup factors for 10-MeV photons incident on

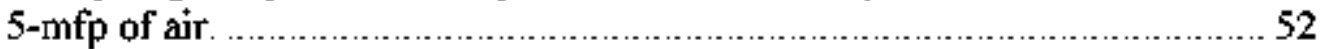

Figure 5.4: Purely-angular photon buildup factors for $10-\mathrm{MeV}$ photons incident on

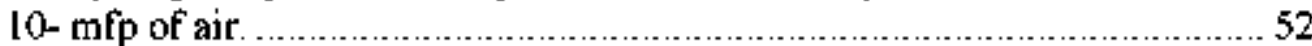

Figure 5.5: Purely-angular photon buildup factors for 1-MeV photons incident on $1-m f p$ of water............................................................................. $\$ 3$

Figure 5.6: Purely-angular photon buildup facters for 1-MeV photons incident on

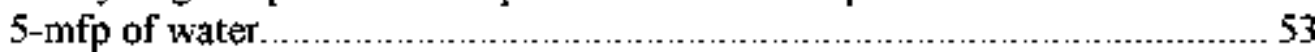

Figure 5.7: $\quad$ Purely-angular photon buildup factors for 1-MeV photons incident on 10 -mfp of water.

Figure 5.8: Purely-angular photon buildup factors for $10-\mathrm{keV}$ photons incident on

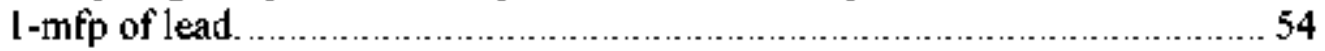

Figure 5.9: Purely-angular photon buildup factors for 10-keV photons incident on 5-mtp of lead. 55

Figure 5.10: Purely-angular photon buildup factors for $10-\mathrm{keV}$ photons incident on lo-mfp of lead. 


\section{INTRODUCTION}

\subsection{Background}

The plutonium facilities located at Los Alamos National Laboratory include rooms of gloveboxes manned by workers. One of the necessary tasks that must be done is modeling these facilities to ensure the workers radiological safety. PANDEMONIUM [ $\mathrm{I}]$ is a tool developed at Los Alamos that models these radiation facilities and complex radiation fields. This code determines the radiation dose received by workers given a set of source characteristics (nuclides, emitted radiation types and energy, material form, and density), physical distributions of sources and workers, and the shielding between them [2-4].

There are existing radiation transport codes that can model these facilities, such as the Monte Carlo N-Particle MCNPX [5] code that uses stochastic methods to stimulate particle transport using libraries of particle interaction cross sections, or the code ONEDANT [6] that solves the one-dimensional Boltzmann equation using the discrete-ordinates method. These codes are able to model complex geometries and compute the photon and neutron fluxes at almost any desired point in a given facility, but the main drawbacks with these codes are the difficulty to learn how to use them, and secondly, the more complex the model becomes, the longer the computer time it takes to obtain the desired results. Pandernonium, on the other hand, predicts time-dependent neutral particle dose fields with reasonable accuracy using two-dimensional physical and one-dimensional calculational models. It has been demonstrated by Wooten in Pandemonium 2.0 [7] that this code can compute doses in a plutonium facility within a fraction of the time of the previously used radiation transport codes with reliable accuracy.

\subsection{Pandemonium mode/s}

\subsubsection{Pandemonium 1.0}

The first version of Pandemonium (ㅁhoton $\underline{A}$ nd Neutron Dose Equivalent Model $\underline{Q}$ Nuclear Materials In Uncomplicated Geometry Models) [2] was developed by Komreich and Dooley. 
Pandemonium was developed to model LANL plutonium facilities, even though there are mumerous shielding software models already available. This was because of their unique need to model a nuclear processing facility from a radiation dose perspective. This timeindependent model determines dose rates in a facility based upon user-supplied source characteristics and geometrical layout of gloveboxes. Pandemonium 1.0 calculates doseequivalent rates for both neutrons and photons that compare reasonably well with Monte Carlo results, and with experiments. This version of the code that incorporated both neutron and photon transport theories would later be improved to simulate the time-dependence and changing dose fields that often exists within a glovebox facility.

Photons modeled in Pandemonium 1.0 span energies between $10 \mathrm{keV}$ and I MeV, which were represented in a 17 -photon-group structure. The photons that originate in an energy group remained in that group throughout the calculation and point kemel theory is applied to simulate attenuation and buildup of photons. Photon sources are determined from a library of mass-nomalized photon source strengths for the various transuranic isotopes, and photon buildup factors are applied to approximate the scattered photons in the different groups [2].

\subsubsection{Pandemonium 2.0}

In the second version of Pandemonium, Wooten implemented geometry and photon model improvements along with time dependence to produce a more realistic model representing doses that would be present in a transient glovebox facility. In Pandemonium 2.0, the glovebox models are based on blueprints of curently used gloveboxes at Los Alamos, including windows and gloveports rather than the simple slabs of lead, stainless steel, and hydrogenous shielding used for Pandemonium 1.0. The sources are modeled as solid spheres and spherical shells of user-defined radii. The dose calculations were defined to be at the constant height above the floor where the average worker's dosimeter would be.

The incorporation of time dependence in this version allows the necessary calculations to be perfomed to simulate the dynamic and transient nature of nuclear facilities. By introducing time as a variable, the sources and detectors are allowed to change positions and shielding is 
automatically determined by the code. In addition to dose rates, a time-integrated total dose calculation is performed, allowing the user to obtain valuable information about doses received during a specific process, rather than at a particular instant in time. The photon modeling capability of Pandemonium 2.0 was also improved with the maximum photon energy expanded from $1 \mathrm{MeV}$ to $10 \mathrm{MeV}$, allowing for the inclusion of higher energy fission photons, and by incorporating the most recent photoatomic cross-section data available.

\subsubsection{Pandemonium 2.0.a}

As noted by Wooten, Pandemonium 2.0 included modifications to incomporate more realistic glovebox features such as windows and gloveports to obtain more accurate estimates of the necessary shielding present to obtain more realistic doses. But all the materials necessary for these additional features were not incorporated. As a result, this research of calculating an exhaustive set of slant-path photon buildup factors for the five existing glovebox materials (aluminum, concrete, iron, lead, and water) and the four newly calculated glovebox materials (air, leaded glass, polyethylene, and stainless steel) will enable the desired realistic dose estimates to be obtained once these buildup factors are incorporated into Pandemonium.

The compilation of these buildup factors tor the nine glovebox materials was performed for al1 25 source energies present in Pandemonium 2.0. In Wooten's work, buildup factors were calculated for only 10 of these 25 source energies. To calculate the entire range of source energies, the energy group structure had to be extended down to an energy of $1 \mathrm{keV}$ with the inclusion of the most recent photoatomic cross-section data. Lastly, the results from this study on slant-path photon buildup factors are of interest not only to Pandemonium providing a more realistic glovebox composition, but also to the larger radiation shielding community. This study includes the most comprehensive comparisons of slant-path photon buildup for different transport calculation techniques to date for these nine materials. 


\section{The PANDEMONIUM PHOTON MODEL}

\subsection{Energy Structures}

In Pandemonium 1.0, the photon energy range was divided into seventeen different energy groups that spanned an energy range from $10 \mathrm{keV}$ to $1 \mathrm{MeV}$. Both Pandemonium 1.0 and 2.0 take a conservative approach assuming that all photons in a group exist at the higher energy limit of that group. In theory, for radiation transport in a multigroup structure, the photons' energies would be tracked and there would be cross-group communication within the different energy groups when these photons changed energy. But Pandemonium I.0 ignores cross-group communication and instead applies point kemel theory in each separate group. The buildup factors were attained by studying the photons within a specific energy group that downscattered to lower energy groups as a result of interactions within the different material shields.

A major difference between Pandemonium 1.0 and 2.0 is their buildup factors, and how they are determined. In Pandemonium I.0, spherical infunite media buildup factors are calculated using the Geometric Progression formula. In Pandemonium 2.0, the buildup factors are calculated with Monte Carlo and Discrete-Ordinates methods as a slab geometry which is much more appropriate for the study of gloveboxes. The Pandemonium $2.0^{\circ}$ s energy bin structure is shown in Table 2. 1. Pandemonium 2.0 further identifies the angular dependence of buildup because of the way the code performs its geometry calculation. In the past, angular buildup factors were studied by keeping the normal slab thickness constant when varying the different particle's incident angle on the material slab as shown in Figure 2.1(a). Wooten's research supporting Pandemonium 2.0 was the first to show the relationship between incident angle and angular buldup factor while keeping the uncollided (slant-path) photon slab thickness constant as shown in Figure 2. l(b). Figure 2.3 shows the uncollided photon path length is now the same in both the slant-path and normal case. As a result, Wooten's work identified the 'purely-angular effect' of photon buildup by maintaining the slant-path thickness constant through the process of adjusting the normal-path thickness as the photon's incident angle is varied on the given slab [7]. 
Table 2.1: Energy bin structure for photon model in PANDEMONIUM 2.0

\begin{tabular}{cccc}
\hline Bin & \multicolumn{3}{c}{ Energy (MeV) } \\
& lover limit & & upper limit \\
\hline 1 & 0 & - & 0.01 \\
2 & 0.01 & - & 0.015 \\
3 & 0.015 & - & 0.02 \\
4 & 0.02 & - & 0.03 \\
5 & 0.03 & - & 0.04 \\
6 & 0.04 & - & 0.05 \\
7 & 0.05 & - & 0.06 \\
8 & 0.06 & - & 0.08 \\
9 & 0.08 & - & 0.1 \\
10 & 0.1 & - & 0.15 \\
11 & 0.15 & - & 0.2 \\
12 & 0.2 & - & 0.3 \\
13 & 0.3 & - & 0.4 \\
14 & 0.4 & - & 0.5 \\
15 & 0.5 & - & 0.6 \\
16 & 0.6 & - & 0.8 \\
17 & 0.8 & - & 1 \\
18 & 1 & - & 1.5 \\
19 & 1.5 & - & 2 \\
20 & 2 & - & 3 \\
21 & 3 & - & 4 \\
22 & 4 & - & 5 \\
23 & 5 & - & 6 \\
24 & 6 & - & 8 \\
25 & 8 & - & 10 \\
\hline
\end{tabular}




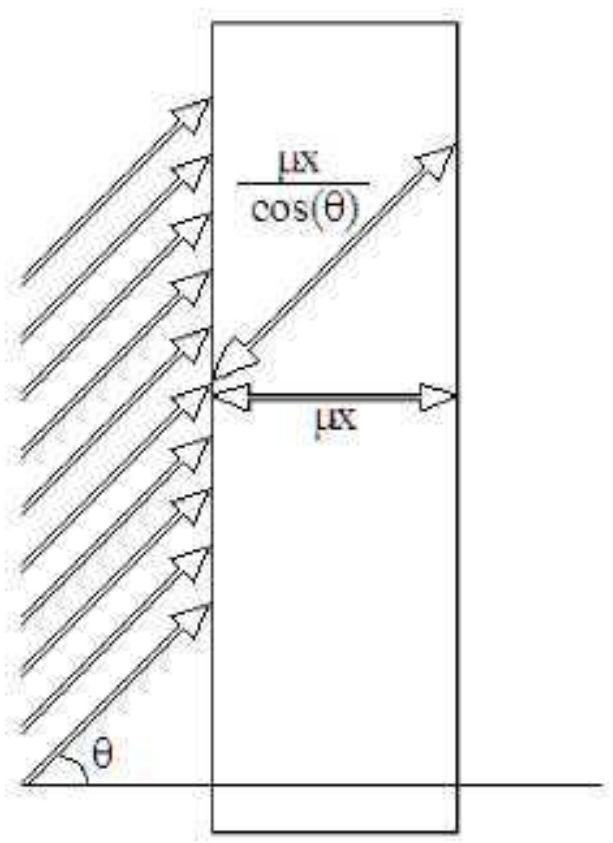

(a)

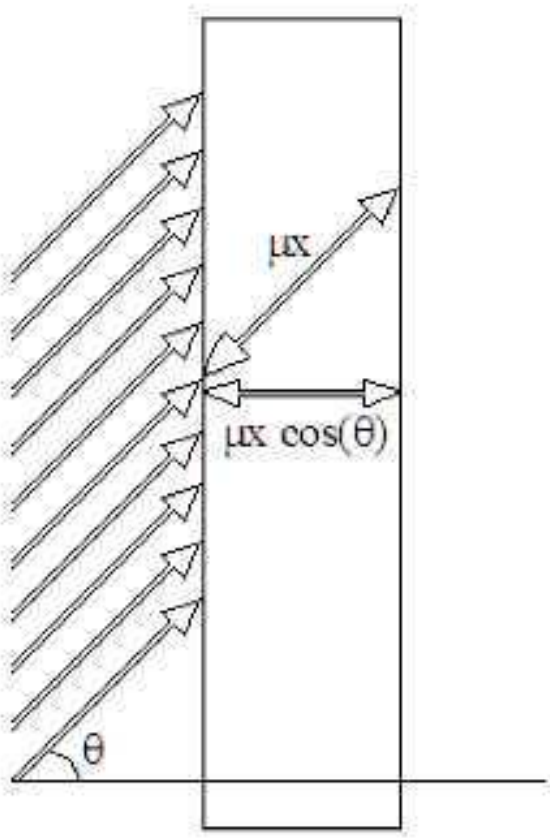

(b)

Figure 2.1: Geometry for previous angular buildup factors keeping (a) normal slab thickness constant, and geometry for identifying (b) purely angular effect on buildup.

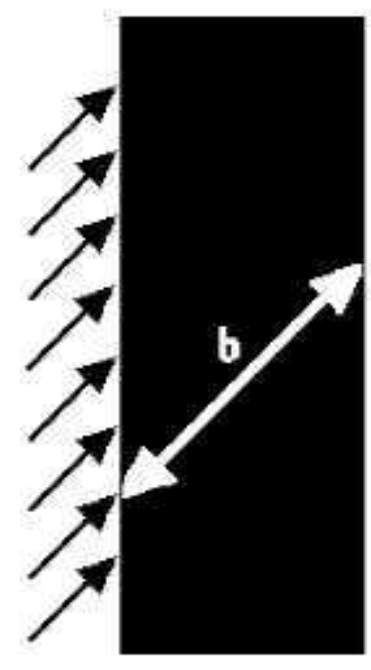

(a)

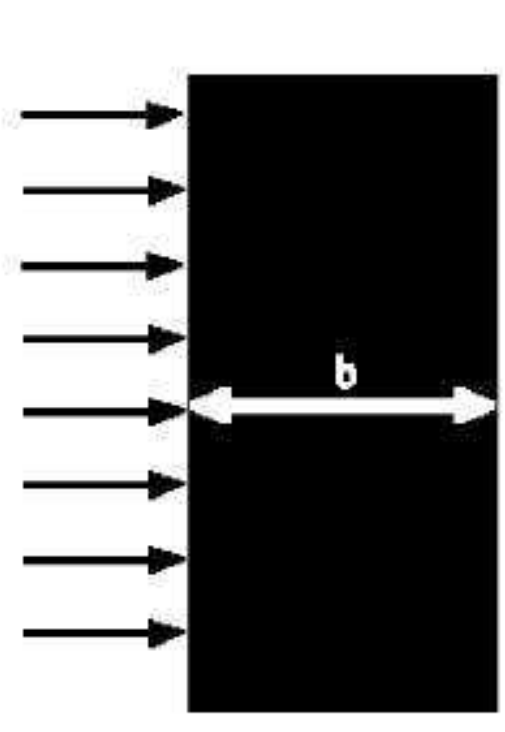

(b)

Figure 2.2: Purely-angular effect of photon buildup is evident by comparing the results from (a) the slant-path and (b) the normal-incident case. 


\subsection{Photon model Improvements}

\subsubsection{Energy range extension}

The incorporation of photons in Pandemonium 2.0 that spanned from $10 \mathrm{MeV}$ to $10 \mathrm{keV}$ accounted for higher energy penetrating photons produced during fission and to ensure the entire decay scheme of the transuranic photons of Plutonium-238, $-239,-240,-241,-242$ and Americum-24] were considered. The present research pertormed for Pandemonium 2.0.a further investigated the contribution to buildup factors from lower energy photons down to 1 $\mathrm{keV}$, and to obtain the desired buildup factor at a source energy of $10 \mathrm{keV}$. The buildup factors for Pandemonium 2.0.a used the same pointwise cross-section data, namely, the ENDF photoatomic data library and the photon mass attenuation coefficients derived from the National Institute of Standards and Technology (NIST), as Pandemonium 2.0 for consistency. 


\section{METHODOLOGY TO CALCULATE PHOTON BUILDUP FACTORS}

Pandemonium 1.0 applied point-isotropic buildup factors in glovebox geometries in which the source-to-detector line of sight intersects slab shields at oblique angles. Improvements made in version 2.0 provided more accurate angular buildup factors in slab geometry. In addition, buildup factors calculated in this work by transport calculations performed with the most recent cross sections and the extension of the multigroup structure from $\mathrm{l} \mathrm{keV}$ to 10 $\mathrm{MeV}$ with the 25 source energies, has been an improvement to Pandemonium 2.0 .

Since photon buildup factors were introduced, there have been numerous methods that use the continual improvements in the cross-section data to perform photon transport calculations for determining buildup factors. Moments method, discrete-ordinates, and Monte Carlo methods are the most widely used techniques that have been developed to calculate the particle flux densities. The moments method solves for the angular moments of the flux density in simple geometries, whereas discrete-ordinates methods determine flux density by directly numerically integrating a form of the transport equation in which the energy, angle, and space are discretized. The Monte Carlo method does not explicitly solve the transport equation, but instead obtains answers by simulating individual particles and recording aspects of their average behavior. These methods have provided a means to develop empirical formulas for buildup factors. Along with these methods, the development of photon cross sections with the inclusion of coherent scattering, the electron binding effect on incoherent scattering, bremsstrahlung, and fluorescence has greatly improved buildup factor studies and analysis [7-10]

Pandemonium 2.0 includes buildup factors calculated as shown in Figure 2.2, assuming that an oblique photon beam on a slab of given slant-path optical thickness, $b$, would have the same uncollided flux as a nomal photon beam on a slab of optical thickness $b$. As a result, the uncollided photon contribution would remain the same no matter the angle of photon incidence on the slab as long as the slant-path optical thickness is constant. These slant-path photon buildup factors were computed using both the discrete-ordinates and Monte Carlo photon transport codes with the most recent cross sections that include secondary-photon 
effects of fluorescence and bremsstrahlung, to determine the purely-angular effect of incident angle on the exit flux, exposure, and dose buildup factors. The Monte Carlo method was used as a benchmarking code to the discrete-ordinates photon transport calculations.

The photon build-up factor, $B$, is defined as the ratio of the total response from all photons to the response from uncollided photons after transmission through a slab of a given optical thickness (b). The definition of the photon buildup factor is [11]

$$
B_{x}=\frac{\int R_{x}(E) \phi(E) d E}{R_{x}\left(E_{0}\right) \phi_{0}\left(E_{0}\right)}
$$

where

$$
\begin{aligned}
R_{x}(E)= & \text { response function for quantity desired (flux, exposure, dose, etc), } \\
& \text { for flux (or number) buildup, } R_{x}(E)=1, \\
\phi(E)= & \text { total flux spectrum, and } \\
\phi_{0}\left(E_{0}\right)= & \text { uncollided flux at initial energy } E_{n} .
\end{aligned}
$$

The exposure response function is given by

$$
R_{\mathrm{eq}}=C \times E \times\left(\frac{\mu_{e n}(E)}{\rho}\right)_{a r}\left(\mathrm{R}-\mathrm{cm}^{2}\right)
$$

where

$$
\begin{array}{ll}
\mu_{e n}(E) / \rho & =\text { mass energy absorption coefficient }\left(\mathrm{cm}^{2} / \mathrm{g}\right) \\
E & =\text { photon energy }(\mathrm{MeV}) \\
C & =1.835 \times 10^{-*}(\mathrm{R}-\mathrm{g} / \mathrm{MeV})
\end{array}
$$

The dose response function is given by

$$
R_{\text {dise }}=H^{*}(10)(E) \quad\left(\mathrm{pS} v-\mathrm{cm}^{2}\right)
$$

where

$$
\begin{aligned}
H^{*}(10)(E)= & \text { dose coefficient at a } 10-\mathrm{mm} \text { depth in the tissue spherical } \\
& \text { phantom }\left(\mathrm{pSv}^{\left.-\mathrm{cm}^{2}\right)} .\right.
\end{aligned}
$$

Both the discrete-ordinates (PARTISN) [12] and the Monte Carlo (MCNPX) [5] calculations rely heavily on the quality of their data. For a meaningful comparison of the two codes' 
buildup factors, consistency had to be maintained between the two. The cross-section data that were supplied to both codes had to be from as common a source as possible (e.g., ENDF), and the slab thickness at which the flux is determined and the two responses calculated had to be the same.

In MCNPX, these calculations for buildup factors at the exit surface can be obtained by simply inputting the slab thickness in the MCNPX code because of its capability to model in 3D. In PARTISN, this is not the case, because the discrete-ordinates code partitions the slab into a finite number of meshes and secondly the discrete-ordinates code determines values at the midpoint of these meshes, i.e., just inside of the slab at both front and back faces. That is, PARTISN calculates the flux and the buildup factors at the mid point of a mesh interval. To be able to make the necessary comparison of the exit buildup factors, the following steps were included in PARTISN input files to obtain a similar slab thickness with MCNPX values:

For a given slab with an arbitrary mean free path thickness, the linear thickness is based on the photon's source energy and the macroscopic cross section of the slab material. Assuming this given optical thickness is $D$ and the slab is divided into $n$ meshes, the thickness of a mesh is $\frac{D}{n}$. The slab thickness inputted in PARTISN is increased to $D$ ' so that the last mesh point calculation corresponds to the thickness $D$ of MCNPX. As shown below, the thickness implemented into PARTISN is $\mathrm{D}^{\prime}=D\left(1+\frac{1}{2 n}\right)$, an addition of one-half of a mesh thickness.

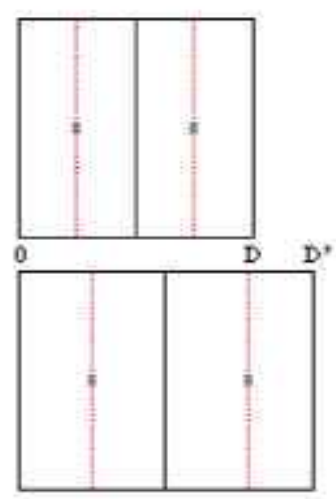

Figure 3.1: Modification of the PARTISN slab thickness to correspond to the MCNPX thickness. 
To complete the overall discussion, the equation that is used to obtain the thickness for a group-averaged energy in PARTISN for 100 mesh intervals per mfp is:

$$
\text { thichotex: }=\cos (\theta) \times\left(\frac{m f p}{\mu}\right) \times\left(1+\left(\frac{1}{2^{*} 100^{*} m p}\right)\right)
$$

and the MCNPX mean free path thickness is obtained through a simplified version of the equation above:

$$
\text { thickness }=\cos (\theta) \times\left(\frac{m f p}{\mu}\right)
$$

where

$\mu \quad=$ the macroscopic cross section,

$m f p=$ the mean free path number value,

$\theta=$ the angle (in degrees) with respect to the normal at which photons are incident on the material slab.

\subsection{Cross sections}

Based on the study of photoatomic interaction cross sections, the four major photon interactions that significantly contribute to the attenuation of photons through a given material for the energy range of $l \mathrm{keV}$ to $10 \mathrm{MeV}$ are the photoelectric effect. Compton scattering, coherent scattering, and pair production. As a result, photon transport calculations used to obtain buildup factors must include the cross sections that are discussed below.

Photoelectric effect is usually an important process for low-energy photons, where an energetic incident photon interacts with an atomic electron, usually ejecting an energetic photoelectron from the $\mathrm{K}$ shell. The atom recoils with very little kinetic energy, whereas the photoelectron's kinetic energy is equal to

$$
E_{c}=h r-E_{b}
$$

where $k$ is the photon energy and $E_{b}$ is the electron binding energy. The ejected electron leaves a vacancy in the atomic electron structure that is filled by an outer electron. Each 
electronic transition fills a vacancy in the electron structure is accompanied by the emission of a characteristic fluorescence $\mathrm{x}$-ray or by the ejection of a less tightly bound outer Auger electron.

Compton scattering is a major photon interaction for energies above about $100 \mathrm{keV}$, in which a photon of energy $E$ interacts with an electron initially at rest where both energy and momentum are conserved. This interaction results in the transfer of kinetic energy $T$ from the photon to an electron that moves at an angle of $\theta_{\theta}$ measured from the initial direction of the photon, while the secondary photon has an energy of $E^{\prime}-E-T$ which moves at angle $\theta_{s}$ This interaction is depicted in the formula below

$$
E=\frac{E}{1+\left(E / m_{e} c^{2}\right)\left(1-\cos \theta_{s}\right)}
$$

where $m_{e} c^{2}$ is the electron rest mass. The Compton effect is the cause of many difficult problems encountered in the shielding of photons. This is because the photon does not disappear in the interaction as it does in the photoelectric effect and in pair production, so this Compton-scattered photon is free to penetrate the shield or interact again. Corrections factors are included in photoatomic data libraries for the Klein-Nishina formula when photon energies approach electron binding energies to account for electron binding effects [11].

Two interactions that are competition with one another at low photon energies are coherent and incoherent scattering. In coherent scattering, photons interact with the collective atomic electrons of an atom, while incoherent scattering occurs when photons interact with individual electrons. For coherent scattering, there are minimal changes in photon energy and direction because the recoil momentum of the interaction is taken up by the atom.

The last major photon interaction discussed is pair production, which occurs when an incident photon is completely absorbed and is replaced by a positron-electron pair with kinetic energies of $T$ - and $T$. respectively. The phenomenon is an interaction with a strong electric field in the vicinity of the nucleus, and has a photon threshold energy of 
$2 m_{\varepsilon} c^{2}=1.022 \mathrm{MeV}$. In this reaction, the nucleus acquires indeterminate momentum but negligible kinetic energy, where the equation,

$$
T_{+}+T .-E-2 m \alpha^{2}
$$

suggests that the photon energy must be in excess of $1.022 \mathrm{MeV}$ (twice the rest energy of an electron) for the interaction to occur. Based on an approximation, the total atomic pair

production cross section varies as $Z^{2}$ and this cross section increases with photon energy, eventually approaching a constant value at high energies. The ultimate fate of the positron is its annihilation with an electron, after slowing to practically zero kinetic energy. This annihilation process of the positron usually results in the creation of two photons of energy $\left.m_{e} c^{2}=0.51\right] \mathrm{MeV}$ moving in opposite directions $[1,13]$.

\subsubsection{Cross-section Ilbraries}

There are numerous compilations or libraries today that contain cross-section data, but not all of them are useful to every user. For buildup factor calculations, one needs photoatomic cross-section database in a specific format. The most suitable library that is used for the primary photon transpon cross sections in this research is the Evaluated Nuclear Data File (ENDF/B-VI.8) [14]. ENDF data can not be directly used in the desired radiation codes, but has to be processed into multigroup and point-wise tables of macroscopic cross-section values sufficient for both Monte Carlo and discrete-ordinates codes by the cross-section processing code NJOY [15].

\subsection{Discrete-ordinates calculations}

Pandemonium 2.0's buildup factors were calculated with the discrete-ordinates code PARTISN, the most recent version of the DANTSYS family of codes [6]. For discreteordinates calculations, the user has more freedom with how to perform one's transport calculations from an energy point of view. The buildup factor calculations implemented into Pandemonium 2.0 were based on a 220-group structure. For the PARTISN input file to be complete, the response functions for exposure and dose must be known to calculate the buildup factor results. 


\subsubsection{Group structure and cross sections}

For these buildup calculations, the first step is choosing a group structure that encompassed the range of photon energies within Pandemonium of $10 \mathrm{keV}$ to $10 \mathrm{MeV}$. The multigroup structure below $100 \mathrm{keV}$ was based on the work of Daskalov [16] whose structure focused on low energy analysis of transport, particularly those in the vicinity of the $\mathrm{K}$-electron binding energies. In this energy range, the group widths also decreased in width as the energy decreases because the cross-section values change more drastically with decreasing energy. To ensure the discrete-ordinates code and the Monte Carlo calculations had similar total cross sections at a given photon source energy, to limit the variation in the two different codes slab thicknesses, a source group of I keV was added above these 10 photons source energies as shown in Table 3.1. This 220-group structure was used for the multigroup discrete-ordinates calculations. The application of two modules, RECONR and GAMINR, in the NJOY [15] cross-section processing code constructed the pointwise, energy dependent cross sections from the ENDF photoatomic files into a multigroup photon structure that could be used for primary photon interactions. Scattering cross section calculations were

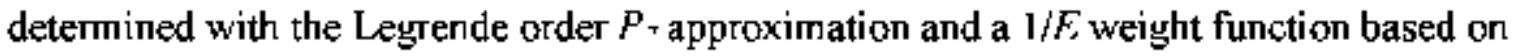
Kitsos' analysis of Legrende expansions [17]. The Legrende order is a polynomial equation that is fitted to the stated ENDF probability $P(w)$ of a photon's interaction as a function of the cosine of the angle at which it interacts, whereas the Monte Carlo code tabulates the probability from the specific ENDF curve Lastly, the buildup factor calculations incorporated the Coupled Electron/Photon Cross-Section generating (CEPXS) code [18] to include the secondary effects of bremsstrahlung and fluorescence. 
Table 3. 1: 220-group structure for discrete-ordinates photon buildup calculations of Wooten which includes the group index number, the energy of the group's upper limit and the group width in keV.

\begin{tabular}{|c|c|c|c|c|c|c|c|c|}
\hline goup & $\mathrm{E}(\mathrm{keV})$ & $\Delta \mathrm{E}(\mathrm{keV})$ & group & $\mathrm{E}(\mathrm{keV})$ & $\Delta \mathrm{E}(\mathrm{keV})$ & group & $\mathrm{E}(\mathrm{keV})$ & $\Delta \mathrm{E}(\mathrm{keV})$ \\
\hline 1 & 10001 & 1 & 37 & 2666 & 166 & 73 & 550 & 49 \\
\hline 2 & 10000 & 500 & 38 & 2500 & 167 & 74 & 501 & 1 \\
\hline 3 & 9500 & 500 & 39 & 2333 & 167 & 75 & 500 & 50 \\
\hline 4 & 9000 & 500 & 40 & 2166 & 165 & 76 & 450 & 50 \\
\hline 5 & 8500 & 499 & 41 & $200 \mathrm{I}$ & l & 77 & 400 & 15 \\
\hline 6 & 8001 & 1 & 42 & 2000 & 125 & 78 & 385 & 15 \\
\hline 7 & 8000 & 250 & 43 & 1875 & 125 & 79 & 370 & 10 \\
\hline 8 & 7750 & 250 & 44 & 1750 & 90 & 80 & 360 & 10 \\
\hline 9 & 7500 & 250 & 45 & 1660 & 60 & 81 & 350 & 12.5 \\
\hline 10 & 7250 & 250 & 46 & 1600 & 100 & 82 & 337.5 & 12.5 \\
\hline 11 & 7000 & 250 & 47 & 1500 & 100 & 83 & 325 & 12.5 \\
\hline 12 & 6750 & 250 & 48 & 1400 & 65 & 84 & 312.5 & 12.5 \\
\hline 13 & 6500 & 250 & 49 & 1335 & 5 & 85 & 300 & 15 \\
\hline 14 & 6250 & 249 & $\$ 0$ & 1330 & 230 & 86 & 285 & 10 \\
\hline 15 & $600]$ & 1 & 51 & 1100 & 99 & 87 & 275 & 15 \\
\hline 16 & 6000 & 250 & 52 & 1001 & 1 & 88 & 260 & 10 \\
\hline 17 & 5750 & 250 & 53 & 1000 & 50 & 89 & 250 & 25 \\
\hline 18 & 5500 & 100 & 54 & 950 & 50 & 90 & 225 & 25 \\
\hline 19 & 5400 & 200 & 55 & 900 & so & 91 & 200 & $s$ \\
\hline 20 & 5200 & 199 & 56 & 850 & 25 & 92 & 195 & 5 \\
\hline 21 & 5001 & 1 & 57 & 825 & 25 & 93 & 190 & 5 \\
\hline 22 & 5000 & 300 & 58 & 800 & 20 & 94 & 185 & 5 \\
\hline 23 & 4700 & 200 & 59 & 780 & 30 & 95 & 180 & 5 \\
\hline 24 & 4500 & 100 & 60 & 750 & 15 & 96 & 175 & 2.5 \\
\hline 25 & 4400 & 200 & 61 & 735 & 15 & 97 & 172.5 & 2.5 \\
\hline 26 & 4200 & 199 & 62 & 720 & 20 & 98 & 170 & 5 \\
\hline 27 & $400]$ & 1 & 63 & 700 & 10 & 99 & 165 & 2.5 \\
\hline 28 & 4000 & 100 & 64 & 690 & 10 & 100 & 162.5 & 5.5 \\
\hline 29 & 3900 & 100 & 65 & 680 & 15 & 101 & 157 & $l$ \\
\hline 30 & 3800 & 150 & 66 & 665 & 30 & 102 & 156 & 6 \\
\hline 31 & 3650 & 150 & 67 & 635 & 15 & 103 & 150 & 5 \\
\hline 32 & 3500 & 167 & 68 & 620 & 20 & 104 & 145 & 5 \\
\hline 33 & 3333 & 167 & 69 & 600 & 2.5 & 105 & 140 & 2.5 \\
\hline 34 & 3166 & 166 & 70 & 597.5 & 2.5 & 106 & 137.5 & 2.5 \\
\hline 35 & 3000 & 167 & 71 & 595 & 20 & 107 & 135 & 5 \\
\hline 36 & 2833 & 167 & 72 & 575 & 25 & 108 & 130 & 5 \\
\hline
\end{tabular}


Table 3.1 (continued).

\begin{tabular}{|c|c|c|c|c|c|c|c|c|}
\hline group & $E(\mathrm{keV})$ & $\Delta \mathrm{E}(\mathrm{keV})$ & group & $\mathrm{E}(\mathrm{keV})$ & $\Delta \mathrm{E}(\mathrm{keV})$ & group & $\mathrm{E}(\mathrm{keV})$ & $\Delta \mathrm{E}(\mathrm{keV})$ \\
\hline 109 & 125 & 25 & 147 & 42.5 & 0.25 & 185 & 29.75 & 0.25 \\
\hline 110 & 100 & 1 & 148 & 42.25 & 0.25 & 186 & 29.5 & 0.25 \\
\hline 111 & 99 & I & 149 & 42 & 0.25 & 187 & 29.25 & 0.25 \\
\hline 112 & 98 & 1 & 150 & 41.75 & 0.25 & 188 & 29 & 0.3 \\
\hline 113 & 97 & 1 & 151 & 41.5 & 0.25 & 189 & 28.7 & 0.2 \\
\hline 114 & 96 & 1 & 152 & 41.25 & 0.25 & 190 & 28.5 & 0.3 \\
\hline 115 & 95 & 1 & 153 & 4] & 0.5 & 191 & 28.2 & 0.2 \\
\hline 116 & 94 & 1 & 154 & 40.5 & 0.5 & 192 & 28 & 0.4 \\
\hline 117 & 93 & 1 & 155 & 40 & 0.25 & 193 & 27.6 & 0.35 \\
\hline 118 & 92 & l & 156 & 39.75 & 0.25 & 194 & 27.25 & 0.25 \\
\hline 119 & 91 & 1 & 157 & 39.5 & 0.25 & 195 & 27 & 0.75 \\
\hline 120 & 90 & 2 & 158 & 39.25 & 0.25 & 196 & 26.25 & 0.736 \\
\hline 121 & 88 & 2 & 159 & 39 & 0.25 & 197 & 25.514 & 1.764 \\
\hline 122 & 86 & 2.8977 & 160 & 38.75 & 0.25 & 198 & 23.75 & 1.25 \\
\hline 123 & 83.1023 & 2.3774 & 161 & 38.5 & 0.25 & 199 & 22.5 & 1.25 \\
\hline 124 & 80.7249 & 3.2249 & 162 & 38.25 & 0.25 & 200 & 21.25 & 1.25 \\
\hline 125 & 77.5 & 1.389 & 163 & 38 & 0.25 & 201 & 20 & 1.03 \\
\hline 126 & 76.111 & 6.586 & 164 & 37.75 & 0.25 & 202 & 18.97 & 1.04 \\
\hline 127 & 69.525 & 4.525 & 165 & 37.5 & 0.25 & 203 & 17.93 & 1.03 \\
\hline 128 & 65 & 5 & 166 & 37.25 & 0.25 & 204 & 16.9 & 1.04 \\
\hline 129 & 60 & 2.5 & 167 & 37 & 0.25 & 205 & 15.86 & 0.66 \\
\hline 130 & 57.5 & 2.5 & 168 & 36.75 & 0.25 & 206 & 15.2 & 0.2 \\
\hline 131 & 55 & 1.5 & 169 & 36.5 & 0.25 & 207 & 15 & 0.1607 \\
\hline 132 & 53.5 & 1 & 170 & 36.25 & 0.2654 & 208 & 14.8393 & 0.4865 \\
\hline 133 & 52.5 & 1.5 & 171 & 35.9846 & 0.4346 & 209 & 14.3528 & 0.4729 \\
\hline 134 & 51 & 1 & 172 & 35.55 & 0.55 & 210 & 13.8799 & 0.4614 \\
\hline 135 & 50 & 1.5 & 173 & 35 & 0.25 & 211 & 13.4185 & 0.3785 \\
\hline 136 & 48.5 & 1 & 174 & 34.75 & 0.25 & 212 & 13.04 & 0.2159 \\
\hline 137 & 47.5 & 1.5 & 175 & 34.5 & 0.5 & 213 & 12.8241 & 0.5402 \\
\hline 138 & 46 & 1 & 176 & 34 & 0.5 & 214 & 12.2839 & 0.1841 \\
\hline 139 & 45 & 0.75 & 177 & 33.5 & 0.3306 & 215 & 12.0998 & 0.1898 \\
\hline 140 & 44.25 & 0.25 & 178 & 33.1694 & 0.6694 & 216 & 11.91 & 0.3463 \\
\hline 141 & 44 & 0.3 & 179 & 32.5 & 0.5 & 217 & 11.5637 & 0.3483 \\
\hline 142 & 43.7 & 0.2 & 180 & 32 & 0.5 & 218 & 11.2154 & 0.4554 \\
\hline 143 & 43.5 & 0.25 & 181 & 31.5 & 0.5 & 219 & 10.76 & 0.3929 \\
\hline 144 & 43.25 & 0.25 & 182 & 31 & 0.5 & 220 & 10.3671 & 0.3671 \\
\hline 145 & 43 & 0.25 & 183 & 30.5 & 0.5 & & 10 & \\
\hline 146 & 42.75 & 0.25 & 184 & 30 & 0.25 & & & \\
\hline
\end{tabular}

In order to incorporate the additional 15 gamma-ray source energies into this updated revision of Pandemonium 2.0, one has to know the limitations of the cross-section processing codes NJOY and CEPXS and determine how sensitive the cross sections are in the 220-group structure for the photons and electrons to ensure that any modification to the group structure 
will not change the transport results significantly. The limitations of CEPXS as stated in its manual emphasizes that the code will solve the Boltzmann-CSD transport equation for electrons and the Boltzmann transport equation for photons over the energy range from 100 MeV to $1.0 \mathrm{keV}$. The limitations of NJOY are based on the Evaluated Nuclear Data File ENDF/B-VI photoatomic data file. Based on the Photon Data and Evaluated Photon Data Libraries (EPDL) [14] manual, the ENDF/B-VI file includes data from $1 \mathrm{eV}$ to $100 \mathrm{GeV}$, but for the results to be considered accurate, it is recommended to use photoatomic data only to a lower energy limit of $1 \mathrm{keV}$. Therefore, to ensure accurate results and limit the uncertainty in the data, the limitations enforced by NJOY and CEPXS restrict the lower energy limit of the new group structure to be $1 \mathrm{keV}$, which was sufficient to calculate photon buildup factors with source energies down to $10 \mathrm{keV}$. The existing upper limit energy of $10.00 \mathrm{l} \mathrm{MeV}$ was still sufficient for this research because the photons that will be observed to calculate buildup factors will never be more energetic than the source group for $10 \mathrm{MeV}$. Due to these constraints, the new group structure will range from $\mathrm{l} k \mathrm{kV}$ to $10.00 \mathrm{~J} \mathrm{MeV}$.

To determine slant-path buildup factors for all 25 source energies, modifications were made to Wooten's group structure to account for the additional 15 source energies and the extended energy range. The newly-established group stucture was constructed through in-depth studies into the effects on very small-width energy groups in Wooten's group structure, comparative studies of both the 220- and 244-group structures with different responses, and studying the effects of constant and extrapolated dose responses at energies lower than 10 $\mathrm{keV}$. With the inclusion of the newest cross-section data, an extensive compilation of buildup factors calculations was performed using PARTISN and MCNPX.

The process of extending the 220-group structure and extending the energy down to $1 \mathrm{keV}$ was developed through a series of sudies to determine the sensitivity of the cross-section data, and thus became a significant contribution to understanding the effect that a group structure has on buildup factor results. One of the first steps was to generate photon cross sections for the different groups as seen in the extension of the energy range between groups $75(500 \mathrm{keV})$ and $76(450 \mathrm{keV})$ into 5 equally spaced intervals, both logarithmically and linearly, to determine if the given cross sections vary significantly for normally incident $500-$ 
$\mathrm{keV}$ photons on $1 \mathrm{mfp}$ and $10 \mathrm{mfp}$ thick lead slabs. One reason that this material and energy were chosen is because these results could be compared to Wooten's work. The energy interval over which the cross-section sensitivity was performed is shown below:

Table 3.2: Energy interval of group 75 and 76 in the original 220-group structure.

\begin{tabular}{ccc}
\hline Group & $\mathrm{E}(\mathrm{keV})$ & $\Delta \mathrm{E}(\mathrm{keV})$ \\
\hline 74 & 501 & ] \\
75 & 500 & 50 \\
76 & 450 & 50 \\
\hline
\end{tabular}

The 220-group structure was slighlly modified by removing the highest 5 groups [group ] (10.001 MeV) to group $5(8.5 \mathrm{MeV})$ ] and incorporating new groups to maintain a 220 -group structure, which enabled the use of NJOY, CEPXS, and PARTISN input files developed by Wooten specifically for the 220 groups. This alteration will not affect the results of the sensitivity study because the incident photons of $500 \mathrm{keV}$ will only downscatter in energy as the photons and electrons transport through the lead slab. The two methods are shown below with their respectively spaced energy intervals.

Table 3.3: Linearly and logarithmically spaced intervals between group $75(500 \mathrm{keV})$ and $76(450 \mathrm{keV})$.

\begin{tabular}{ccc}
\hline Group & $\begin{array}{c}\text { Linearly Spaced } \\
\mathrm{E}(\mathrm{keV})\end{array}$ & $\begin{array}{c}\text { Logarithmically Spaced } \\
\mathrm{E}(\mathrm{keV})\end{array}$ \\
\hline 75 & 500 & 500 \\
$75 \mathrm{a}$ & 491.6667 & 491.2966 \\
$75 \mathrm{~b}$ & 483.3333 & 482.7447 \\
$75 \mathrm{c}$ & 475 & 474.3416 \\
$75 \mathrm{~d}$ & 466.6667 & 466.0849 \\
$75 \mathrm{e}$ & 458.3333 & 457.9718 \\
76 & 450 & 450 \\
\hline
\end{tabular}

After generating photon cross-sections for the different energy-group scenarios for lead, the scalar flux at the slab's exit face for both scenarios is compared. The tables shown below demonstrate that the modification in the group structure does not significantly affect cross section sensitivity $[<2.2 \%]$ for photons and electrons in the lead slab. 
Table 3.4: Total exit flux for linearly spaced intervals between modified groups 75 and 76.

\begin{tabular}{cccc}
\hline $\begin{array}{c}\text { Exit Flux } \\
\left(\mathrm{cm}^{-2} \mathrm{~s}^{-1}\right)\end{array}$ & \multicolumn{3}{c}{ 220-group structure } \\
& Standard & Modified & Difference \\
\hline $1 \mathrm{mfp}$ & $5.02897 \mathrm{E}-01$ & $4.99540 \mathrm{E}-01$ & $-0.66753 \%$ \\
$10 \mathrm{mfp}$ & $1.71310 \mathrm{E}-04$ & $1.75000 \mathrm{E}-04$ & $2.15399 \%$ \\
\hline
\end{tabular}

Table 3.5: Total exit flux for logarithmically spaced intervals between modified groups 75 and 76.

\begin{tabular}{cccc}
\hline $\begin{array}{c}\text { Exit Flux } \\
\left(\mathrm{cm}^{-2} \mathrm{~s}^{-1}\right)\end{array}$ & \multicolumn{3}{c}{ 220-group structure } \\
& Standard & Modified & Difference \\
\hline $1 \mathrm{mfp}$ & $5.02897 \mathrm{E}-01$ & $4.99771 \mathrm{E}-0 \mathrm{l}$ & $-0.62160 \%$ \\
$10 \mathrm{mfp}$ & $1.71310 \mathrm{E}-04$ & $1.80251 \mathrm{E}-04$ & $5.21919 \%$ \\
\hline
\end{tabular}

In both of these cases, the different group scenarios with $500-\mathrm{keV}$ photons normally incident on lead demonstrate that there is very little difference in the total exit flux when comparing the PARTISN results. These results conclude that one may be able to successfully expand Wooten's 220-group stnucture into a larger group structure that will accommodate calculations for all of the 25 source groups for which buildup factors are needed. The Monte Carlo code MCNPX was also used to determine the total flux for this scenario as a benchmarking tool against the PARTISN results. The comparisons of the total flux for 500 $\mathrm{keV}$ photons normally incident on l-mfp and $10-\mathrm{mfp}$ lead slabs between MCNPX with the different PARTISN results are shown in the tables below. The definition of percent difference shown in the tables is:

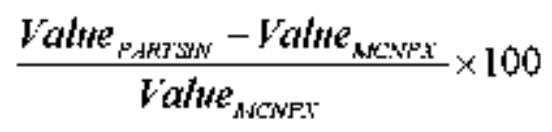

Table 3.6: MCNPX total flux for 500-keV photons incidemt on lead.

\begin{tabular}{ccc}
\hline & Exit Flux $\left(\mathrm{cm}^{-2} \mathrm{~s}^{-1}\right)$ & Relative Error \\
\hline $1 \mathrm{mfp}$ & $5.0569 \mathrm{E}-01$ & 0.0003 \\
$10 \mathrm{mfp}$ & $1.7384 \mathrm{E}-04$ & 0.0069 \\
\hline
\end{tabular}


Table 3.7: Percent difference for different group structures when compared to MCNPX for $500-\mathrm{keV}$ photons incident on lead.

\begin{tabular}{cccc}
\hline \multirow{3}{*}{ Exit Flux } & \multicolumn{3}{c}{ Percent difference when compared to MCNPX } \\
& Standard & Linear & Logarithmic \\
\hline $1 \mathrm{mfp}$ & $-0.5523 \%$ & $-1.2162 \%$ & $-1.1705 \%$ \\
$10 \mathrm{mfp}$ & $-1.4554 \%$ & $0.6673 \%$ & $3.6879 \%$ \\
\hline
\end{tabular}

This sensitivity study demonstrates that changing the 220 -group structure for $500-\mathrm{keV}$ photons nomally incident on lead slabs of different thicknesses produces similar values to MCNPX. It must be noted that even though the MCNPX also produces approximale results, Monte Carlo calculations are expected to be more accurate than PARTISN. Furthermore, as shown in Table 3.6, MCNPX calculations produce statistically well-behaved results with small relative error values $(<0.05)$ implying extremely reliable results [5]. This study concludes that cross sections are not sensitive in this group range allowing one to devise a new group structure, modifying the 220 -group structure, to include the additional I5 source groups and extending the energy range down to $1 \mathrm{keV}$ to determine buildup factors for all 25 source energies.

In this new group structure, the first task was to include specific groups for the 15 source energies that were not present in the previous model and also create a small group above each of the 25 source groups whose group width is one-thousandth (1/1000 $)$ or less of the value of that source energy. This group will act as a source group in the discrete-ordinates code. The reason for this structure was to produce thin enough groups whose averaged total cross sections are almost identical to MCNPX's point-wise cross sections. The second task was to extend the group structure lower bound from $10 \mathrm{keV}$ to I keV. To accomplish this, 5 additional groups were arbitrary added based on the equation developed by Microsoft Excel, fitting a logarithmic equation $(y=-4.6521 \times \ln (x)+10)$ to the endpoints of $10 \mathrm{keV}$ to $1 \mathrm{keV}$. Hence, the new group structure consists of 244 groups that range from $1 \mathrm{keV}$ to $10.01 \mathrm{MeV}$.

These initial modifications to the group structure could be altered if further sensitivity studies demonstrate the need. A method to detemine if this new group structure is comparable to Wooten's 220 -group structure was to perform another sensitivity analysis by generating cross 
sections and comparing the total flux at a modified source group. The group chosen to perform this study occurred at the 50-keV energy level, where the 220-group structure has an energy width of $1 \mathrm{keV}(51 \mathrm{keV}$ ) before the $50-\mathrm{keV}$ source energy, while the 244-group structure has an energy width of $0.05 \mathrm{keV}(50.05 \mathrm{keV})$ before this same source energy. These are called the "50-keV source group." For consistency purposes with the previous study, the slab was chosen to be lead with the same mean-free-path thicknesses, and benchmarked once again with MCNPX to determine which of these two PARTISN group structures produce "better" results. The results of this sensitivity study are shown below.

Table 3.8: PARTISN total flux for 50-keV source group on lead. Group Structure

\begin{tabular}{cccc} 
Exit Flux & & & \\
& 220 & 244 & Difference \\
\hline $1 \mathrm{mfp}$ & $4.21521 \mathrm{E}-01$ & $4.21216 \mathrm{E}-01$ & $-0.07236 \%$ \\
$10 \mathrm{mfp}$ & $7.81867 \mathrm{E}-05$ & $7.77242 \mathrm{E}-05$ & $-0.59153 \%$ \\
\hline
\end{tabular}

Table 3.9: MCNPX total flux for 50-keV photons incident on lead.

\begin{tabular}{ccc}
\hline & Exit Flux $\left(\mathrm{cm}^{-2} \mathrm{~s}^{-1}\right)$ & Relative Епо \\
\hline $1 \mathrm{mfp}$ & $4.0641 \mathrm{E}-01$ & 0.0005 \\
$10 \mathrm{mfp}$ & $7.8011 \mathrm{E}-05$ & 0.0014 \\
\hline
\end{tabular}

Table 3.10: Percent difference for different group structures when compared to MCNPX for $50-\mathrm{keV}$ photons incident on lead.

\begin{tabular}{|c|c|c|}
\hline \multicolumn{3}{|c|}{ Percent difference between the group structures and MCNPX } \\
\hline Exit Flux & $\begin{array}{l}\text { 220-group structure } \\
\text { Difference }\end{array}$ & $\begin{array}{l}\text { 244-group structure } \\
\text { Difference }\end{array}$ \\
\hline $1 \mathrm{mfp}$ & $3.7182 \%$ & $3.6431 \%$ \\
\hline $10 \mathrm{mfp}$ & $0.2252 \%$ & $-0.3676 \%$ \\
\hline
\end{tabular}

The results of this sensitivity study demonstrate for $50-\mathrm{keV}$ photons normally incident on 1mfp and I0-mfp lead slabs that the 220- and 244-group structures produce similar values for total exit flux to that expected with MCNPX, implying that both of these group structures are valid. The two sensitivity studies performed for $500-\mathrm{keV}$ and $50-\mathrm{keV}$ photons demonstrates that the total exit flux values changed very little when the group structure was modified from the 220-group structure to the 244-group structure. In conclusion, these results confirm that the previous model developed by Wooten is valid and demonstrates that by changing the cross-section groups in the 220-group structure does not have a significant effect on total exit flux values. 
As an additional check, a table of mean-free-path thickness is shown below for 50 -keV photons incident on a lead slab with both the 220- and 244-group structure to demonstrate that the change in the source group does not have a significant effect on the lead thickness. The ratio of the two groups' mean-free-path thickness is a constant because the averaged macroscopic cross-section value used for each group structure is dependent on the group's source group width. These results conclude that the 244-group structure is acceptable; allowing one to proceed and perform buildup calculations for all 25 source groups that will be implemented into PANDEMONIUM 2.0.a.

Table 3. 1]: Lead thickness for the different mean-free-path thicknesses for both group structures at an energy of $50 \mathrm{keV}$.

\begin{tabular}{cccc}
\hline Mean free path & \multicolumn{3}{c}{ Group Structure } \\
& $220(\mathrm{~cm})$ & $244(\mathrm{~cm})$ & $\%$ thinner \\
\hline 1 & $1.148 \mathrm{IE}-02$ & $1.1203 \mathrm{E}-02$ & $2.42 \%$ \\
2 & $2.2962 \mathrm{E}-02$ & $2.2406 \mathrm{E}-02$ & $2.42 \%$ \\
3 & $3.4443 \mathrm{E}-02$ & $3.3609 \mathrm{E}-02$ & $2.42 \%$ \\
4 & $4.5924 \mathrm{E}-02$ & $4.4812 \mathrm{E}-02$ & $2.42 \%$ \\
5 & $5.7405 \mathrm{E}-02$ & $5.6015 \mathrm{E}-02$ & $2.42 \%$ \\
6 & $6.8886 \mathrm{E}-02$ & $6.7218 \mathrm{E}-02$ & $2.42 \%$ \\
7 & $8.0366 \mathrm{E}-02$ & $7.8421 \mathrm{E}-02$ & $2.42 \%$ \\
8 & $9.1847 \mathrm{E}-02$ & $8.9624 \mathrm{E}-02$ & $2.42 \%$ \\
9 & $1.0333 \mathrm{E}-01$ & $1.0083 \mathrm{E}-01$ & $2.42 \%$ \\
10 & $1.1481 \mathrm{E}-01$ & $1.1203 \mathrm{E}-01$ & $2.42 \%$ \\
\hline
\end{tabular}

Before finalizing the new group structure, it was decided to modify the source groups above $1 \mathrm{MeV}$ to have an energy interval of $1 \mathrm{keV}$, while the source groups below $1 \mathrm{MeV}$ would keep the energy interval of $1 / 1000^{\text {th }}$ of that corresponding source energy. This was done to ensure that the source groups in the discrete-ordinates code would be a small energy interval to obtain a similar group-averaged cross section to that which MCNPX uses at a single point (at the source energy). 
Table 3.12: 244-group structure for discrete-ordinates photon buildup calculations (for Pandemonium 2.0.a) which includes the group index number, the energy of the group's upper limit, and the group width in keV.

\begin{tabular}{|c|c|c|c|c|c|c|c|c|}
\hline group & $\mathrm{E}(\mathrm{keV})$ & $\Delta \mathrm{E}(\mathrm{keV})$ & group & $\mathrm{E}(\mathrm{keV})$ & $\Delta \mathrm{E}(\mathrm{keV})$ & group & $E(\mathrm{keV})$ & $\Delta \mathrm{E}(\mathrm{keV})$ \\
\hline 1 & 10001 & 1 & 42 & 2001 & 1 & 83 & 385 & 15 \\
\hline 2 & 10000 & 500 & 43 & 2000 & 125 & 84 & 370 & 10 \\
\hline 3 & 9500 & 500 & 44 & 1875 & 125 & 85 & 360 & 10 \\
\hline 4 & 9000 & 500 & 45 & 1750 & 90 & 86 & 350 & 12.5 \\
\hline 5 & 8500 & 499 & 46 & 1660 & 60 & 87 & 337.5 & 12.5 \\
\hline 6 & 8001 & l & 47 & 1600 & 99 & 88 & 325 & 12.5 \\
\hline 7 & 8000 & 250 & 48 & 1501 & 1 & 89 & 312.5 & 12.2 \\
\hline 8 & 7750 & 250 & 49 & 1500 & 100 & 90 & 300.3 & 0.3 \\
\hline 9 & 7500 & 250 & 50 & 1400 & 65 & 91 & 300 & 15 \\
\hline 10 & 7250 & 250 & 51 & 1335 & $s$ & 92 & 285 & 10 \\
\hline 11 & 7000 & 250 & 52 & 1330 & 230 & 93 & 275 & 15 \\
\hline 12 & 6750 & 250 & 53 & 1100 & 99 & 94 & 260 & 10 \\
\hline 13 & 6500 & 250 & 54 & 1001 & 1 & 95 & 250 & 25 \\
\hline 14 & 6250 & 249 & 55 & 1000 & 50 & 96 & 225 & 24.8 \\
\hline 15 & 6001 & l & 56 & 950 & 50 & 97 & 200.2 & 0.2 \\
\hline 16 & 6000 & 250 & 57 & 900 & 50 & 98 & 200 & 5 \\
\hline 17 & 5750 & 250 & 58 & 850 & 25 & 99 & 195 & 5 \\
\hline 18 & 5500 & 100 & 59 & 825 & 24.2 & 100 & 190 & 5 \\
\hline 19 & 5400 & 200 & 60 & 800.8 & 0.8 & 101 & 185 & 5 \\
\hline 20 & 5200 & 199 & 61 & 800 & 20 & 102 & 180 & 5 \\
\hline 21 & 5001 & J & 62 & 780 & 30 & 103 & 175 & 2.5 \\
\hline 22 & 5000 & 300 & 63 & 750 & 15 & 104 & 172.5 & 2.5 \\
\hline 23 & 4700 & 200 & 64 & 735 & 15 & 105 & 170 & 5 \\
\hline 24 & 4500 & 100 & 65 & 720 & 20 & 106 & 165 & 2.5 \\
\hline 25 & 4400 & 200 & 66 & 700 & 10 & 107 & 162.5 & 5.5 \\
\hline 26 & 4200 & 199 & 67 & 690 & 10 & 108 & 157 & l \\
\hline 27 & 4001 & 1 & 68 & 680 & 15 & 109 & 156 & 5.85 \\
\hline 28 & 4000 & 100 & 69 & 665 & 30 & 110 & 150.15 & 0.15 \\
\hline 29 & 3900 & 100 & 70 & 635 & 15 & 111 & 150 & 5 \\
\hline 30 & 3800 & 150 & 71 & 620 & 19.4 & 112 & 145 & 5 \\
\hline 31 & 3650 & 150 & 72 & 600.6 & 0.6 & 113 & 140 & 2.5 \\
\hline 32 & 3500 & 167 & 73 & 600 & 2.5 & 114 & 137.5 & 2.5 \\
\hline 33 & 3333 & 167 & 74 & 597.5 & 2.5 & 115 & 135 & 5 \\
\hline 34 & 3166 & 165 & 75 & 595 & 20 & 116 & 130 & 5 \\
\hline 35 & 3001 & ] & 76 & 575 & 25 & 117 & 125 & 24.9 \\
\hline 36 & 3000 & 167 & 77 & 550 & 49.5 & 118 & 100.1 & 0.1 \\
\hline 37 & 2833 & 167 & 78 & 500.5 & 0.5 & 119 & 100 & 1 \\
\hline 38 & 2666 & 166 & 79 & 500 & 50 & 120 & 99 & l \\
\hline 39 & 2500 & 167 & 80 & 450 & 49.6 & 121 & 98 & 1 \\
\hline 40 & 2333 & 167 & 81 & 400.4 & 0.4 & 122 & 97 & 1 \\
\hline 41 & 2166 & 165 & 82 & 400 & 15 & 123 & 96 & I \\
\hline
\end{tabular}


Table 3.12 (continued).

\begin{tabular}{|c|c|c|c|c|c|c|c|c|}
\hline group & E(keV) & $\Delta \mathrm{E}(\mathrm{keV})$ & group & $E(\mathrm{keV})$ & $\Delta \mathrm{E}(\mathrm{keV})$ & group & $\mathrm{E}(\mathrm{keV})$ & $\Delta \mathrm{E}(\mathrm{keV})$ \\
\hline 124 & 95 & 1 & 165 & 41.25 & 0.25 & 206 & 28.2 & 0.2 \\
\hline 125 & 94 & 1 & 166 & 41 & 0.5 & 207 & 28 & 0.4 \\
\hline 126 & 93 & 1 & 167 & 40.5 & 0.46 & 208 & 27.6 & 0.35 \\
\hline 127 & 92 & 1 & 168 & 40.04 & 0.04 & 209 & 27.25 & 0.25 \\
\hline 128 & 9] & 1 & 169 & 40 & 0.25 & 210 & 27 & 0.75 \\
\hline 129 & 90 & 2 & 170 & 39.75 & 0.25 & 211 & 26.25 & 0.736 \\
\hline 130 & 88 & 2 & 171 & 39.5 & 0.25 & 212 & 25.514 & 1.764 \\
\hline 131 & 86 & 2.8977 & 172 & 39.25 & 0.25 & 213 & 23.75 & 1.25 \\
\hline 132 & 83.1023 & 2.3774 & 173 & 39 & 0.25 & 214 & 22.5 & 1.25 \\
\hline 133 & 80.7249 & 0.6449 & 174 & 38.75 & 0.25 & 215 & 21.25 & 1.23 \\
\hline 134 & 80.08 & 0.08 & 175 & 38.5 & 0.25 & 216 & 20.02 & 0.02 \\
\hline 135 & 80 & 2.5 & 176 & 38.25 & 0.25 & 217 & 20 & 1.03 \\
\hline 136 & 77.5 & 1.389 & 177 & 38 & 0.25 & 218 & 18.97 & 1.04 \\
\hline 137 & 76.111 & 6.586 & 178 & 37.75 & 0.25 & 219 & 17.93 & 1.03 \\
\hline 138 & 69.525 & 4.525 & 179 & 37.5 & 0.25 & 220 & 16.9 & 1.04 \\
\hline 139 & 65 & 4.94 & 180 & 37.25 & 0.25 & 221 & 15.86 & 0.66 \\
\hline 140 & 60.06 & 0.06 & 181 & 37 & 0.25 & 222 & 15.2 & 0.185 \\
\hline 141 & 60 & 2.5 & 182 & 36.75 & 0.25 & 223 & 15.015 & 0.015 \\
\hline 142 & 57.5 & 2.5 & 183 & 36.5 & 0.25 & 224 & 15 & 0.1607 \\
\hline 143 & 55 & 1.5 & 184 & 36.25 & 0.2654 & 225 & 14.8393 & 0.4865 \\
\hline 144 & 53.5 & 1 & 185 & 35.9846 & 0.4346 & 226 & 14.3528 & 0.4729 \\
\hline 145 & 52.5 & 1.5 & 186 & 35.55 & 0.55 & 227 & 13.8799 & 0.4614 \\
\hline 146 & 51 & 0.95 & 187 & 35 & 0.25 & 228 & 13.4185 & 0.3785 \\
\hline 147 & 50.05 & 0.05 & 188 & 34.75 & 0.25 & 229 & 13.04 & 0.2159 \\
\hline 148 & 50 & 1.5 & 189 & 34.5 & 0.5 & 230 & $12.824 \mathrm{I}$ & 0.5402 \\
\hline 149 & 48.5 & 1 & 190 & 34 & 0.5 & 231 & 12.2839 & 0.1841 \\
\hline 150 & 47.5 & 1.5 & 191 & 33.5 & 0.3306 & 232 & 12.0998 & 0.1898 \\
\hline 151 & 46 & 1 & 192 & 33.1694 & 0.6694 & 233 & 11.91 & 0.3463 \\
\hline 152 & 45 & 0.75 & 193 & 32.5 & 0.5 & 234 & 11.5637 & 0.3483 \\
\hline 153 & 44.25 & 0.25 & 194 & 32 & 0.5 & 235 & 11.2154 & 0.4554 \\
\hline 154 & 44 & 0.3 & 195 & 31.5 & 0.5 & 236 & 10.76 & 0.3929 \\
\hline 155 & 43.7 & 0.2 & 196 & 31 & 0.5 & 237 & 10.3671 & 0.3571 \\
\hline 156 & 43.5 & 0.25 & 197 & 30.5 & 0.47 & 238 & 10.01 & 0.01 \\
\hline 157 & 43.25 & 0.25 & 198 & 30.03 & 0.03 & 239 & 10 & 3.2059 \\
\hline 158 & 43 & 0.25 & 199 & 30 & 0.25 & 240 & 6.7941 & 1.8753 \\
\hline 159 & 42.75 & 0.25 & 200 & 29.75 & 0.25 & 241 & 4.9188 & 1.3306 \\
\hline 160 & 42.5 & 0.25 & 201 & 29.5 & 0.25 & 242 & 3.5882 & 1.0321 \\
\hline 161 & 42.25 & 0.25 & 202 & 29.25 & 0.25 & 243 & 2.5562 & 0.8433 \\
\hline 162 & 42 & 0.25 & 203 & 29 & 0.3 & 244 & 1.7129 & 0.7129 \\
\hline 163 & 41.75 & 0.25 & 204 & 28.7 & 0.2 & & l & \\
\hline 164 & 41.5 & 0.25 & 205 & 28.5 & 0.3 & & & \\
\hline
\end{tabular}


In Wooten's buildup factor calculations, the CEPXS code incorporates secondary photon effects; however since the code's primary photon cross sections that are based upon empirical formulas that are fit to experimental data determined by Biggs and Lighthill [19, 20], Wooten modified CEPXS as described below. The methods to include the electron cross section for bremsstrahlung production and fluorescence are based on the Integrated Tiger Series (ITS) Monte Carlo code [21]. The CEPXS code not only accounts for interactions between photons and electrons, but also elastic and inelastic electron-electron collisions, and positron interactions with other positrons, electrons, and photons. Shown in the table below is the complete range of interactions modeled by CEPXS.

Wooten created a new version of CEPXS that enables the user to replace the Biggs-Lighthil] data with the NJOY processed ENDF cross sections for coherent, incoherent, pair production, and absorption interactions. This allows the CEPXS cross sections to include not only the incoherent scattering and photoionization for photon-photon interactions, but also the coherent scattering and electron binding effect on the incoherent scattering cross section for different interactions that are included in newer ENDF data files. CEPXS creates the coupled-cross-section tables for electrons and photons in two group structures which for this research are kept identical, resulting in a coupled cross-section table of 440 and 488 groups for Wooten and this research, respectively.

Table 3. 13: CEPXS particle interactions and physical phenomena accounted for in coupled cross section tables.

\begin{tabular}{|c|c|c|}
\hline Interaction type & \multicolumn{2}{|c|}{ Physical process } \\
\hline$\Sigma_{\text {elvitran-eliketrom }}$ & $\begin{array}{l}\text { knock-on } \\
\text { elastic scattering } \\
\text { Auger production }\end{array}$ & $\begin{array}{l}\text { radiative scattering } \\
\text { inelastic scattering } \\
\text { ionization }\end{array}$ \\
\hline$\sum_{\text {electroll-photon }}$ & bremsstrahlung & fluorescence \\
\hline$\Sigma_{\text {uhroton-pholon }}$ & incoherent scattering & photoionization \\
\hline$\overline{\sum_{\text {phrton-Electron }}}$ & $\begin{array}{l}\text { compton production } \\
\text { pair production }\end{array}$ & $\begin{array}{l}\text { photoelectron production } \\
\text { Auger production }\end{array}$ \\
\hline$\sum_{\text {pholen-pustresti }}$ & pair positron production & \\
\hline$\Sigma_{\text {pasiturnt.posituren }}$ & $\begin{array}{l}\text { collisional scattering } \\
\text { elastic scattering }\end{array}$ & radiative scattering \\
\hline$\overline{\sum_{\text {posurom-photerl }}}$ & $\begin{array}{l}\text { bremsstrahlung } \\
\text { annihilation }\end{array}$ & fluorescence \\
\hline 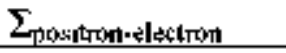 & knock-on production & Auger production \\
\hline
\end{tabular}




\subsubsection{Quadrature details}

Similar to Wooten's approach, for the discrete-ordinates calculations, the Gauss-Lobatto

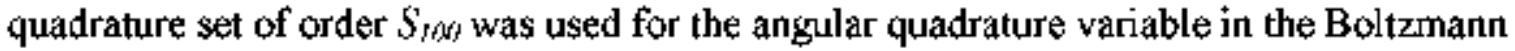
transport equation, and Kim's Gauss-Lobatto calculator [22] was used to obtain the quadratures and respective weights. The $S_{\text {m }}$ quadrature order was applied because the study focused on the radiation transport of photons through a slab for a variety of incident angles that incorporated the normal direction that corresponds to quadratures ranging from $\mu=-1.0$ to $\mu=1.0$ as shown below.

Table 3.14: First 50 guadratures and weights of the $S_{100}$ set used in PARTISN; the remaining 50 are negative values of these listed.

\begin{tabular}{cccccc}
\hline & quadrature & weight & & quadrature & weight \\
\hline $\mathrm{I}$ & $\mathrm{l}$ & 0.00010101010 & 26 & 0.69871161020 & 0.01129483679 \\
2 & 0.99925857797 & 0.00062253833 & 27 & 0.67577744426 & 0.01163742386 \\
3 & 0.99751524904 & 0.00112053988 & 28 & 0.65216964865 & 0.01196841049 \\
4 & 0.9947770719 & 0.00161716296 & 29 & 0.62791175614 & 0.01228746675 \\
5 & 0.99104769371 & 0.00211213817 & 30 & 0.60302794752 & 0.01259427460 \\
6 & 0.98633016382 & 0.00260499904 & 31 & 0.57754302752 & 0.01288852819 \\
7 & 0.98062943072 & 0.00309526016 & 32 & 0.55148240007 & 0.01316993423 \\
8 & 0.97395118101 & 0.00358243461 & 33 & 0.52487204296 & 0.01343821218 \\
9 & 0.96630207344 & 0.00406603742 & 34 & 0.49773848198 & 0.01369309463 \\
10 & 0.95768973368 & 0.00454558681 & 35 & 0.47010876445 & 0.01393432751 \\
11 & 0.94812274716 & 0.00502060489 & 36 & 0.44201043227 & 0.01416167035 \\
12 & 0.93761065074 & 0.00549061821 & 37 & 0.41347149448 & 0.01437489652 \\
13 & 0.92616392325 & 0.00595515830 & 38 & 0.38452039931 & 0.01457379349 \\
14 & 0.91379397517 & 0.00641376212 & 39 & 0.35518600584 & 0.01475816298 \\
15 & 0.90051313718 & 0.00686597253 & 40 & 0.32549755523 & 0.01492782121 \\
16 & 0.88633464797 & 0.00731133877 & 41 & 0.29548464157 & 0.01508259907 \\
17 & 0.87127264099 & 0.00774941690 & 42 & 0.26517718240 & 0.01522234226 \\
18 & 0.85534213042 & 0.00817977022 & 43 & 0.23460538884 & 0.01534691149 \\
19 & 0.83855899613 & 0.00860196977 & 44 & 0.20379973553 & 0.01545618259 \\
20 & 0.82093996795 & 0.00901559468 & 45 & 0.17279093021 & 0.01555004662 \\
21 & 0.80250260891 & 0.00942023264 & 46 & 0.14160988313 & 0.01562841004 \\
22 & 0.78326529779 & 0.00981548031 & 47 & 0.11028767624 & 0.01569119471 \\
23 & 0.76324721074 & 0.01020094369 & 48 & 0.07885553219 & 0.01573833806 \\
24 & 0.74246830226 & 0.01057623855 & 49 & 0.04734478323 & 0.01576979309 \\
25 & 0.72094928520 & 0.01094099078 & 50 & 0.01578683997 & 0.01578552845 \\
\hline
\end{tabular}




\subsubsection{Response functions}

To calculate buildup factors for different response functions, the Boltzmann transport equation has to be solved for the flux. As shown in Equations 3.1 - 3.3, the exit flux is integrated with an appropriate response function to obtain the flux (or number) buildup factor, the exposure buildop factor, and the dose buildup factor. For the exposure buildup factor, the discrete-ordinates response function is obtained from the compilation of photon attenuation coefficients of Berger, Hubbell and Seltzer [23], whereas the dose response function is obtained from the compilation of the International Commission on Radiological Protection (ICRP) Publication 74 [24], which are both listed in Table 3.15.

The set of parameters that were used in the PARTISN input file to obtain the buildup factors only differed in the number of groups as listed in Table 3.16. It should be noted that in Berger, Hubbell, and Seltzer's data there are two possible values for the mass-energy absorption for air at the energy of $0.0032029 \mathrm{MeV}$, but to be conservative it was decided to use the mass-energy absorption coefficient for air that occurs at the $\mathbf{K}$ edge because it will calculate a larger $\mu_{\text {en }}(E) / \rho$ value and thus exposure buildup factor. Unlike the dose response, the exposure response was determined by multiplying each referenced coefficient by its corresponding energy such that $K(E)=E \mu_{k \pi}(E) \cdot \rho$ which is also shown in the definition of the different response buildup factors.

The response functions of the 244-group structure were determined through the process of logarithmically interpolating given coefficients at the midpoint of each group and logarithmically extrapolating the coefficients that were not listed in Table 3.15 [7]. The dose response functions of the 244-group structure were the only extrapolations performed because all of the exposure coefficients from $1 \mathrm{keV}$ to $15 \mathrm{MeV}$ were incorporated from Berger, Hubbell, and Seltzer's data. These dose extrapolated response coefficients of $1 \mathrm{keV}$ to $10 \mathrm{keV}$ and $10.001 \mathrm{MeV}$ were obtained from the linear logarithmic equations for 0.015 to $0.01 \mathrm{MeV}$ and 8 to $10 \mathrm{MeV}$, respectively, which were assumed valid approximation for these outlying energy ranges. Lastly, a study was performed to determine the effect of extrapolation versus constant response coefficients below $10 \mathrm{keV}$ on buildup factors. The 
exposure coefficients and the two different dose coefficients schemes [extrapolation and constant] are shown in Figure 3.2.

Table 3. 15: Mass-energy absorption for air $\left(\mathrm{cm}^{2} / \mathrm{g}\right)$ and dose $\left(\mathrm{pSv}-\mathrm{cm}^{2}\right)$ response tunctions coefficients used for the PARTISN and MCNPX response functions.

\begin{tabular}{ccc}
\hline energy $(\mathrm{MeV})$ & $\mu_{\text {in }}(\mathrm{E}) \rho$ & $\mathrm{H}^{*}(10)$ \\
\hline 0.001 & 3599.0 & - \\
0.0015 & 1188.0 & - \\
0.002 & 526.2 & - \\
0.003 & 161.4 & - \\
0.0032029 & 146.0 & - \\
0.004 & 76.36 & - \\
0.005 & 39.31 & - \\
0.006 & 22.7 & - \\
0.008 & 9.446 & - \\
0.01 & 4.742 & 0.061 \\
0.015 & 1.334 & 0.83 \\
0.02 & 0.5389 & 1.05 \\
0.03 & 0.1537 & 0.81 \\
0.04 & 0.06833 & 0.64 \\
0.05 & 0.04098 & 0.55 \\
0.06 & 0.03041 & 0.51 \\
0.08 & 0.02407 & 0.53 \\
0.1 & 0.02325 & 0.61 \\
0.15 & 0.02496 & 0.89 \\
0.2 & 0.02672 & 1.2 \\
0.3 & 0.02872 & 1.8 \\
0.4 & 0.02949 & 2.38 \\
0.5 & 0.02966 & 2.93 \\
0.6 & 0.02953 & 3.44 \\
0.8 & 0.02882 & 4.38 \\
1 & 0.02789 & 5.2 \\
1.25 & 0.02666 & - \\
1.5 & 0.02547 & 6.9 \\
2 & 0.02345 & 8.6 \\
3 & 0.02057 & 11.1 \\
4 & 0.0187 & 13.4 \\
5 & 0.0174 & 15.5 \\
6 & 0.01647 & 17.6 \\
8 & 0.01525 & 21.6 \\
10 & 0.0145 & 25.6 \\
15 & 0.01353 & - \\
\hline & & \\
\hline & &
\end{tabular}




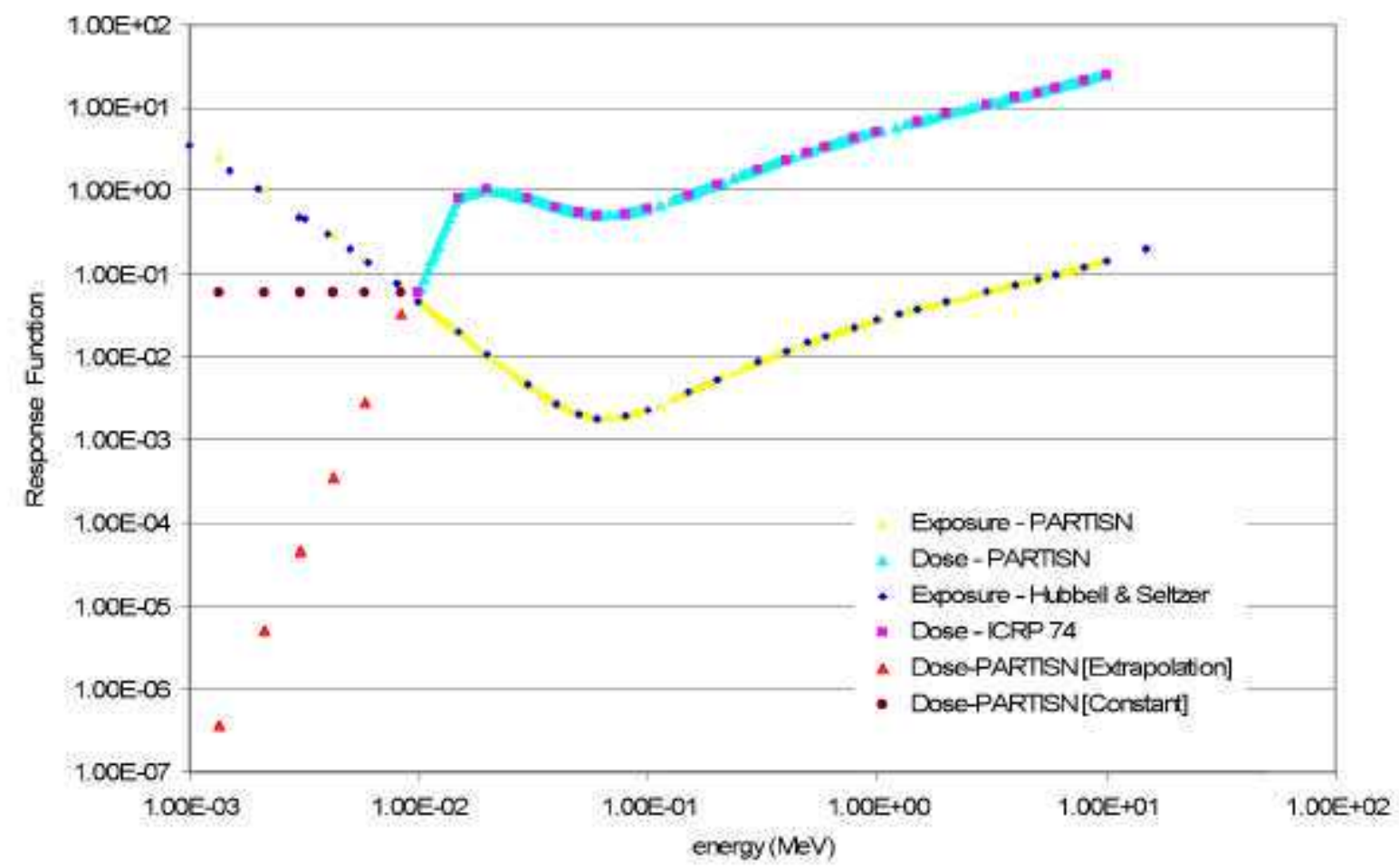

Figure 3.2: Extrapolation and constant scheme for the ICRP dose conversion coefficients $\left(\mathrm{pSv}-\mathrm{cm}^{2}\right)$ and the exposure response function of Berger, Hubbell, and Seltzer $\left(\mathrm{MeV}-\mathrm{cm}^{2} / \mathrm{g}\right)$

Buildup factors as discussed before are dependent on the source energy, the number of mean free paths, and the nature of the medium. As shown in the figure above, the response functions coefficients for exposure and dose are based on the source energy and the corresponding nature of the interactions at these corresponding energies. The trends for the response function coefficients for both the exposure and dose are discussed below.

The point of inflection for the exposure and dose response function coefficients around the energy of $80 \mathrm{keV}$ is a result of the $\mathrm{K}$-edge, where the production of $\mathrm{K}$-shell $\mathrm{x}$-rays occurs [11]. For the exposure response function coefficients, the response function coefficients increase in magnitude for both the higher and lower energy-photons. For the higher-energy photons, the dominant attenuation mechanisms are pair production and Compton scattering. For lower-energy photons, the cross section increases rapidly as the photons become less energetic, increasing the likelihood that the photons will interact with electrons in the photoelectric effect. The response function coefficients for the dose experiences another point of inflection at an energy around $20 \mathrm{keV}$ because the attenuation of these lower energy- 
photons are dominated by the photoelectric effect when compared to Compton scattering [1]]. The response function coefficients for dose decrease significantly below this maximum point of inflection because these lower energy-photons are becoming less likely to penetrate and interact with other matter at a $10 \mathrm{~mm}$-depth in a spherical phantom. The response function coefficients increase from the $\mathrm{K}$-edge to the maximum point of inflection because of the increasing influence of the photoelectric effect over Compton scattering. The more energetic photons above the $\mathbf{K}$-edge have increasing dose response function coefficients as seen in the exposure coefficients because both pair production and Compton scattering are the dominant attenuation interactions with these photons [I I].

Table 3. 16: $\quad$ Parameters used in the discrete-ordinates calculations.

\begin{tabular}{cc}
\hline PARTISN properties & value \\
\hline convergence criteria & $1.0 \mathrm{E}-04$ \\
geometry & infinite slab \\
legrendre scattering order & 7 \\
quadrature order & $\mathrm{S}_{100}$ \\
number of groups & 488 \\
& 244 photon \\
fine mesh density & 244 electron \\
\hline
\end{tabular}

\subsection{Monte Carlo calculations}

As previously discussed, the Monte Carlo code MCNPX was also used in this work as both a comparison and verification of the discrete-ordinates calculalions of PARTISN. Even though the two codes differ, the best way to ensure consistency between them would be to use similar cross section. Another important reason that the primary photon data from ENDF/BVI.8 were used in the discrete-ordinates calculations is because these photon data are processed and formatted for Monte Carlo codes in the MCPLIB04 photon library [25].

The Monte Carlo calculations are based on an infinite slab geometry in a vacuum sphere that is achieved by using reflective boundary conditions on the slab side-walls to ensure any particles that may exit the sides of the material slab will be reflected and re-enter the slab. The incident monenergetic photons are initially "born" in the vacuum and eventually enter uniformally on the entrance of the slab. The photons are then tallied on the slab's exit surtace 
corresponding to a given optical mean free path with the F2 cumulative tally. Shown below are the MCNPX Type 2 tallies that were performed to determine the transmitted flux of photons and responses over a given material's exit surface. A sample MCNPX input file is shown in Appendix D.

Table 3. 17: Different Response Names for the Type 2 Tally in the Monte Carlo code.

\begin{tabular}{cc}
\hline Tally & Name \\
\hline F12 & Transmitted Flux \\
F22 & Transmitted H*(10) \\
F32 & Transmitted Exposure \\
\hline
\end{tabular}

One difference between the two photoatomic data libraries is that the Monte Carlo crosssection libraries are continuous energy whereas the PARTISN cross-section libraries are multigroup. In the case of the Monte Carlo code, a specific energy value will have a prescribed cross-section value, or it is logarithmically interpolated if it is not tabulated, whereas in discrete-ordinates the cross section for an group is averaged over that predetermined group's energy limits. As a result, the Monte Carlo calculation tends to have more accurate results than discrete-ordinates, but can take significant more computer time to obtain a result [7]. 


\section{VALIDITY OF THE 244-GROUP STRUCTURE}

A check was performed to determine the validity of the attenuation coefficients $(\mu / \rho)$ at the 25 source-energy groups with lead with both the CEPXS code and the referenced XCOM's attenuation coefficient data [23]. The reason for this comparison of the attenuation coefficients was to determine if the NJOY's photoatomic data found in the ENDF file and Hubbell \& Seltzer's Data on the NIST website XCOM: Photon Cross Sections Database [23] would result in different macroscopic cross-sections. The comparison that was performed at these 25-source-energy groups was not completely straightforward because the XCOM data produces an attenuation coefficient value $(\mu / \rho)$ at a given point, whereas with NJOY and CEPXS, processing of the ENDF file produces an attenuation coefficient value $(\mu / \rho)$ for the group average. As shown in Table 4.] below with the CEPXS results, the given energy value corresponds to the lower energy of that source energy group and its corresponding attenuation coefficient's group average over that group's energy range.

The detinition of the percent difference that was implemented to compare the ENDF and Hubbell data's attemuation coefficients is:

$$
\frac{C E P X S-X C O M}{C E P X S} \times 100
$$


Table 4. 1: Corresponding Attenuation Coefficient Values at the Group's Lower Energy for lead.

\begin{tabular}{|c|c|c|c|}
\hline $\begin{array}{l}\text { Energy } \\
(\mathrm{MeV})\end{array}$ & $\begin{array}{c}\text { CEPXS } \\
(\mu / \rho) \\
\left(\mathrm{cm}^{2} / \mathrm{g}\right)\end{array}$ & $\begin{array}{c}\mathrm{XCOM} \\
(\mu / \rho) \\
\left(\mathrm{cm}^{2} / \mathrm{g}\right)\end{array}$ & $\%$ Difference \\
\hline 10 & $4.9666 \mathrm{E}-02$ & $4.9720 \mathrm{E}-02$ & -0.10873 \\
\hline 8 & 4.6679E-02 & $4.6750 \mathrm{E}-02$ & -0.15210 \\
\hline 6 & 4.3816E-02 & $4.3910 \mathrm{E}-02$ & -0.21453 \\
\hline 5 & $4.2618 \mathrm{E}-02$ & $4.2720 \mathrm{E}-02$ & -0.23934 \\
\hline 4 & 4. $1845 \mathrm{E}-02$ & 4. $1970 \mathrm{E}-02$ & -0.29872 \\
\hline 3 & $4.2150 \mathrm{E}-02$ & $4.2340 \mathrm{E}-02$ & -0.45077 \\
\hline 2 & $4.5796 \mathrm{E}-02$ & $4.6060 \mathrm{E}-02$ & -0.57647 \\
\hline 1.5 & $5.1817 \mathrm{E}-02$ & $5.2220 \mathrm{E}-02$ & -0.77774 \\
\hline l & $7.0408 \mathrm{E}-02$ & $7.1020 \mathrm{E}-02$ & -0.86922 \\
\hline 0.8 & $8.7927 \mathrm{E}-02$ & $8.8700 \mathrm{E}-02$ & -0.87914 \\
\hline 0.6 & 1.2377E-01 & $1.2480 \mathrm{E}-01$ & -0.83219 \\
\hline 0.5 & 1. $6017 \mathrm{E}-0 \mathrm{l}$ & $1.6 \mathrm{I} 40 \mathrm{E}-0 \mathrm{I}$ & -0.76793 \\
\hline 0.4 & $2.3085 \mathrm{E}-01$ & $2.3230 \mathrm{E}-01$ & -0.62811 \\
\hline 0.3 & $4,0168 \mathrm{E}-01$ & $4.0310 \mathrm{E}-01$ & -0.35352 \\
\hline 0.2 & $9.9728 \mathrm{E}-0 \mathrm{l}$ & $9.9850 \mathrm{E}-0 \mathrm{I}$ & -0.12233 \\
\hline 0.15 & $2,0103 \mathrm{E}+00$ & $2,0140 \mathrm{E}+00$ & -0.18405 \\
\hline 0.$]$ & $5.5095 \mathrm{E}+00$ & $5.5490 \mathrm{E}+00$ & -0.71694 \\
\hline 0.08 & $2.3409 \mathrm{E}+00$ & $2.4190 \mathrm{E}+00$ & -3.33632 \\
\hline 0.06 & $4.8966 \mathrm{E}+00$ & $5.0210 \mathrm{E}+00$ & -2.54054 \\
\hline 0.05 & $7.8645 \mathrm{E}+00$ & $8.0410 \mathrm{E}+00$ & -2.24426 \\
\hline 0.04 & $1.4111 \mathrm{E}+01$ & $1.4360 \mathrm{E}+01$ & -1.76458 \\
\hline 0.03 & $3.0009 \mathrm{E}+01$ & $3.0320 \mathrm{E}+0 \mathrm{I}$ & -1.03636 \\
\hline 0.02 & $8.5623 E+01$ & $8.6360 \mathrm{E}+01$ & -0.86075 \\
\hline 0.015 & $1.1067 \mathrm{E}+02$ & $1.1160 \mathrm{E}+02$ & -0.84034 \\
\hline 0.01 & $1.2735 \mathrm{E}+02$ & I. $3060 \mathrm{E}+02$ & -2.55202 \\
\hline
\end{tabular}

These results demonstrate that the group-averaged and point-wise attenuation coefficient values are similar for 25 -source-energy groups and a systematic consistent difference between the CEPXS and Hubbell data could be a result of the difterent approaches to obtain the attenuation coefficients. Also, the differences between the two libraries begin to deviate a little more at the lower energy values, but this maximum difference of $3.34 \%$ is not substantial. A reason for this deviation is because the attenuation coefficient value obtained for the group-average ENDF data in CEPXS is logarithmically interpolated between the energy groups limits, whereas the XCOM data is determined at a single point. This difference was anticipated and for this reason the source groups were kept at a very thin energy width. 
A point of concem is that theoretically there should be a sign change around 3 to $4 \mathrm{MeV}$ when comparing the point-wise attenuation coefficients of the XCOM data with the groupaveraged attenuation coefticients of the ENDF data as shown in Figure 4.I for the material lead. A plausible reason for this disparity is that similar data libraries are not being used, but once the average grouped attenuation coefficients of the ENDF data are compared with the point-wise attenuation coefficients used by MCNPX, the desired result should be obtained.

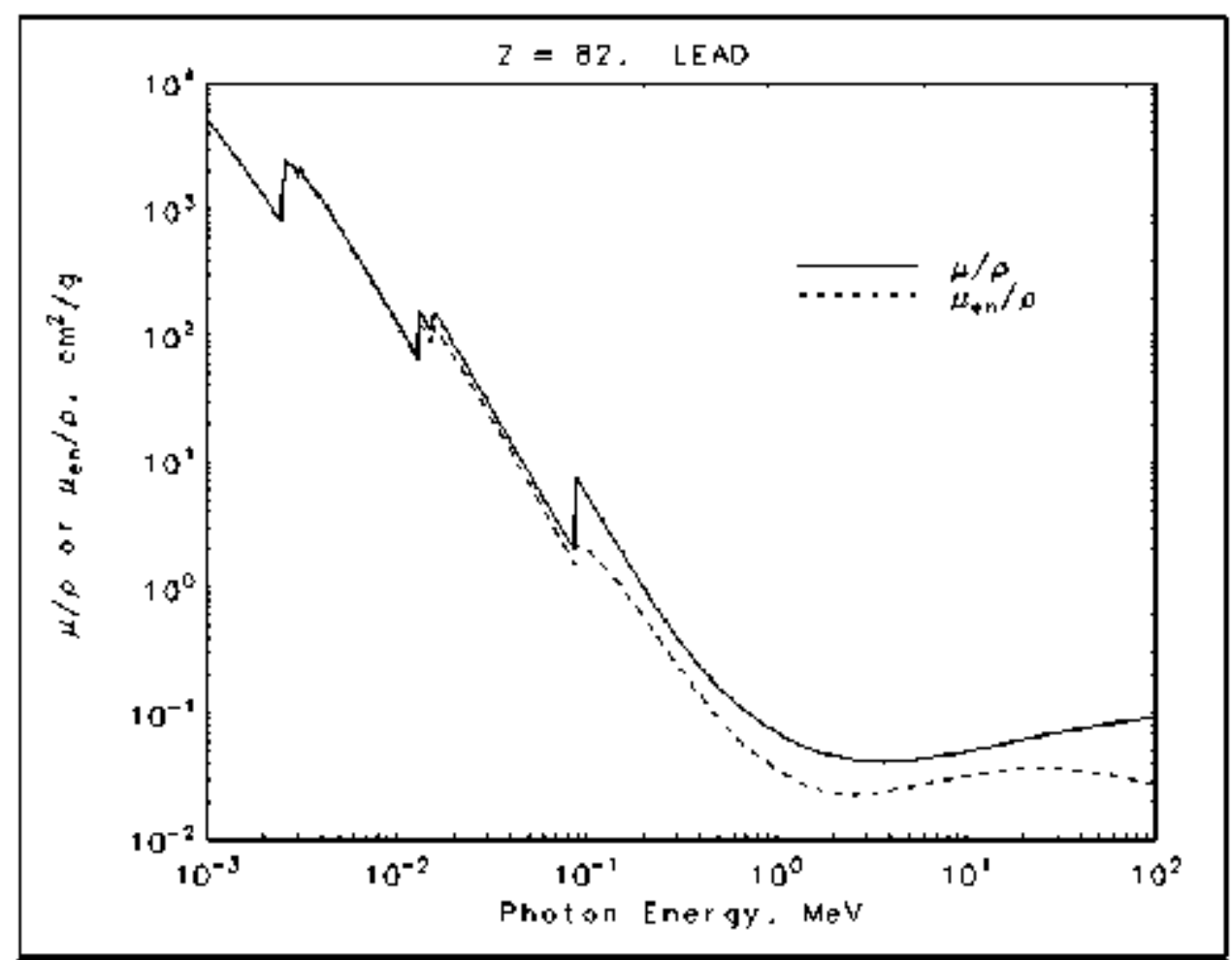

Figure 4.1: Values of the mass attenuation coefficient $(\mu / \rho)$ and mass energy-absorption coefficient $\left(\mu_{\text {en }} / \rho\right)$ of lead as a function of photon energy [23].

To make a comparison between the group-averaged and point-wise ENDF data, the two sources of cross-section data had to be manipulated into comparable units. The groupaveraged ENDF data that was implemented into CEPXS was outputted as a cross-section value in $\mathrm{cm}^{2}$, whereas the MCNPX outputted the point-wise ENDF data as its given cross section in units of barns $\left(10^{-24} \mathrm{~cm}^{2}\right)$. The comparison of the cross-section values were studied with the units of $\mathrm{cm}^{2}$. The equations that were used to obtain the end results are shown below: 
ENDF

$$
\sigma=\frac{\mu}{\rho} \times \frac{A}{N_{-1}}
$$

where

$$
\begin{aligned}
& \sigma=\text { the cross section }\left[\mathrm{cm}^{2}\right] \\
& \mu / \rho=\text { the group-averaged attenuation coefficient }\left[\mathrm{cm}^{2} / \mathrm{g}\right] \\
& A=\text { the atomic weight of lead }[\mathrm{g} / \mathrm{mo}]] \\
& N_{A}=\text { Avogadro's number }\left[6.022 \times 10^{23} \mathrm{l} / \mathrm{mol}\right]
\end{aligned}
$$

\section{ENDF $_{\text {poill-wise: }}$}

$$
\sigma_{p}=\sigma_{\mathrm{t}} \times 10^{-3+t}
$$

where:

$$
\begin{aligned}
& \sigma_{p}=\text { the cross section }\left[\mathrm{cm}^{2}\right] \\
& \sigma_{h}=\text { the cross section [bams] }
\end{aligned}
$$

The definition of the percent difference that was implemented to compare the group averaged and point-wise ENDF data's cross-section values is:

$$
\frac{E N D F_{\text {zroup }}-E N D F_{\text {pount- xrye }}}{E N D F_{\text {gromp }}} \times 100
$$


Table 4.2: $\quad$ ENDF Cross-Section Values for CEPXS and MCNPX at the Group's Lower Energy for Lead.

\begin{tabular}{|c|c|c|c|}
\hline $\begin{array}{l}\text { Energy } \\
\text { (MeV) }\end{array}$ & $\begin{array}{c}\text { CEPXS } \\
\sigma \\
\mathrm{cm}^{2}\end{array}$ & $\begin{array}{c}\text { MCNPX } \\
\sigma \\
\mathrm{cm}^{2}\end{array}$ & $\%$ Difference \\
\hline 10 & 1.7089E-23 & $1.7089 \mathrm{E}-23$ & $-0.00225 \%$ \\
\hline 8 & 1. $606 \mathrm{IE}-23$ & $1.6063 \mathrm{E}-23$ & $-0.01298 \%$ \\
\hline 6 & $1.5076 \mathrm{E}-23$ & $1.5081 \mathrm{E}-23$ & $-0.03125 \%$ \\
\hline 5 & 1.4664E-23 & $1.4671 \mathrm{E}-23$ & $-0.05102 \%$ \\
\hline 4 & 1.4398E-23 & 1.4409E-23 & $-0.07959 \%$ \\
\hline 3 & $1.4503 \mathrm{E}-23$ & 1. $4522 \mathrm{E}-23$ & $-0.13254 \%$ \\
\hline 2 & $1.5757 \mathrm{E}-23$ & $1.5792 \mathrm{E}-23$ & $-0.22203 \%$ \\
\hline 1.5 & 1. $7829 \mathrm{E}-23$ & 1. $7878 \mathrm{E}-23$ & $-0.27846 \%$ \\
\hline ] & $2.4225 \mathrm{E}-23$ & $2.4303 \mathrm{E}-23$ & $-0.31966 \%$ \\
\hline 0.8 & $3.0253 \mathrm{E}-23$ & $3.03 \mathrm{~L} 9 \mathrm{E}-23$ & $-0.21916 \%$ \\
\hline 0.6 & $4.2586 \mathrm{E}-23$ & 4. $2643 \mathrm{E}-23$ & $-0.13424 \%$ \\
\hline 0.5 & $5.5110 \mathrm{E}-23$ & $5.5154 \mathrm{E}-23$ & $-0.07944 \%$ \\
\hline 0.4 & $7.9429 \mathrm{E}-23$ & $7.9460 \mathrm{E}-23$ & $-0.03859 \%$ \\
\hline 0.3 & $1,3821 \mathrm{E}-22$ & 1.3804E-22 & $0.12036 \%$ \\
\hline 0.2 & $3.43 \mathrm{I} 4 \mathrm{E}-22$ & 3.426IE-22 & $0.15447 \%$ \\
\hline 0.15 & $6.9169 \mathrm{E}-22$ & $6.9073 \mathbf{E}-22$ & $0.13829 \%$ \\
\hline 0.1 & $1.8957 \mathrm{E}-2 \mathrm{I}$ & $1.9078 \mathrm{E}-2 \mathrm{I}$ & $-0.63861 \%$ \\
\hline 0.08 & $8.0544 \mathrm{E}-22$ & 8. $1552 \mathrm{E}-22$ & $-1.25242 \%$ \\
\hline 0.06 & $1.6848 \mathrm{E}-21$ & $1.7131 \mathrm{E}-21$ & $-1.67919 \%$ \\
\hline 0.05 & $2.7060 \mathrm{E}-21$ & $2.7527 \mathrm{E}-21$ & $-1.72583 \%$ \\
\hline 0.04 & $4.8552 \mathrm{E}-21$ & $4.9286 \mathrm{E}-21$ & $-1.51255 \%$ \\
\hline 0.03 & $1.0325 \mathrm{E}-20$ & $1.042 \mathrm{IE}-20$ & $-0.93167 \%$ \\
\hline 0.02 & $2.9460 \mathrm{E}-20$ & $2.9591 \mathrm{E}-20$ & $-0.44432 \%$ \\
\hline 0.015 & $3.8078 \mathrm{E}-20$ & $3.8286 \mathrm{E}-20$ & $-0.54532 \%$ \\
\hline 0.01 & 4. $3818 E-20$ & $4.4686 \mathrm{E}-20$ & $-1.98279 \%$ \\
\hline
\end{tabular}

This comparison of the different ENDF cross-section values demonstrate that the attenuation coefficient values are similar for 25 -source-energy groups and the systematic consistent difference between the group-averaged and point-wise ENDF data is probably because of the width of the energy groups compared to a single point. Another realization is that the differences between the two cross sections also increase a little more at the lower energy values, as also seen before, but this maximum difference of $1.98 \%$ is not substantial. The point of concem still exists, that there was no sign change around the energy level of 3 to 4 $\mathrm{MeV}$ when comparing the group-averaged and point-wise cross section values of the ENDF data. But instead, there was a sign change at 0.4 to $0.3 \mathrm{MeV}$ and 0.15 to $0.1 \mathrm{MeV}$, where the 
differences were fractions of a percent. A possible reason for the inconsistency in the sign changes could be because of noise and round-off errors; for example, the attenuation coefficient $(\mu / \rho)$ is a derived quantity and the pure cross section, in units of bams, is a multiplication of a material's density and Avogadro's constant. As a result, the density and Avogadro's constant may be slightly different than the values used by the National Institute of Standards and Technology. Even though this study did not follow the theoretical curve of the mass-attenuation coefficients of Figure 4. ] with its sign changes, the results further show that the group-averaged values that are dictated by the multigroup structure will produce similar results to the point-wise values.

\subsection{Response comparisons}

The next step in confirming the $244-\mathrm{group}$ structure was a test trial with $500-\mathrm{keV}$ and $10-\mathrm{keV}$ photons normally incident on a lead slab with a thickness of 1 mean free path with MCNPX, Wooten's 220-group structure, and the new 244-group structure to determine how the results for the exit flux and the two response functions compare, assuming at this time that only the dose extrapolation scheme was considered. In theory, the 244-group structure's results should be more comparable to MCNPX than the 220-group structure because the source group for the $500-\mathrm{keV}$ source energy was modified from $50 \mathrm{keV}$ to $500.5 \mathrm{keV}$.

For the $500-\mathrm{keV}$ and $10-\mathrm{keV}$ photons normally incident on the lead slab at 1 mean free path, the percent difference for the 220-and 244-group structure calculations are based on the MCNPX benchmark values for the given points. The results for the two scenarios are shown below.

Difference:

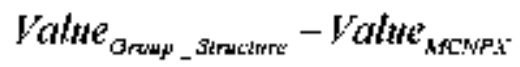

Percent Difference:

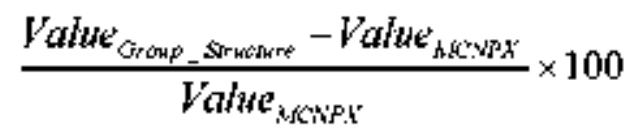


Table 4.3: Responses for $500-\mathrm{keV}$ photons normally incident on a lead slab at $1 \mathrm{mfp}$.

\begin{tabular}{lccc}
\hline & & \multicolumn{2}{c}{ Energy-Group Structure } \\
Responses & MCNPX & 220 & 244 \\
\hline Exit Flux & $5.0448 \mathrm{E}-01$ & $5.02310 \mathrm{E}-01$ & $5.02453 \mathrm{E}-01$ \\
Exposure & $7.0227 \mathrm{E}-03$ & $6.92930 \mathrm{E}-03$ & $7.19974 \mathrm{E}-03$ \\
Dose & $1.3919 \mathrm{E}+00$ & $1.37330 \mathrm{E}+00$ & $1.37239 \mathrm{E}+00$ \\
\hline
\end{tabular}

Table 4.4: Responses for $10-\mathrm{keV}$ photons normally incident on a lead slab at $\mathrm{lmfp}$.

\begin{tabular}{lccc}
\hline & & \multicolumn{2}{c}{ Energy-Group Structure } \\
Responses & MCNPX & 220 & 244 \\
\hline Exit Flux & $3.78066 \mathrm{E}-01$ & $3.78435 \mathrm{E}-01$ & $3.96986 \mathrm{E}-01$ \\
Exposure & $1.79386 \mathrm{E}-02$ & $1.72638 \mathrm{E}-02$ & $2.71026 \mathrm{E}-02$ \\
Dose & $2.32109 \mathrm{E}-02$ & $2.59535 \mathrm{E}-02$ & $2.33531 \mathrm{E}-02$ \\
\hline
\end{tabular}

Table 4.5: Percent difference between the MCNPX value and the different group structures for the $500-\mathrm{keV}$ photons.

\begin{tabular}{lcc}
\hline Responses & $\begin{array}{c}220 \text {-Group Structure } \\
\text { Difference }\end{array}$ & $\begin{array}{c}\text { 244-Group Structure } \\
\text { Difference }\end{array}$ \\
\hline Exit Flux & $-0.4301 \%$ & $-0.4018 \%$ \\
Exposure & $-1.3300 \%$ & $2.5210 \%$ \\
Dose & $-1.3363 \%$ & $-1.4017 \%$ \\
\hline
\end{tabular}

Table 4.6: Percent difference between the MCNPX value and the different group structures for the $10-\mathrm{keV}$ photons.

\begin{tabular}{lcc}
\hline & 220 -Group Structure & 244-Group Structure \\
Responses & Difference & Difference \\
Exit Flux & $0.0976 \%$ & $5.0044 \%$ \\
Exposure & $-3.7617 \%$ & $51.0854 \%$ \\
Dose & $11.8160 \%$ & $0.6126 \%$ \\
\hline
\end{tabular}

Because the 220- and 244-group structures are different, their respective slabs thickness are also different because the group-averaged macroscopic cross sections are based on the different energy groups of photons that are interacting with the material slab at both the 500 $\mathrm{keV}$ and $\mathrm{t} 0-\mathrm{keV}$ studies. A table is shown below to help visualize this difference in the difterent thicknesses used. As a result, the exit flux and the two response functions that are calculated in PARTISN should have values that are fairly close to one another. 
Table 4.7: Lead slab thickness differences for different group structures.

\begin{tabular}{|c|c|c|c|c|}
\hline & \multicolumn{2}{|c|}{ 10-keV lead slab $@$ I mfp } & \multicolumn{2}{|c|}{ 500-keV lead slab @ I mfp } \\
\hline energy group structure & 220 & 244 & 220 & 244 \\
\hline energy grou & $10.3671-10$ & $10.01-10$ & $50]-500$ & $500.5-500$ \\
\hline$\mu(\mathrm{J} / \mathrm{cm})$ & 1. $3830 \mathrm{E}+03$ & ]. $4454 \mathrm{E}+03$ & $1.8166 \mathrm{E}+00$ & $1.8179 \mathrm{E}+00$ \\
\hline thickness (cm) & 0.000726682 & 0.000695298 & 0.55324121 & 0.552826719 \\
\hline
\end{tabular}

This sensitivity study demonstrates that the 220 - and $244-$ group structures produce very similar results when compared to MCNPX results with $500-\mathrm{keV}$ photons. This is not the case with 10 -keV photons, where the 220 -group structure produces more similar results with the MCNPX results at every calculation, except with the dose response function. These results are fairly reasonable at this low energy because the transport of these $10-\mathrm{keV}$ photons interacting on the lead slab is primarily of only uncollided photons. Down-scattered photons are primarily absotbed in the lead slab. The following discussion also states why the 220and 244-group structure produce fairly reasonable results when compared to the MCNPX results with the $10-\mathrm{keV}$ photons.

There are two reasons for the large difference in the dose response and the exposure response with l0-keV photons when compared to MCNPX results for the 220- and 244-groupstructures. The first reason is that the coefficients for the mass-energy absorption for air that are used in the exposure response function as shown in Figure 3.I increase rapidly at extremely low energies, (10 keV to $1 \mathrm{keV})$ while the coefficients for the dose response function as shown in the same figure decrease rapidly at extremely low energies. This affects the multigroup averaged coefficient values. The second reason is that at these extremely low energies the cross sections are rapidly increasing, which will affect the macroscopic cross section that one obtains for a given energy group.

Two checks shown below demonstrate that the results stated above at both energies, $10 \mathrm{keV}$ and $500 \mathrm{keV}$, are correct with supporting evidence. The first check is that smaller energy ranges for the source-energy have higher fluxes because the average attenuation coefficient is higher with increased scattering. As shown, the 244-group structure has a higher flux than the 220 -group structure at both energy levels. The second check demonstrates that the smaller energy groups (244-group structure) al a given energy level have a larger mean free path 
thickness because the macroscopic cross section in these smaller energy groups are steeper than the macroscopic cross section in the larger energy groups (220-group structure).

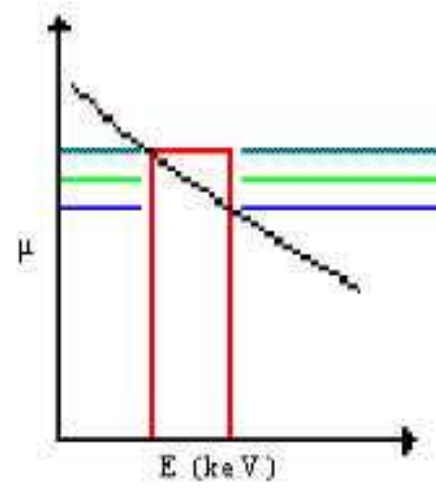

(a)

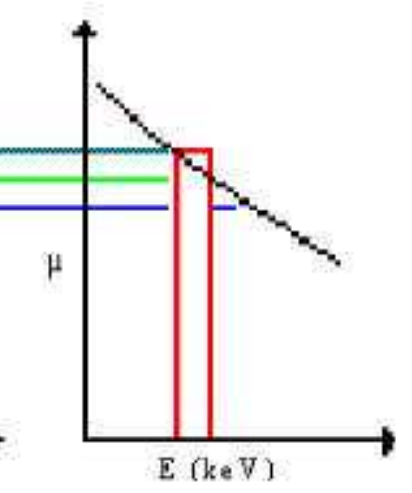

(b)

Figure 4.2: Macroscopic cross section at a given energy level in (a) a larger energy group compared to (b) a smaller energy group.

Table 4.8: Checks for the $10-\mathrm{keV}$ and $500-\mathrm{keV}$ incident photons for both energy group structures.

\begin{tabular}{ccccc}
\hline & \multicolumn{2}{c}{$10-\mathrm{keV}$ lead slab @ 1 mfp } & \multicolumn{2}{c}{$500-\mathrm{keV}$ lead slab @ 1 mfp } \\
\hline $\begin{array}{c}\text { energy group structure } \\
\text { energy group (keV) }\end{array}$ & 220 & 244 & 220 & 244 \\
& $10.3671-10$ & $10.01-10$ & $501-500$ & $500.5-500$ \\
exit flux & $3.78435 \mathrm{E}-01$ & \multicolumn{4}{c}{$\begin{array}{c}\text { Check \#1 } \\
\end{array}$} & \multicolumn{4}{c}{ Check \#2 } \\
$\mu(1 / \mathrm{cm})$ & $1.3830 \mathrm{E}+03$ & $1.4454 \mathrm{E}+03$ & $1.8166 \mathrm{E}+00$ & $1.8179 \mathrm{E}+00$ \\
thickness $(\mathrm{cm})$ & 0.000726682 & 0.000695298 & 0.55324121 & 0.552826719 \\
\hline
\end{tabular}

The next test performed was with $500-\mathrm{keV}$ and $10-\mathrm{keV}$ photons normally incident on a lead slab with a thickness of 1 mean free path with both energy group structures, but with a modified 244-group CEPXS file to determine if the attenuation coefficients and buildup factors will be significantly different. In theory, the buildup factor results for the $500-\mathrm{keV}$ photons will not differ much because absorption is not a dominant effect at this energy level, but a modification of the CEPXS file may be significant at the low energy of $10 \mathrm{keV}$ where absorption is a dominant effect. This modified CEPXS file incorporates pair production, coherent scattering, incoherent scattering, and absorption from the ENDF data file, while the previous 220-group CEPXS file developed by Wooten did not include the ENDF data for absorption, but instead uses the older Biggs-Lighthill data. 
As stated before, the percent difference for the 220 and 244-group structure calculations are based on the MCNPX benchmark values for the $500-\mathrm{keV}$ and $10-\mathrm{keV}$ photons normally incident on the lead slab at 1 mean free path. Results for the two scenarios are shown below.

Difference:

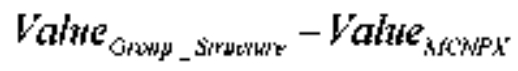

Percent Difference:

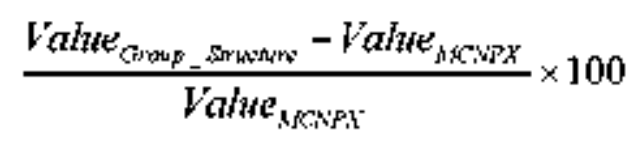

Table 4.9: Responses of the different CEPXS files for 500-keV photons normally incident on a lead slab at $\mathrm{lmfp}$ with the 220 -group structure.

\begin{tabular}{cccc}
\hline & & \multicolumn{2}{c}{$220-$ Group Struclure } \\
& MCNPX & Biggs-Lighthill & ENDF \\
\hline Cross Section & & $5.5069 \mathrm{E}-23$ & $5.5072 \mathrm{E}-23$ \\
Responses & & & \\
Exit Flux & $5.0448 \mathrm{E}-01$ & $5.02310 \mathrm{E}-01$ & $5.02262 \mathrm{E}-01$ \\
Exposure & $7.0227 \mathrm{E}-03$ & $6.92930 \mathrm{E}-03$ & $6.92887 \mathrm{E}-03$ \\
Dose & $1.3919 \mathrm{E}+00$ & $1.37330 \mathrm{E}+00$ & $1.37322 \mathrm{E}+00$ \\
\hline
\end{tabular}

Table 4. 10: Responses of the different CEPXS files for $500-\mathrm{keV}$ photons normally incident on a lead slab at $\mathrm{Imfp}$ with the 244-group structure.

$$
\text { 244-Group Structure }
$$

MCNPX Biggs-Lighthill ENDF

\begin{tabular}{cccc}
\hline $\begin{array}{c}\text { Cross Section } \\
\text { Responses }\end{array}$ & & $5.5110 \mathrm{E}-23$ & $5.5113 \mathrm{E}-2 \hat{3}$ \\
Exit Flux & $5.0448 \mathrm{E}-01$ & $5.02453 \mathrm{E}-01$ & $5.02403 \mathrm{E}-01$ \\
Exposure & $7.0227 \mathrm{E}-03$ & $7.19974 \mathrm{E}-03$ & $7.20124 \mathrm{E}-03$ \\
Dose & $1.3919 \mathrm{E}+00$ & $1.37239 \mathrm{E}+00$ & $1.37230 \mathrm{E}+00$ \\
\hline
\end{tabular}

Table 4.1 1: Percent difference between the MCNPX value and the different group structures with the different CEPXS files for $500-\mathrm{keV}$ photons.

\begin{tabular}{ccccc}
\hline & \multicolumn{2}{c}{ Biggs-Lighthill absorption } & \multicolumn{2}{c}{ ENDF absorption } \\
Energy group structure & 220 & 244 & 220 & 244 \\
Responses & Difference & Difference & Difference & Difference \\
\hline Exit Flux & $-0.4301 \%$ & $-0.4018 \%$ & $-0.4397 \%$ & $-0.4117 \%$ \\
Exposure & $-1.3300 \%$ & $2.5210 \%$ & $-1.3361 \%$ & $2.5423 \%$ \\
Dose & $-1.3363 \%$ & $-1.4017 \%$ & $-1.3421 \%$ & $-1.4081 \%$ \\
\hline
\end{tabular}


Table 4.12: Responses of the different CEPXS files for 10-keV photons normally incident on a lead slab at $1 \mathrm{mfp}$ with the 220-group structure.

\begin{tabular}{cccc}
\hline & & \multicolumn{2}{c}{$220-$ Group Structure } \\
& MCNPX & Biggs-Lighthill & ENDF \\
\hline $\begin{array}{c}\text { Cross Section } \\
\text { Reponses }\end{array}$ & & $4.1925 \mathrm{E}-20$ & $4.2679 \mathrm{E}-20$ \\
Exit Flux & $\mathbf{3 . 7 8 0 6 6 \mathrm { E } - 0 1}$ & $\mathbf{3 . 7 8 4 3 5 \mathrm { E } - 0 1}$ & $3.78165 \mathrm{E}-01$ \\
Exposure & $1.79386 \mathrm{E}-02$ & $1.72638 \mathrm{E}-02$ & $1.72515 \mathrm{E}-02$ \\
Dose & $2.32109 \mathrm{E}-02$ & $2.59535 \mathrm{E}-02$ & $2.59350 \mathrm{E}-02$ \\
\hline
\end{tabular}

Table 4.13: Responses of the different CEPXS files for $10-\mathrm{keV}$ photons normally incident on a lead slab at $1 \mathrm{mfp}$ with the 244-group structure.

\begin{tabular}{cccc}
\hline & & \multicolumn{2}{c}{ 244-Group Structure } \\
& MCNPX & Biggs-Lighthill & ENDF \\
\hline Cross Section & & $4.3818 \mathrm{E}-20$ & $4.4633 \mathrm{E}-20$ \\
Responses & & & \\
Exit Flux & $3.78066 \mathrm{E}-01$ & $3.96986 \mathrm{E}-01$ & $3.96087 \mathrm{E}-01$ \\
Exposure & $1.79386 \mathrm{E}-02$ & $2.71026 \mathrm{E}-02$ & $2.69180 \mathrm{E}-02$ \\
Dose & $2.32109 \mathrm{E}-02$ & $2.33531 \mathrm{E}-02$ & $2.33191 \mathrm{E}-02$ \\
\hline
\end{tabular}

Table 4. 14: Percent difference between the MCNPX value and the different group structures with the different CEPXS files for the $10-\mathrm{keV}$ photons.

\begin{tabular}{ccccc}
\hline & \multicolumn{2}{c}{ Biggs-Lighthill absorption } & \multicolumn{2}{c}{ ENDF absorption } \\
Energy group stucture & 220 & 244 & 220 & 244 \\
Responses & Difference & Difference & Difference & Difference \\
\hline Exit Flux & $0.0976 \%$ & $5.0044 \%$ & $0.0262 \%$ & $4.7666 \%$ \\
Exposure & $-3.7617 \%$ & $51.0854 \%$ & $-3.8303 \%$ & $50.0563 \%$ \\
Dose & $11.8160 \%$ & $0.6126 \%$ & $11.7363 \%$ & $0.4662 \%$ \\
\hline
\end{tabular}

This sensitivity test with $500-\mathrm{keV}$ and $10-\mathrm{keV}$ photons demonstrates that the both the 220 and 244-group structures produce very similar results when compared to MCNPX results with both CEPXS files. These results also demonstrate that the modification of the CEPXS file to include the updated ENDF absorption data did not change the values of the flux and the two responses significantly. As a result, the modified CEPXS file with absomption data was used to obtain the buildup factors at all 25 -source energies.

These tests further confirmed the initial assumptions that the flux, dose and exposure responses that were obtained for the $500-\mathrm{keV}$ photons would not differ much with the different energy group structure or CEPXS files because absorption is nol a dominant effect at that energy level, whereas at the low energies like $10 \mathrm{keV}$ where absorption is a dominant 
effect there was a significant effect in the response values for both group structures.

Furthemore, these sensitivity tests with both 500 and $10-k e V$ photons normally incident on a lead slab of 1 mean fee path allow one to conclude that the modified CEPXS file with the ENDF absorption file in the 244-group stncture will produce similar results as compared to both MCNPX and Wooten's buildup factors.

\subsection{Dose analysis}

In the previous discussed study, the dose response in the 244-group structure was performed with the extrapolation scheme only. In this sensitivity study, similar trials were performed with the lead slab in PARTISN at energies of $10 \mathrm{keV}$ and $500 \mathrm{keV}$ with the different dose schemes. Percent difference for the 244-group stnucture calculations are based on the MCNPX benchmark values for $500-\mathrm{keV}$ and $10-\mathrm{keV}$ photons normally incident on the lead slab at 1 mean free path with the constant dose scheme. The results for the two scenarios are shown below.

Difference:

$$
V_{\text {ahe }}-\text { Vahe }_{\text {MCWPi }}
$$

Percent Difference:

$$
\frac{\text { Valte }_{2,4}-\text { Valhe }_{\text {MONEX }}}{\text { Vahie }_{\text {MCNPI }}} \times 100
$$

\subsubsection{Responses at $500 \mathrm{keV}$}

Table 4.15: Responses for 500-keV photons normally incident on a $1-\mathrm{mfp}$ lead slab with

\begin{tabular}{|c|c|c|c|}
\hline \multirow[t]{2}{*}{ Responses } & \multirow{2}{*}{$\begin{array}{l}\text { MCNPX } \\
\text { Constant }\end{array}$} & \multicolumn{2}{|c|}{ PARTISN } \\
\hline & & Extrapolation & Constant \\
\hline Exit Flux & $5.04480 \mathrm{E}-01$ & \multicolumn{2}{|c|}{$5.02403 \mathrm{E}-01$} \\
\hline Exposure & $7.02270 \mathrm{E}-03$ & \multicolumn{2}{|c|}{$7.20124 \mathrm{E}-03$} \\
\hline Dose & $1.39190 \mathrm{E}+00$ & $1.37230 \mathrm{E}+00$ & $1.37232 \mathrm{E}+00$ \\
\hline
\end{tabular}
both dose response function coefficient $\mathrm{H}^{*}(10)$ schemes. 
Table 4. 16: Comparison of MCNPX and PARTISN codes' responses for 500-keV photons nomally incident on a l-mfp lead slab with two dose response function coefficient $\mathrm{H}^{*}(10)$ schemes.

\begin{tabular}{ccc}
\hline Responses & Extrapolation $\mathrm{H}^{*}(10)$ & Constant $\mathrm{H}^{*}(\mathrm{I} 0)$ \\
\hline Exi1 Flux & \multicolumn{2}{c}{$-0.4117 \%$} \\
Exposure & & $2.5423 \%$ \\
Dose & $-1.4081 \%$ & $-1.4067 \%$ \\
\hline
\end{tabular}

The results demonstrate that both 244 -group calculations produce essentially the same values when compared to the Monte Carlo results with $500-\mathrm{keV}$ photons. The next step to validate the different dose response function coefficient schemes is to compare the buildup factors determined in PARTISN with the benchmarked MCNPX values. Buildup factors for both codes are shown below concluding that either dose response function scheme implemented into the 244-energy group structure will have comparable resuls to the Monte Carlo results.

Table 4. 17: Buildup factors for $500-\mathrm{keV}$ photons normally incident on a 1-mfp lead slab with both dose response function coefficient $\mathrm{H}^{*}(\mathrm{l} 0)$ schemes.

\begin{tabular}{|c|c|c|c|}
\hline \multirow{2}{*}{ Buildup factors } & MCNPX & \multicolumn{2}{|c|}{ PARTISN } \\
\hline & Constant & Extrapolation & Constant \\
\hline Exit Flux & 1.3709 & \multicolumn{2}{|c|}{1.36567} \\
\hline Exposure & 1.2856 & \multicolumn{2}{|c|}{1.31867} \\
\hline Dose & 1.2898 & 1.27202 & 1.27204 \\
\hline
\end{tabular}

Table 4.18: Percent difference between the MCNPX and PARTISN buildup factors at 500 keV with two dose response function coefficient $H^{*}(10)$ schemes.

\begin{tabular}{ccc}
\hline Buildup factors & Extrapolation $\mathrm{H}^{*}(10)$ & Constant $\mathrm{H}^{*}(10)$ \\
\hline Exit Flux & \multicolumn{2}{c}{$-0.3837 \%$} \\
Exposure & \multicolumn{2}{c}{$2.5713 \%$} \\
Dose & $-1.3803 \%$ & $-1.3789 \%$ \\
\hline
\end{tabular}

\subsubsection{Responses at $10 \mathrm{keV}$}

Table 4. 19: Responses for l0-keV photons normally incident on a l-mfp lead slab with both dose response function coefficient $\mathrm{H}^{*}(10)$ schemes.

\begin{tabular}{cccc}
\hline Responses & MCNPX & \multicolumn{2}{c}{ PARTISN } \\
& Constant & Extrapolation & Constant \\
\hline Exit Flux & $3.78066 \mathrm{E}-01$ & \multicolumn{2}{c}{$3.96087 \mathrm{E}-01$} \\
Exposure & $1.79386 \mathrm{E}-02$ & \multicolumn{2}{c}{$2.69180 \mathrm{E}-02$} \\
Dose & $2.32109 \mathrm{E}-02$ & $2.33191 \mathrm{E}-02$ & $2.42357 \mathrm{E}-02$ \\
\hline
\end{tabular}


Table 4.20: Comparison of MCNPX and PARTISN codes' responses for 10-keV photons normally incident on a l-mfp lead slab at with two dose response function coefficient $\mathrm{H}^{*}(10)$ schemes.

\begin{tabular}{ccc}
\hline Responses & Extrapolation $\mathrm{H}^{*}(10)$ & Constant $\mathrm{H}^{*}(10)$ \\
\hline Exit Flux & \multicolumn{2}{c}{$4.7666 \%$} \\
Exposure & \multicolumn{2}{c}{$50.0563 \%$} \\
Dose & $0.4662 \%$ & $4.4152 \%$ \\
\hline
\end{tabular}

These results demonstrate that both 244-group calculations produce fairly similar values when compared to the Monte Carlo results with $10-\mathrm{keV}$ photons. The percent differences between these two codes are because of the extension of the multigroup structure down to 1 $\mathrm{keV}$. At these extremely low energies, the cross sections increase rapidly resulting in different macroscopic cross sections obtained in the two codes. Furthemore, the exposure response function coefficients as shown in Figure 3.1 increase rapidly at extremely low energies affecting the multigroup averaged coefficient values of PARTISN and the pointwise coefficient values of MCNPX. The validation of the dose response function schemes was performed again by comparing the buildup factors determined in PARTISN and MCNPX with 10-keV source photons. The results conclude that either response function scheme implemented into the 244-group structure will have comparable results to the Monte Carlo results.

Table 4.21: Buildup factors for $10-\mathrm{keV}$ photons normally incident on a l-mfp lead slab with both dose response function coefficient $\mathbf{H}^{*}(10)$ schemes.

\begin{tabular}{cccc}
\hline & MCNPX & \multicolumn{2}{c}{ PARTISN } \\
Buildup factors & Constant & Extrapolation & Constant \\
\hline Exit Flux & 1.0273 & & \multicolumn{2}{c}{1.0767} \\
Exposure & 1.0300 & & 1.5463 \\
Dose & 1.0273 & 1.0325 & 1.0731 \\
\hline
\end{tabular}

Table 4.22: Percent difference between MCNPX and PARTISN Buildup factors at $10 \mathrm{keV}$ with two dose response function coefficient $\mathrm{H}^{*}(10)$ schemes.

\begin{tabular}{ccc}
\hline Buildup factors & Extrapolation $\mathrm{H}^{*}(10)$ & Constant $\mathrm{H}^{*}(10)$ \\
\hline Exil Flux & $4.8106 \%$ & $4.8106 \%$ \\
Exposure & $50.1194 \%$ & $50.1194 \%$ \\
Dose & $0.5083 \%$ & $4.4590 \%$ \\
\hline
\end{tabular}

In conclusion, both studies with photons at energies of $10 \mathrm{keV}$ and $500 \mathrm{keV}$ normally incident on a 1-mean-free-path thick lead slab demonstrate that that both 244-group response functions produce very similar results using discrete-ordinates and Monte Carlo. The main 
reason that the buildup factors are fairly close when comparing the two different sets of dose coefficients with both $500-\mathrm{keV}$ and $10-\mathrm{keV}$ photons is because of the definition of buildup factors which involves the contribution of scattered photons. At the low energies, primarily only uncollided photons pass through the lead slab, which leaves only a small percentage of the scattered photons to eventually reach the slab exit surface. This small percentage of scattered photons is then the contribution to the slight change in the buildup factor where these lower energy photons would be affected by the different dose response functions in the two different $\mathrm{H}^{*}(10)$ schemes implemented.

Both dose response function coefficjent schemes will be implemented in PARTISN assuming that these two extrapolation schemes for the dose coefficients are considered the extreme options. 


\section{COMPARISONS OF RESULTS}

For each of the materials and source energies, discrete-ordinates buildup factors were calculated at thickness that ranged from 1 to 10 mean free paths and at the 10 different photon incident angles. One of the main concerns for obtaining the buildup factors for all nine glovebox materials was to ensure the material composition were all from a single and reliable source. As a result, the following material compositions were referenced from the National Institute of Standards and Technology (NIST) [23] as shown below. In all of these cases, the optical mean free path thickness for a given material and source energy was maintained to ensure the uncollided radiation was constant [7]. The compilation of PARTISN buildup factors are shown in Appendix A.

Monte Carlo calculations were used as a benchmark and comparison to the PARTISN results. Performing MCNPX calculations for all materials at the seven energies [ $10 \mathrm{MeV}, 5 \mathrm{MeV}$, $\mathrm{MeV}, 500 \mathrm{keV}, 100 \mathrm{keV}, 50 \mathrm{keV}$, and $10 \mathrm{keV}]$, three slant-path thicknesses $[1,5$, and 10 mean free paths], and at least three photon incident angles [0.00, 49.29, and 85.48 degrees] enables one to obtain a comprehensive assessment of how the two codes compared over the entire photon energy spectnum and incident angles with the different coupled photon-electron cross sections. MCNPX buildup factor results are tabulated in Appendix B.

The two codes used for the buildup factor calculations demonstrate reasonable similarity. Some trends that were observed for all materials and energies between MCNPX and PARTISN were that the buildup factor values increased as a function of decreasing photon incident angle for I mean free path thicknesses, the buildup factors values increased and then eventually decreased for the 5 mean free path thickness as a function of decreasing incident angle, and lastly the buildup factors values decreased as a function of decreasing photon incident angle for 10 mean free paths. Another trend that occurred for all materials and energies studied was that the buildup factor values of the two codes began to differ substantially for photons at the most oblique incident angle. Reasons for these trends are discussed below. 
Table 5.1: Glovebox materials and physical properties used for discrete-ordinates and Monte Carlo buildup-factor calculations.

\begin{tabular}{|c|c|}
\hline element & density $\left(\mathrm{g} / \mathrm{cm}^{3}\right)$ \\
\hline aluminum & 2.699 \\
\hline iron & 7.874 \\
\hline lead & $1] .35$ \\
\hline $\begin{array}{l}\text { material \& } \\
\text { components }\end{array}$ & $\begin{array}{l}\text { density }\left(g / \mathrm{cm}^{3}\right) \\
\text { weight fraction }\end{array}$ \\
\hline air & 0.001205 \\
\hline carbon & 0.000124 \\
\hline nitrogen & 0.755268 \\
\hline oxygen & $0.23178 \mathrm{I}$ \\
\hline argon & 0.012827 \\
\hline concrete & 2.3 \\
\hline hydrogen & 0.0221 \\
\hline carbon & 0.002484 \\
\hline oxygen & 0.57493 \\
\hline sodium & 0.015208 \\
\hline magnesium & 0.001266 \\
\hline aluminum & 0.019953 \\
\hline silicon & 0.304627 \\
\hline potassium & 0.010045 \\
\hline calcium & 0.042951 \\
\hline iron & 0.006435 \\
\hline leaded glass & 6.22 \\
\hline oxygen & 0.156453 \\
\hline silicon & 0.080866 \\
\hline titanium & 0.008092 \\
\hline arsenic & 0.002651 \\
\hline lead & 0.751938 \\
\hline polyethylene & 0.93 \\
\hline hydrogen & 0.143716 \\
\hline carbon & 0.856284 \\
\hline
\end{tabular}


Table 5.1 (continued)

\begin{tabular}{cc}
\hline $\begin{array}{c}\text { material } \& \\
\text { components }\end{array}$ & $\begin{array}{c}\text { density }\left(\mathrm{g} / \mathrm{cm}^{3}\right) \\
\text { weight fraction }\end{array}$ \\
\hline stainless steel & 8.03 \\
carbon & 0.000136 \\
silicon & 0.0108 \\
phosphorous & 0.00007 \\
\$ulfur & 0.000078 \\
vanadium & 0.00041 \\
chromium & 0.1846 \\
manganese & 0.00085 \\
iron & 0.701826 \\
cobalt & 0.0009 \\
nickel & 0.1000 \\
copper & 0.00029 \\
molybdenum & 0.00004 \\
water & 1.0 \\
bydrogen & 0.111898 \\
oxygen & 0.888102 \\
\hline
\end{tabular}

Table 5.2: Angles (relative to normal) at which the incident photons are implemented for the buildup factor calculations.

\begin{tabular}{ccc}
\hline & $\cos \left(\theta_{\text {meidcni }}\right)$ & $\theta_{\text {maldanl }}$ (degrees) \\
\hline $\mathrm{I}$ & $\mathrm{l}$ & 0.00 \\
2 & 0.98633 & 9.48 \\
3 & $0.9005]$ & 25.77 \\
4 & 0.74247 & 42.06 \\
5 & 0.65217 & 49.29 \\
6 & 0.49774 & 60.15 \\
7 & 0.35519 & 69.20 \\
8 & 0.26518 & 74.62 \\
9 & 0.17279 & 80.05 \\
10 & 0.07886 & 58.48 \\
\hline
\end{tabular}

A representation of trends between the PARTISN and MCNPX buildup factors is shown in the following figures. The figures represent only a few cases of the slant-path thicknesses of the nine different material's purely angular responses of exit flux, exposure, and the two dose schemes.

The reasons for different buildup factor trends are based on the angle at which a photon scatters after experiencing an interaction within a slab as dictated by the Klein-Nishina formula. When considering a nomally incident photon on a material slab, the azithmuthal 
component of scattering angle has no influence to the remaining pathlength (optical escape path length) that the photon must transverse to exit the slab therefore implying that all the scattered photons exit the slab with equal probability. This is not the case for photons that do not interact normally with the slab. In this example, the azithmuthal component of the Klein-Nishina scattering angle has a significant effect on whether the scattered photon will escape the slab because of the optical escape path length. The optical escape path lengths are dependent on the slab thickness and the scattering angle. The particles that follow the shortest optical escape path length are more likely to cross the exit surface of the slab with lower angles of incidence relative to the normal than the particles escaping along the longer optical escape path length ultimately contributing less to the total exit flux. In general, particles that follow the shorter optical escape path length are more likely to escape the slab than a longer escape path length. Furthermore, as the angle of incidence increases, the normal thickness and the shortest optical escape path length decreases [7].

In the case of a mean-free-path slab, a slab thickness typically corresponding to a single photon interaction, the buildup factor value increases as the angle of the incident photon interacting on the slab decreases. This is because of the incident photon, noting that larger angular incident photons will typical exit the slab on a short escape path length that has a lower angle of incidence on the exit surface than a lower or even normal incident photon as shown in Figure S.l. As a result, the contribution to the total exit flux will be higher for the decreasing photon incident angle which will lead to a higher buildup factor value. In the case of thick slabs, where more collisions take place, the trend is reversed. As the incident angle increases, the nomal thickness and short optical escape path length decrease, allowing these particles to have a shorter optical path length that is more in the normal incident direction which enables these photons to have a higher probability of escaping the slab with fewer interactions. 


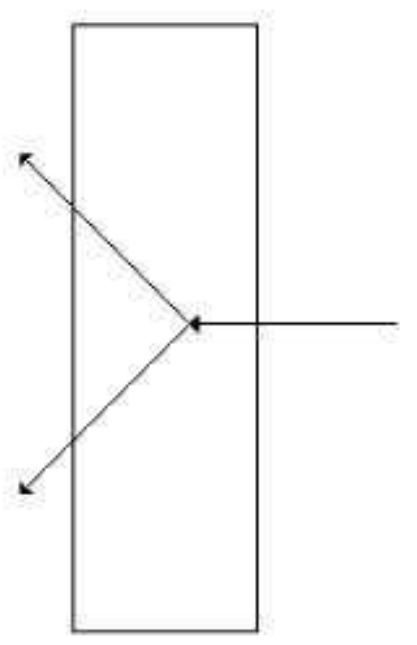

(a)

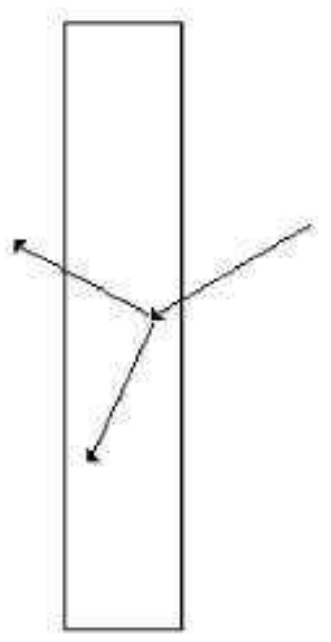

(b)

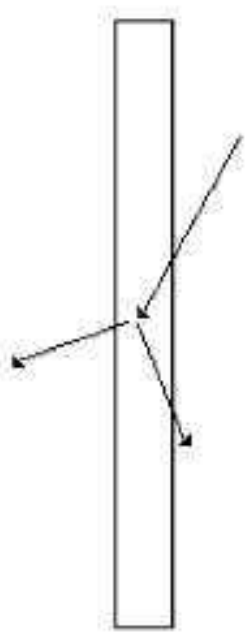

(c)

Figure 5.1: Optical escape path differences for normal, moderate, and oblique incident angles.

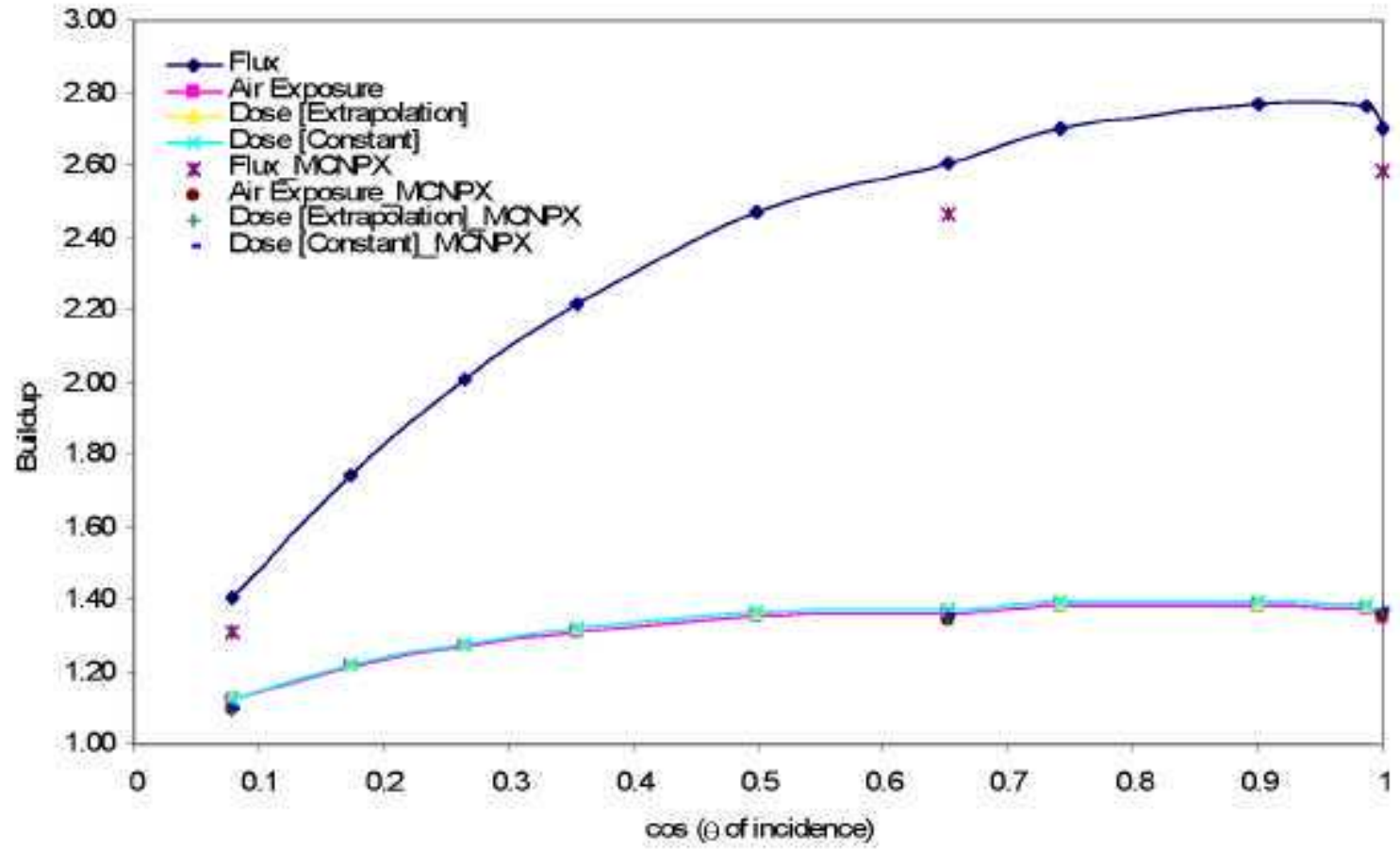

Figure 5.2: Purely-angular photon buildup factors for $10-\mathrm{MeV}$ photons incident on 1-mfp of air. 


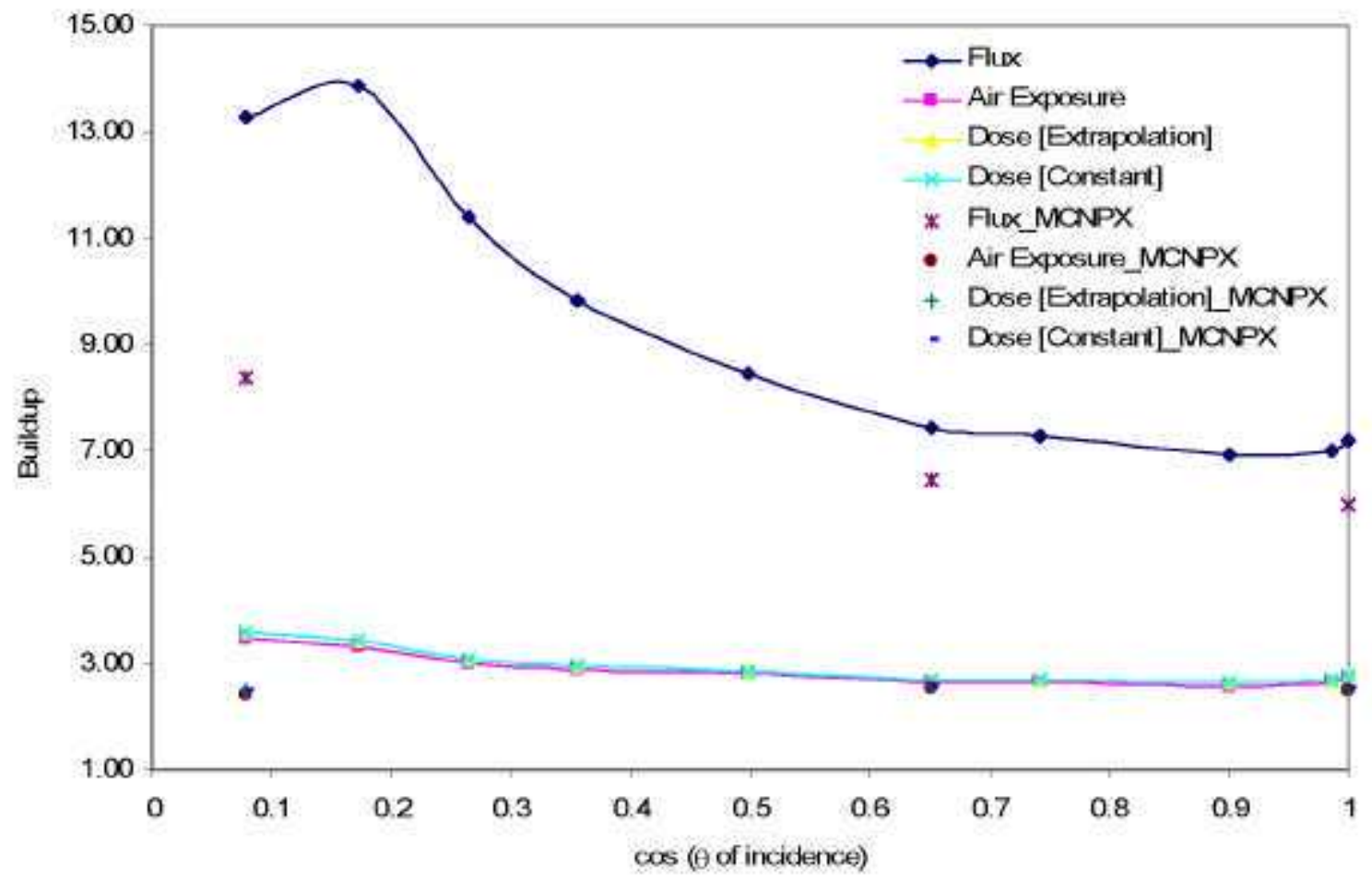

Figure 5.3: Purely-angular photon buildup factors for $10-\mathrm{MeV}$ photons incident on 5-mfp of air.

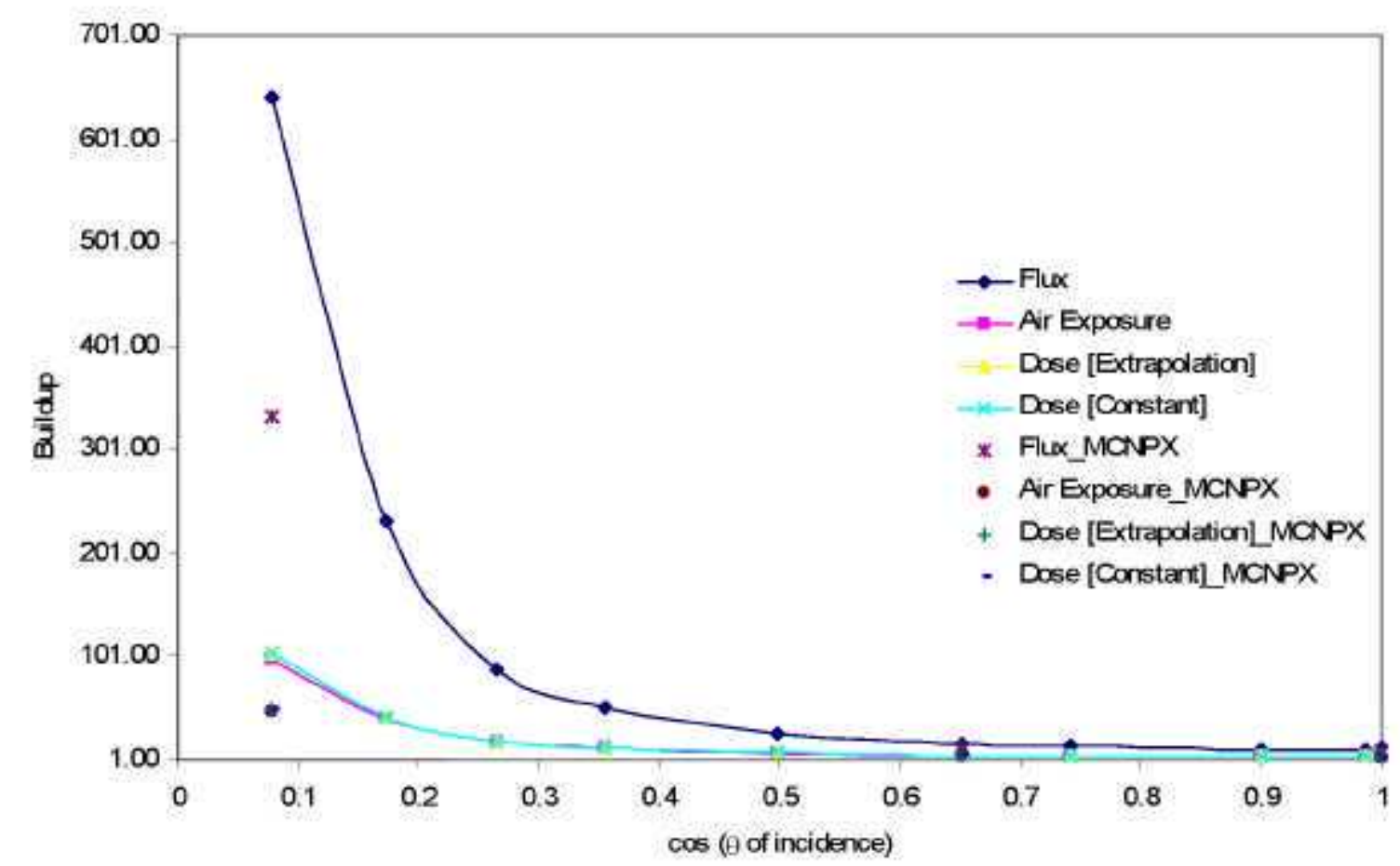

Figure 5.4: Purely-angular photon buildup factors for $10-\mathrm{MeV}$ photons incident on 10- mfp of air. 


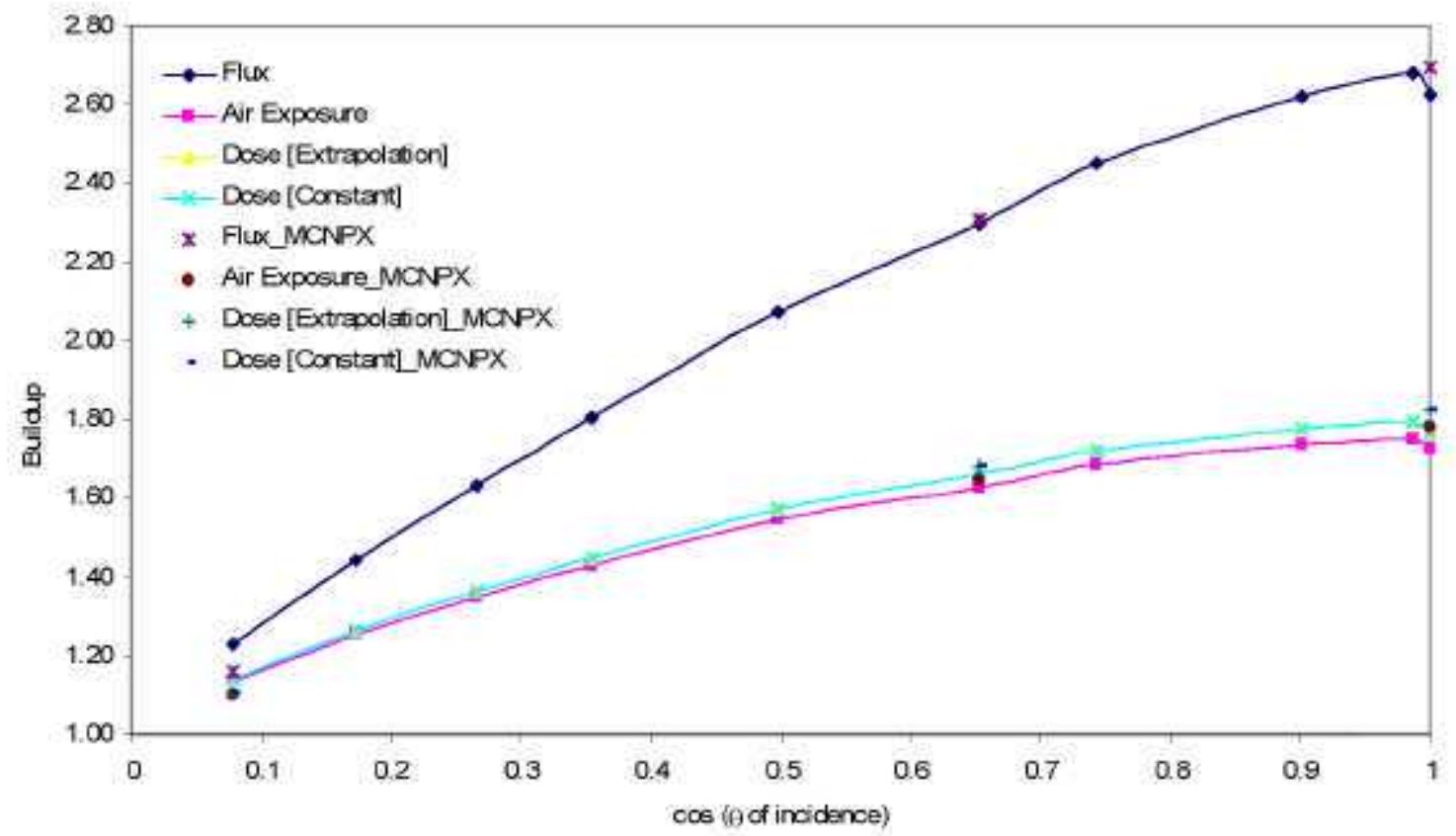

Figure 5.5: Purely-angular photon buildup factors for $1-\mathrm{MeV}$ photons incident on 1-mfp of water.

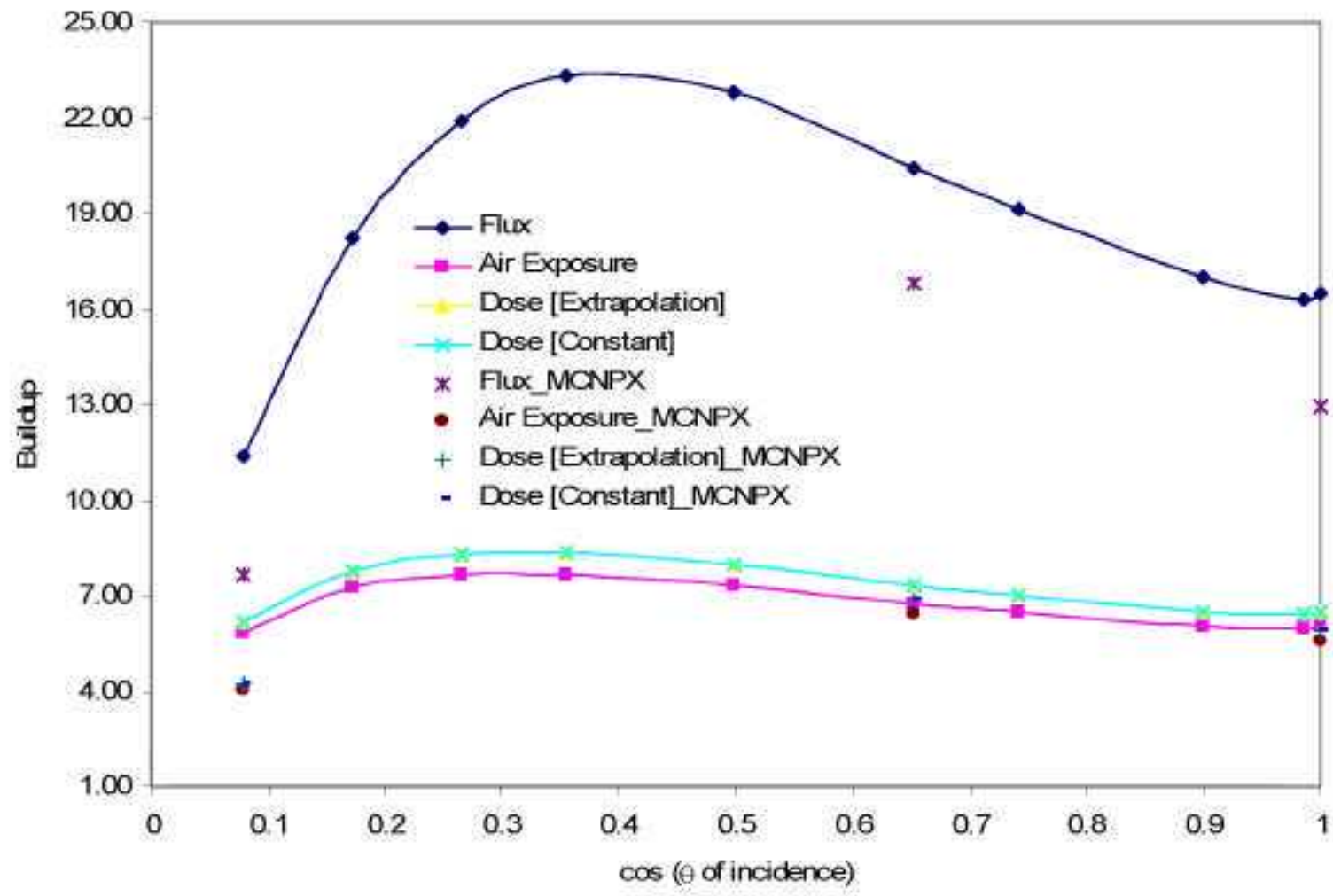

Figure 5.6: Purely-angular photon buildup factors for 1-MeV photons incident on 5-mfp of water. 


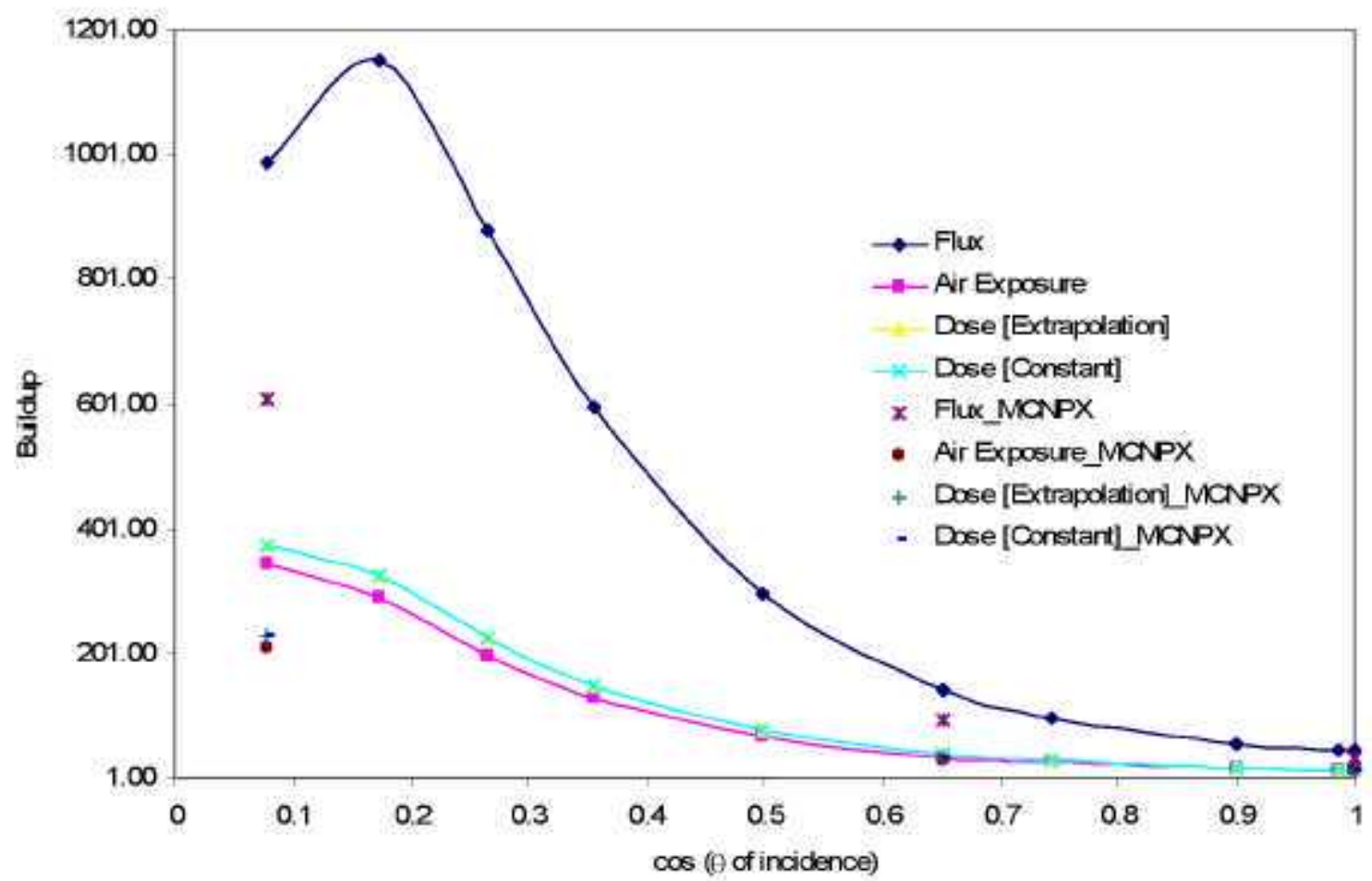

Figure 5.7: Purely-angular photon buildup factors for 1-MeV photons incident on 10-mfp of water.

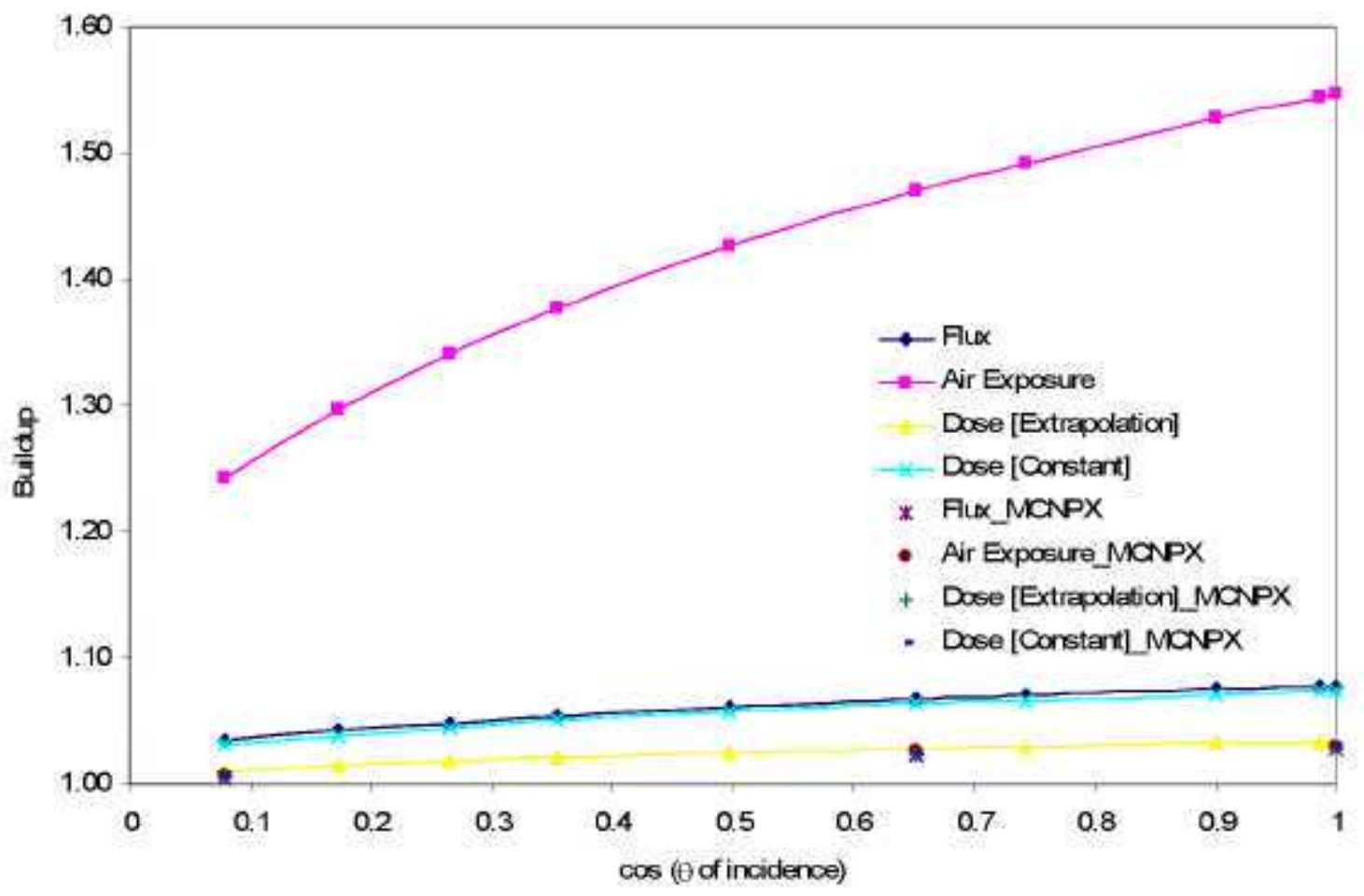

Figure 5.8: Purely-angular photon buildup factors for $10-\mathrm{keV}$ photons incident on $1-\mathrm{mfp}$ of lead. 


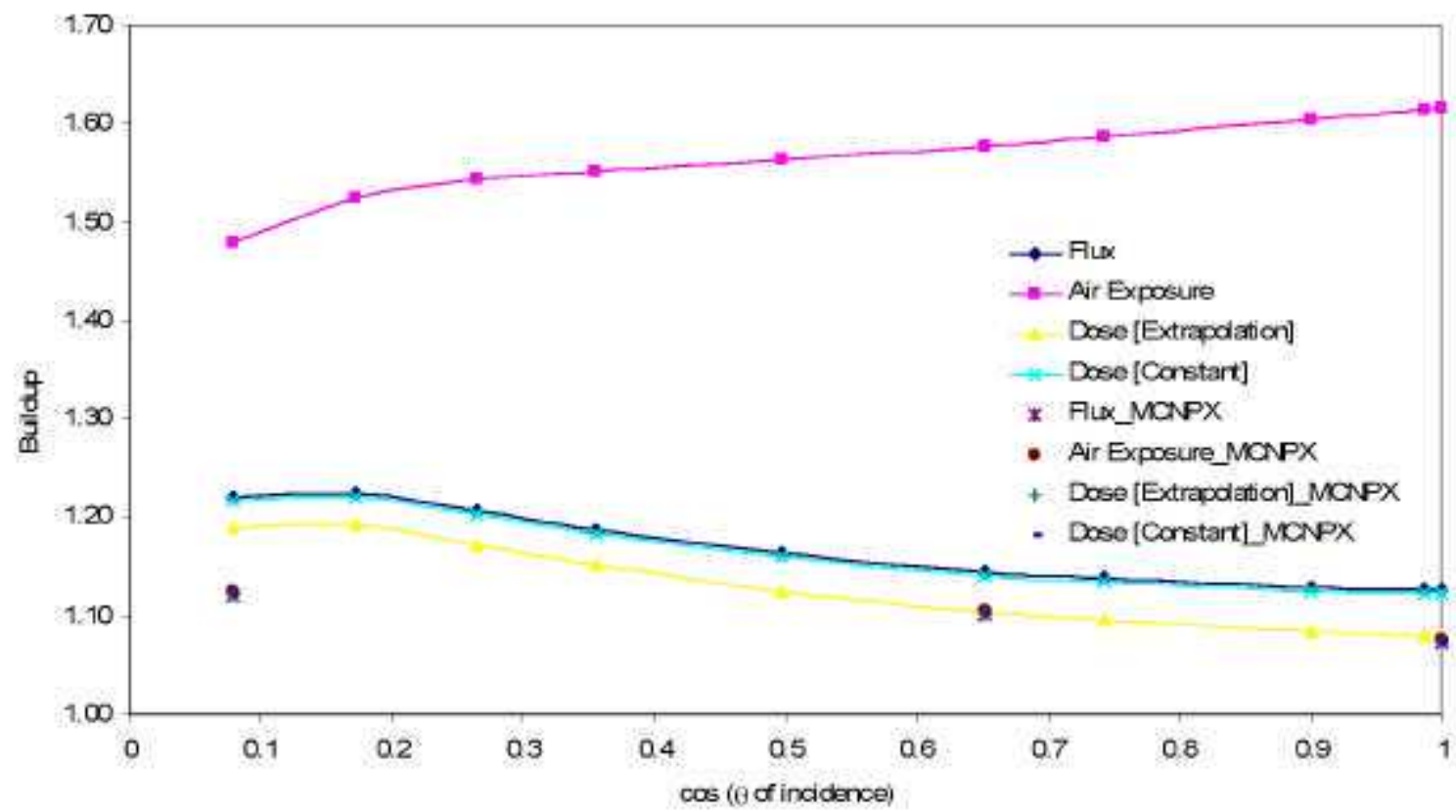

Figure 5.9: Purely-angular photon buildup factors for $10-\mathrm{keV}$ photons incident on 5 - $\mathrm{mfp}$ of lead.

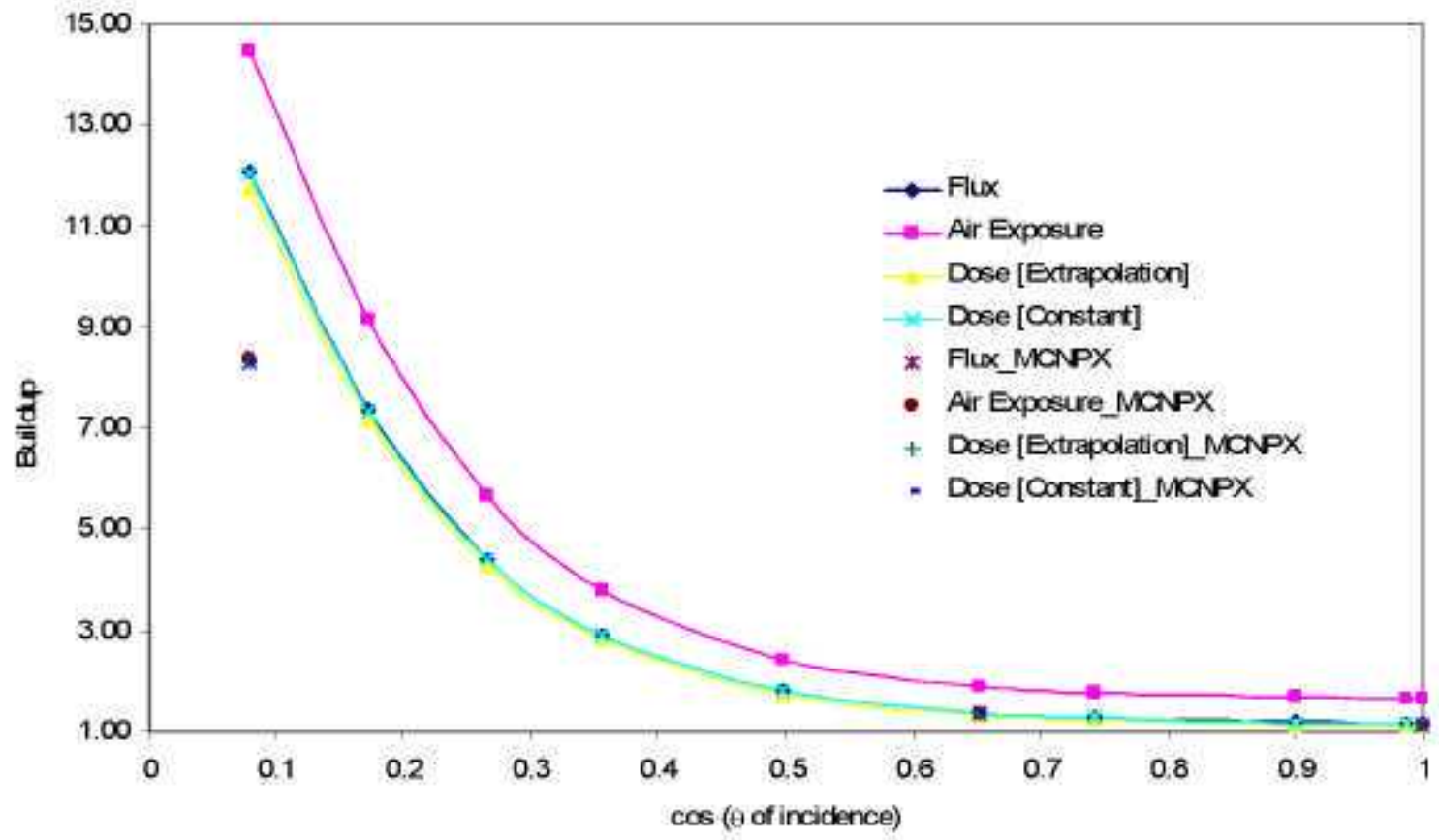

Figure 5.10: Purely-angular photon buildup factors for 10-keV photons incident on 10-mfp of lead. 
As seen in the figures above, discrete-ordinates results generally compare well to Monte Carlo. The main differences between the two codes occur with the large flux buildup factor differences with photon source energies of $500 \mathrm{keV}$ and above and large exposure buildup factor differences with photon source energies of $100 \mathrm{keV}$ and below. The last major trend that was observed between PARTISN and MCNPX results are larger percent differences at the most oblique incident angles and as the mean free path thicknesses increased. For all the given mean free path thicknesses and corresponding incident angles, percent differences between the discrete-ordinates code and Monte Carlo ranged from roughly $1 \%$ to values as high as $161 \%$. This large percent difference can be alarming, but because there are differences between the two codes, a percent difference of this magnitude can be acceptable as explained below.

Two major differences between MCNPX and PARTISN calculations are their treatment of the photon's energy and angular spectra. In Monte Carlo methods, both of these functions are continuous. With the discrete-ordinates method, the user can change the quadrature structure, but even if one continues to increase the number of quadrature angles, these calculations may not be the same as the Monte Carlo results. A reason for this is because photons in Monte Carlo exist at specific energies dictated by the laws of interaction physics, while the PARTISN photons are characterized by the multigroup energy structure's group size and discretization. This is noted in PARTISN's 244-group structure which will yield differences when compared to Monte Carlo methods as depicted in the arbitrary choice of the groups for the source energies when compared to the widths of adjacent energy groups. Another issue is with respect to wider energy groups, where there are larger differences between the group-averaged cross section and the Monte Carlo pointwise cross section at a similar energy. This difference will lead photons in PARTSN to scatter into an adjacent lower energy groups that will be subjected to much different scattering cross sections than a photon scattered in the Monte Carlo calculation [7]. This is why the source energy groups were chosen to minimize the total cross section differences at a given energy for both codes, as discussed eartier to maintain consistent results. 
When comparing Monte Carto and discrete-ordinates results, one needs to be aware that for the most oblique angles, the MCNPX photon flux calculations become less reliable, even though the statistics remain consistency good as stated in the MCNPX manual. The reason for this is because a particle's contribution to flux across a surface is determined by dividing that particle's weight by the cosine of its angle (relative to normal) and when the cosine of the exit angle has a value of $|\mu|<0.1$, MCNPX will set that angle equal to $|\mu|=0.05$ [5] Typically, oblique incident angles will result in more photons crossing the exit surface with cosines less than $|\mu|<0.1$, therefore having their photons assigned cosines much smaller than expected, increasing their respective exit flux values. These results are shown in the figures above with the Monte Carlo calculations become much less reliable at the most oblique angles.

A comparison of the different material buildup factors is based on their atomic number ( $Z$ ) The high- $Z$ materials in this study are comprised of iron, lead, leaded glass, and stainless steel, while the low- $Z$ materials are air, aluminum, concrete, polyethylene, and water. For the high-energy photons ( $10 \mathrm{MeV}-150 \mathrm{keV})$, the high- $Z$ materials attenuated the photons producing lower buildup factors than the low-Z materials, limiting more of the downscattered photons and electrons from transversing the entire material slab, but instead being absorbed or annihilated. At a photon energy of $100 \mathrm{keV}$, the buildup factors are extremely high for lead because of the production of $\mathbf{K}$-shell x-rays, while the materials aluminum, concrete, iron, and stainless steel produce the lowest buildup factors. A similar trend is further noted for the photon energies that range from 10 to $80 \mathrm{keV}$, where these low-Z materials (aluminum and concrete) continually had lower buildup factors than the extremely high and low-Z materials. An explanation for these low buildup factors at these low energies for concrete and stainless steel is that their low $Z$-constituents attenuate the lower energy photons when the photoelectric effect becomes more significant limiting the fluorescence $x$ ray yield [1]].

The desire to perform direct comparisons between different buildup factor calculations can not be fulfilled for all the authors shown below. The reason for this is because each of the different referenced buildup factor results were obtained with different methods, material 
compositions, source energies, geometries, and cross-section data which may or may not have included coherent scattering, bremsstrahlung, fluorescence, and the electron binding energy in the incoherent scattering [7]. Nonetheless, the buildup factors calculated in this study are compared to all of the referenced exposure buildup factors in Appendix $\mathrm{C}$. There was no comparison performed with the buildup factors for the exit flux and dose because previous authors do not typically publish these buildup factors, but rather the conventional exposure buildup factors.

\subsection{Referenced buildup factor comparison}

To ensure that the discrete-ordinates buildup factor results that were obtained for this version of Pandemonium are reasonable, a literature search was performed to compare these buildup factors with previous obtained buildup factors and most importantly the buildup factors developed by Wooten. Shown below in Table 5.3 is the basis by which the following authors calculated their buildup factors. The main emphasis on any comparative buildup factor study was done with Wooten's buildup factor values because the properties of calculating the photon buildup factors were the same except for the exact group structure, source energies, and a slight modification to the cross section data. In this comparison, there is extremely good agreement between the results noting the percent difference between the buildup factor results for the 10 source energies typically range from $\sim 1 \%$ to $\sim 3 \%$, with an occasional difference of $10 \%$. The main discrepancies between the two studies occur at source energies of 100 and $50 \mathrm{keV}$ where the largest percent difference for the dose buildup factor is $\sim 37 \%$ and $\sim 170 \%$ for the exposure buildup factor. The reason for the large difference in the dose and the exposure buildup factors are discussed in the following chapter.

The results of Wooten and the other authors' buildup factors are shown in Appendix C providing a comparison between these previous exposure buildup factor results and this research. Tables 5.4 and 5.5 are a representation of these buildup factor comparisons with the materials iron and water at only 3 source energies [10 MeV, $100 \mathrm{keV}$, and $20 \mathrm{keV}]$. There is generally good agreement between these buildup factors given the difference in methods, geometries, and the cross-section data used as noted in Table 5.3 that account for 
the variation in the results. Furthermore, the differences in the exposure buildup factors for concrete could be because of the different authors' elemental composition for the material.

The method by which the buildup factors calculated in this research are compared to the previously published buildup factors is shown below:

Difference:

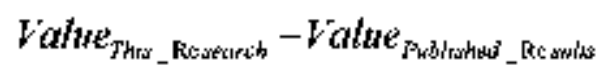

Percent Difference:

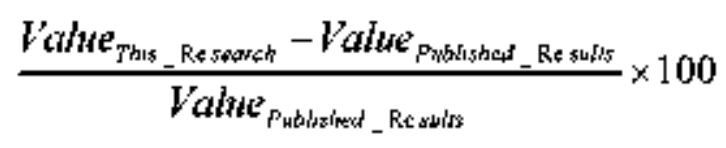


Table 5.3: Properties of buildup factor calculations by previous authors, including geometries, methods, and cross-section specifics [7].

\begin{tabular}{|c|c|c|c|c|c|c|c|}
\hline \multicolumn{8}{|c|}{ Matrix of buildup factor calculation properties } \\
\hline & year & geometry & method & coherent & $\begin{array}{l}\text { bound } \\
\text { electron }\end{array}$ & $\begin{array}{l}\text { bremsstrablung/ } \\
\text { fluorescence }\end{array}$ & $\begin{array}{c}\text { cross } \\
\text { sections }\end{array}$ \\
\hline Chilton [26] & 1980 & \$lab & $\mathrm{MC}$ & no & no & no & Hubbell \\
\hline ANSI $[27]$ & 1991 & PI & $\mathbf{M}$ & no & по & yes & Hubbell \\
\hline Chen [28] & 1993 & slab & $\mathrm{MC}$ & yes & yes & yes & Hubbell \\
\hline Chen* [29] & 1993 & \$lab & $\mathrm{MC}$ & yes & yes & no & Hubbell \\
\hline Kitsos [30] & 1994 & PI & S-N & yes & yes & no & ENDF \\
\hline Hirayama [8] & 1995 & PI & $\mathrm{MC}$ & yes & yes & yes & Hubbell \\
\hline Chibani [פ] & 2000 & PI & $\mathrm{MC}$ & yes & yes & yes & Hubbell \& + \\
\hline Chibani* [9] & 2000 & PI & $\mathrm{MC}$ & no & yes & yes & Hubbell \& + \\
\hline Shimizu [10] & 2003 & PI & $\mathrm{MC} \& \mathrm{IE}$ & yes & yes & yes & Hubbell \& + \\
\hline Wooten [7] & 2005 & slab & S-N & yes & yes & yes & ENDF \\
\hline Schimers & 2006 & slab & $\mathrm{S}-\mathrm{N}$ & yes & yes & yes & ENDF \\
\hline
\end{tabular}

\footnotetext{
Pl = point isotropic

$\mathrm{M}=$ moments

$\mathrm{MC}=$ Monte Carlo

$\mathrm{S}-\mathrm{N}=$ discrete ordinates

IE = invariant embedding

$+\quad=$ other data included
} 
Table 5.4 Exposure buildup factor comparison for iron for normally-incident photons.

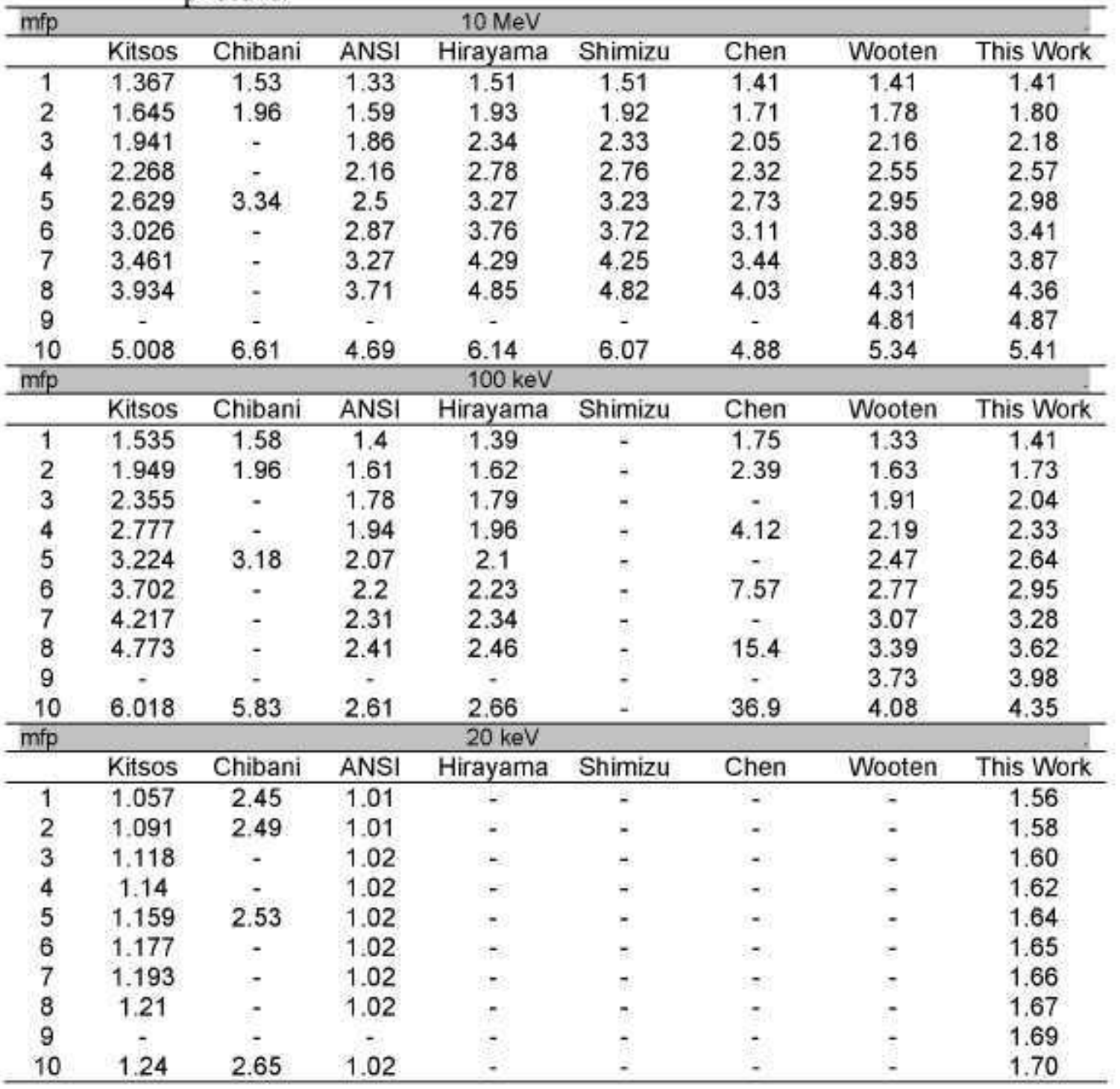


Table 5.5: Exposure buildup factor comparison for water for normally-incident photons.

\begin{tabular}{|c|c|c|c|c|c|c|c|c|c|}
\hline \multirow[t]{2}{*}{ mfp } & \multicolumn{9}{|c|}{$10 \mathrm{MeV}$} \\
\hline & Kitsos & Chibani & ANSI & Hirayama & Chibani ${ }^{\star}$ & Shimizu & Chen & Wooten & This Work \\
\hline 1 & 1.416 & 1.48 & 1.37 & 1.44 & 1.44 & 1.44 & 1.37 & 1.35 & 1.35 \\
\hline 2 & 1.741 & 1.79 & 1.68 & 1.79 & 1.79 & 1.78 & 1.66 & 1.72 & 1.73 \\
\hline 3 & 2.05 & - & 1.97 & 2.11 & 2.11 & 2.1 & 1.92 & 2.07 & 2.08 \\
\hline 4 & 2.354 & - & 2.25 & 2.43 & 2.43 & 2.41 & 2.22 & 2.39 & 2.40 \\
\hline 5 & 2.653 & 2.75 & 2.53 & 2.72 & 2.73 & 2.71 & 2.5 & 2.70 & 2.72 \\
\hline 6 & 2.947 & - & 2.8 & 3.01 & 3.03 & 3 & 2.79 & 3.00 & 3.02 \\
\hline 7 & 3.237 & - & 3.07 & 3.31 & 3.32 & 3.29 & 2.97 & 3.29 & 3.31 \\
\hline 8 & 3.521 & - & 3.34 & 3.58 & 3.63 & 3.57 & 3.26 & 3.58 & 3.60 \\
\hline 9 & - & - & - & - & - & - & - & 3.85 & 3.88 \\
\hline 10 & 4.078 & 4.23 & 3.86 & 4.16 & 4,19 & 4.13 & 3.74 & 4.12 & 4.15 \\
\hline \multirow[t]{2}{*}{$m f p$} & & & & & $100 \mathrm{keV}$ & & & & \\
\hline & Kitsos & Chibani & ANSI & Hirayama & Chibani $^{\star}$ & Shimizu & Chen & Wooten & This Work \\
\hline 1 & 5.08 & 4.53 & 4.55 & 4.68 & 4,59 & - & - & 2.28 & 2.27 \\
\hline 2 & 13.99 & 12.2 & 11.8 & 12.4 & 12.1 & - & - & 4.38 & 4.36 \\
\hline 3 & 29.22 & - & 23.8 & 25 & 24.7 & - & - & 7.32 & 7.27 \\
\hline 4 & 52.34 & - & 41.3 & 43.9 & 42.6 & - & - & 11.28 & 11.16 \\
\hline 5 & 85.09 & 71.6 & 65.2 & 70.1 & 67.5 & - & - & 16.43 & 16.22 \\
\hline 6 & 129.4 & - & 96.7 & 104 & 101 & - & - & 23.00 & 22.65 \\
\hline 7 & 187.5 & - & 137 & 148 & 143 & - & - & 31.21 & 30.66 \\
\hline 8 & 261.9 & - & 187 & 203 & 196 & - & - & 41.34 & 40.53 \\
\hline 9 & - & - & - & - & - & - & - & 53.67 & 52.51 \\
\hline 10 & 471 & 385 & 321 & 354 & 340 & - & - & 68.54 & 66.93 \\
\hline \multirow{2}{*}{ mfp } & & & & & $20 \mathrm{keV}$ & & & & \\
\hline & Kitsos & Chibani & ANSI & Hirayama & Chibani ${ }^{*}$ & Shimizu & Chen & Wooten & This Work \\
\hline 1 & 1.542 & 1.5 & 1.43 & - & - & - & - & - & 1.29 \\
\hline 2 & 1.934 & 1.87 & 1.67 & - & - & - & - & - & 1.48 \\
\hline 3 & 2.296 & - & 1.86 & - & - & - & - & - & 1.66 \\
\hline 4 & 2.647 & . & 2.02 & - & - & - & - & - & 1.83 \\
\hline 5 & 2.998 & 2.86 & 2.16 & - & - & - & - & - & 1.99 \\
\hline 6 & 3.356 & - & 2.28 & - & - & - & - & - & 2.15 \\
\hline 7 & 3.724 & - & 2.39 & - & - & - & - & - & 2.31 \\
\hline 8 & 4.107 & - & 2.5 & - & - & - & - & - & 2.47 \\
\hline 9 & - & $=$ & - & - & - & - & - & - & 2.63 \\
\hline 10 & 4.92 & 4.66 & 2.68 & - & - & - & - & - & 2.79 \\
\hline
\end{tabular}




\section{DATA ANALYSIS}

\subsection{MCNPX}

The analysis discussed below would be ideally performed on the PARTISN code, but because the PARTISN output code does not display the results for each energy group and its respective error as seen in the MCNPX code, the Monte Carlo statistics are used to make a conjecture on the PARTISN results. To achieve the desired results, the input decks for the MCNPX codes were modified to determine if the statistics changed substantially and whether or not the confidence intervals of the different runs were comparable. The different statistical attributes of the MCNPX code were studied by only modifying the number of particles, leaving the rest of the MCNPX input deck the same for consistency. Before the calculations are displayed, some background information is discussed to support the analysis executed. The study was arbitrary performed with $10-\mathrm{MeV}$ source photons interacting normally on a mean free path thick slab of air with the number of particles (nps) chosen to be 10 thousand. 20 million, and 500 million photons.

Monte Carlo results represent an average of all the histories sampled for a given problem whose uncertainty is as important as the tally. The importance of the calculated error when compared to the number of histories allows the user to gain insight into the quality of the result and whether or not the tally appears to be statistically well behaved. For example, if a tally is not well behaved, the estimated error will not produce the true confidence interval of the result ultimately leading to an erroneous answer.

To be able to detine some of the principles, assume the Monte Carlo results are obtained by sampling possible random walks and assigned a score $x$, to each random walk [5]. The probability density function for selecting a random walk that scores $x$ to the tally is estimated as $f(x)$, but is seldom known. As a result, the expected value of $x, E(x)$, or the true mean shown below

$$
\mathrm{E}(\mathrm{x})=\int x f(x) d x=\text { true mean }
$$


normally can not be determined, but is estimated by the sample mean $\bar{x}$,

$$
\overline{\boldsymbol{x}}=\frac{1}{N} \sum_{r=1}^{N} \boldsymbol{x}_{\mathrm{r}}
$$

where $x_{i}$ is the value of the $x$ selected from $f(x)$ for the $i^{\text {th }}$ history and $N$, the number of histories calculated in the problem [5]. The Monte Carlo mean $\bar{x}$ is therefore the average value of the scores $x_{1}$ for all the histories.

The variance of the population of $x$ values is a measure of the spread in these values and is given by [5]

$$
\sigma^{2}=\int(x-E(x))^{2} f(x) d x=E\left(x^{2}\right)-(E(x))^{2}
$$

The standard deviation, $\sigma$, is the square root of the variance and is seldom known but can be estimated by Monte Carlo as $S$, if $N$ is large. The quantity $S$ is the estimated standard deviation of the population of $x$ based on the values of $x$, that were sampled [5]. The equations for the estimated standard deviation can be obtained from

$$
S^{2}=\frac{\sum_{i=1}^{N}\left(x_{1}-\bar{x}\right)^{2}}{N-1} \approx x^{2}-\bar{x}^{2}
$$

and

$$
x^{2}=\frac{1}{N} \sum_{i=1}^{N} x_{1}^{2}
$$

As a result, the estimated variance of $\bar{x}$ is defined as

$$
S_{\bar{x}}^{2}=\frac{S^{2}}{N} .
$$

The Central Limit Theorem enables one to define the confidence interval for a Monte Carlo result where $\alpha$ can be any arbitrary value and $\operatorname{Pr}[Z]$ denotes the probability of $Z$. The definition of confidence interval can be modified to incorporate the estimated standard deviation of $\bar{x}, S_{\bar{x}}$, as shown below 


$$
\operatorname{Pr}\left[-\alpha S_{\bar{x}}<\frac{\bar{x}-E(x)}{\sigma \sqrt{N}}<\alpha S_{\bar{y}}\right] \approx \frac{1}{\sqrt{2 \pi}} \int_{-\alpha}^{\alpha} e^{-i^{2} / 2} d t .
$$

The Central Limit Theorem states that for large values of $N$ and identically distributed independent random variables $x_{t}$ with finite means and variances, the distribution of the $\bar{x}$ 's approaches a normal distribution [5]. Therefore, the distribution of resulting $\bar{x}$ 's will be approximately normally distributed, with a mean of $E(x)$. If $S$ is approximately equal to $\sigma$, which is valid for a statistically significant sampling of a tally, then from standard tables of the normal distribution function [5], the equation for a confidence interval being correct $68 \%$ of the time, a $68 \%$ Confidence Interval, is

$$
\bar{x}-0.995 S_{\bar{x}}<E(x)<\bar{x}+0.995 S_{\bar{x}} .
$$

The value next to the MCNPX tally in the MCNPX output is the estimated relative error $R$. This error value is normalized with respect to the starting particle history and defined as

$$
R \equiv S_{\bar{x}} / \bar{x}
$$

representing the statistical precision as a fractional result to the estimated mean [5]

$$
R=\frac{S / \sqrt{N}}{\bar{x}}
$$

where

$$
\begin{aligned}
& S=\text { estimated standard deviation, } \\
& N=\text { number of particles, and } \\
& \bar{x}=\text { sample mean. }
\end{aligned}
$$

Based on the Monte Carlo manual, the recommended interpretation of the estimated $68 \%$ confidence interval is $\bar{x}(1 \pm R)$. This relative error $R$ represented in the table below depicts the estimated statistical relative error at the 10 level implying that these relative error values assume that the Monte Carlo simulations are well sampled and have satisfied the discussion above. 
Table 6. 1: Guidelines for Interpreting the Relative Error $R$

\begin{tabular}{|c|c|}
\hline \multicolumn{2}{|c|}{ Guidelines for lnterpreting the Relative Error } \\
\hline Range of $R$ & Quality of the Tally \\
\hline 0.5 to 1 & Garbage \\
\hline 0.2 to 0.5 & Factor of a few \\
\hline 0.1 to 0.2 & Questionable \\
\hline$<0.10$ & Generally reliable except for point detector \\
\hline$<0.05$ & Generally reliable for point detector \\
\hline
\end{tabular}

The Monte Carlo code calculates a Figure of Merit, FOM, for each problem to assist the user in determining the statistical behavior as a function of $N$ and the overall efficiency of the tally because of the statistical nature of the tallies in MCNPX may not always follow the Central Limit Theorem [5]. The Figure of Merit can be used for three purposes. The most important use of the $F O M$ is as a tally reliability indicator, by determining if the $F O M$ is approximately a constant (which may not occur early in the sampling because of statistical fluctuations). If the FOM is not a constant, then the user knows that the confidence intervals may not overlap the expected value, $E(x)$. A second application for the $F O M$ is to optimize the efficiency of the Monte Carlo calculation by performing several test nuns with different variance reduction parameters and selecting the problem with the largest FOM [5]. The third use for the FOM is to estimate the computer time required to reach a desired value level of precision, which is proportionally reduced when the Figure of Merit is large. The FOM is defined by the relation

$$
R=\mathrm{l} / \sqrt{F O M * T}
$$

In the previous sections, the relative error $(R)$ and the figure of merit (FOM) were discussed as measures of the quality of the mean. The relative variance of the variance $(V O F)$ is the estimated relative variance of the estimated $R$ that assists the user in establishing more reliable confidence intervals. The $V O V$ is much more sensitive to large history score fluctuations than $R$ and the estimated $V O V$ of the mean is defined as

$$
V O V-S^{2}\left(S_{\bar{x}}^{2}\right) / S_{\bar{x}}^{1}
$$

where $S_{\bar{x}}^{2}$ is the estimated variance of $\bar{x}$ and $S^{2}\left(S_{\bar{x}}^{2}\right)$ is the estimated variance of $S_{\bar{x}}^{2}$ [5].

The VOV' is a measure of the relative statistical uncertainty in the estimated $R$ and is important because $S$ must be a good approximation of $\sigma$ to use the Central Limit Theorem to form confidence intervals [5]. The VOV for a tally history is defined as 


$$
\left.V O V-\sum\left(x_{1}-\bar{x}\right)^{4} /\left(\sum\left(x_{1}-\bar{x}\right)^{2}\right)^{2}-\right] / N .
$$

The statistical experiments based on sampling the truncated positive distribution of the Cauchy formula which is similar in shape to some difficult Monte Carlo tallies concludes that the $\mathrm{IOV}^{\prime}$ should be less than 0.1 to ensure the probability of forming a reliable confidence interval [5].

\subsubsection{Estimated quantities}

Shown below are the estimated quantities for the mean $(E(X))$, relative error $(R)$, figure of merit $(F O M)$, and variance of the variance ( $V O V$ ) for the four different responses for the three different MNCPX input decks. These different values correspond to the number of particles sampled. The two dose schemes, extrapolation and constant, produced the same results and are denoted as Dose.

Table 6.2: Statistics for the three different MCNPX input decks

\begin{tabular}{cccc}
\hline \multicolumn{4}{c}{ Mean } \\
NPS & Exit Flux & Exposure & Dose \\
\hline 10,000 & $9.48974 \mathrm{E}-01$ & $7.17664 \mathrm{E}-02$ & $1.27954 \mathrm{E}+01$ \\
$20,000,000$ & $9.51109 \mathrm{E}-01$ & $7.24174 \mathrm{E}-02$ & $1.29102 \mathrm{E}+01$ \\
$500,000,000$ & $9.51255 \mathrm{E}-01$ & $7.24066 \mathrm{E}-02$ & $1.29085 \mathrm{E}+01$ \\
\hline \multicolumn{4}{c}{ Relative Error } \\
NPS & Exit Flux & Exposure & Dose \\
\hline 10,000 & $1.28369 \mathrm{E}-02$ & $9.11092 \mathrm{E}-03$ & $9.00292 \mathrm{E}-03$ \\
$20,000,000$ & $2.75469 \mathrm{E}-04$ & $2.01536 \mathrm{E}-04$ & $1.98755 \mathrm{E}-04$ \\
$500,000,000$ & $0.00000 \mathrm{E}+00$ & $0.00000 \mathrm{E}+00$ & $0.00000 \mathrm{E}+00$ \\
\hline \multicolumn{4}{c}{ Figure of Merit } \\
NPS & Exit Flux & Exposure \\
\hline 10,000 & $3.13434 \mathrm{E}+05$ & $6.22220 \mathrm{E}+05$ & $6.37237 \mathrm{E}+05$ \\
$20,000,000$ & $3.28907 \mathrm{E}+05$ & $6.14487 \mathrm{E}+05$ & $6.31805 \mathrm{E}+05$ \\
$500,000,000$ & $1.00000 \mathrm{E}+30$ & $1.00000 \mathrm{E}+30$ & $1.00000 \mathrm{E}+30$ \\
\hline \multicolumn{4}{c}{ Variance of the Variance } \\
NPS & Exit Flux & Exposure & Dose \\
\hline 10,000 & $1.21553 \mathrm{E}-02$ & $3.42461 \mathrm{E}-05$ & $4.63837 \mathrm{E}-05$ \\
$20,000,000$ & $6.01639 \mathrm{E}-06$ & $1.44988 \mathrm{E}-06$ & $2.34288 \mathrm{E}-08$ \\
$500,000,000$ & $0.00000 \mathrm{E}+00$ & $0.00000 \mathrm{E}+00$ & $0.00000 \mathrm{E}+00$ \\
\hline \multicolumn{4}{c}{}
\end{tabular}

Based on the guidelines for interpreting the relative error, all three MCNPX simulations with the different number of particles fall within the very reliable section of the chart having a 
value of $R$ less than 0.5 . This implies that all three MCNPX simulations were well sampled and satisfy the Central Limit Theorem. The relative error tended toward a value of zero as the number of particles in the MCNPX simulations increased demonstrating that the simulations with more particles obtain better results. The optimization of the efficiency of the Monte Carlo calculations depicted in these three test runs demonstrate the simulation with 500 million particles had the largest FOM value with an order of magnitude of 13 when compared to the MCNPX simulations with 10 thousand and 20 million particles that produced a FOM value with an order of magnitude equal to only 5 . This implies based on this criteria, the simulation of 500 million particles is the ideal variance reduction input deck to use. Furthemore, from all MCNPX simulations, the values for $\mathrm{VOV}$ (variance of the variance) demonstrate that the probability of forming a reliable confidence interval will occur because all of their respective values for all responses are less than the 0 . $]$ value. It must also be noted that the variance of the variance value tends to zero as the number of particles in a MCNPX simulation increases demonstrating more reliability in these simulation's contidence intervals.

In this next table, additional values are obtained from the three different MCNPX codes for the figure of merit ( $F O M$ ) for the different responses. The initial value for each of these conditions (value af $/ p s$ ) is the corresponding value at the largest history score sampled and the next corresponding value (value at hps $+I$ ) stands for the next scored sample if another history would occur. The last value (valne $(m p s+1) /$ value $(m p s)-I$ ) indicates how this additional history would affect the current results. 
Table 6.3: Figure of Merit for the three different MCNPX input decks

\begin{tabular}{cccc}
\hline NPS & value at nps & $\begin{array}{c}\text { Exit Flux } \\
\text { value at nps }+1\end{array}$ & value(nps+1)/value(nps)-l \\
\hline 10,000 & $3.13434 \mathrm{E}+05$ & $3.03702 \mathrm{E}+05$ & -0.031051 \\
$20,000,000$ & $3.28907 \mathrm{E}+05$ & $3.28888 \mathrm{E}+05$ & -0.000060 \\
$500,000,000$ & $1.00000 \mathrm{E}+30$ & $1.00000 \mathrm{E}+30$ & 0.000000 \\
\hline & & Exposure & \\
NPS & value at nps & value at nps +1 & value(nps+1)/value(nps)-1 \\
\hline 10,000 & $6.22220 \mathrm{E}+05$ & $6.21591 \mathrm{E}+05$ & $-0.0010]$ ] \\
$20,000,000$ & $6.14487 \mathrm{E}+05$ & $6.13780 \mathrm{E}+05$ & -0.001151 \\
$500,000,000$ & $1.00000 \mathrm{E}+30$ & $1.00000 \mathrm{E}+30$ & 0.000000 \\
\hline & & Dose & \\
NPS & value at nps & value at nps +1 & value(nps+1)/value(nps)-1 \\
\hline 10,000 & $6.37237 \mathrm{E}+05$ & $6.36312 \mathrm{E}+05$ & -0.001452 \\
$20,000,000$ & $6.31805 \mathrm{E}+05$ & $6.31803 \mathrm{E}+05$ & -0.000004 \\
$500,000,000$ & $1.00000 \mathrm{E}+30$ & $1.00000 \mathrm{E}+30$ & 0.000000
\end{tabular}

From the additional information for the Figure of Merit, the most important indicator of a good FOM value can be easily distinguished by the MCNPX nu with 500 million particles noting that the FOM is a constant when adding another particle to the history. This same justification can be applied to the MCNPX run with 20 million particles even though it deviates a little bit with the exposure response. It can be shown in both of these cases, but more prominently in the 500 million particle case, that the confidence intervals will overap the expected value, $E(x)$. The MCNPX run with only 10 thousand particles shows fluctuations in the FOM value if another particle history is added demonstrating that the confidence interval may not overlap the expected value as consistently as the other two MCNPX simulations. Lastly, in the table below is the computer time it took to nu each of the different MCNPX input decks.

Table 6.4: Computer Time to run the different MCNPX input decks

\begin{tabular}{cc}
\hline NPS & Computer Time (minutes) \\
\hline 10,000 & 0.03 \\
$20,000,000$ & 40.12 \\
$500,000,000$ & 917.02 \\
\hline
\end{tabular}

As a result of the discussion above regarding the relative error $(R)$, the figure of merit $(H O M)$, and the variance of the variance $(\mathrm{KOV})$, the MCNPX input code with 500 million particles is the ideal code. But this simulation is not all that practical, when the computer time it takes this simulation to run is compared to the MCNPX code with 20 million particles 
which may not be of the same order of magnitude with respect to the relative error, the figure of merit, and the variance, but their mean and variance are fairly similar.

Because the statistics and equations for the confidence interval in the MCNPX manual are based on the $68 \%$ Confidence Interval, the analysis for the three different MCNPX runs will also follow this same confidence level. The table below shows the mean $\bar{x}$ and relative error $R$ for the uncollided and total radiation based on the different number of particles.

Table 6.5: Mean and relative error for the uncollided and total radiation based on the different MCNPX input decks.

\begin{tabular}{ccccc}
\hline \multicolumn{5}{c}{ Exit Flux } \\
NPS & Uncollided Radiation & Error & Tolal Radiation & Error \\
\hline 10,000 & $3.63500 \mathrm{E}-01$ & 0.0132 & $9.48974 \mathrm{E}-01$ & 0.0128 \\
$20,000,000$ & $3.67951 \mathrm{E}-01$ & 0.0003 & $9.51109 \mathrm{E}-01$ & 0.0003 \\
$500,000,000$ & $3.67896 \mathrm{E}-01$ & 0.0001 & $9.51255 \mathrm{E}-01$ & $0.000 \mathrm{l}$ \\
\hline \multicolumn{5}{c}{ Exposure } \\
NPS & Uncollided Radiation & Error & Total Radiation & Eror \\
\hline 10,000 & $5.27119 \mathrm{E}-02$ & 0.0132 & $7.17664 \mathrm{E}-02$ & 0.0091 \\
$20,000,000$ & $5.33573 \mathrm{E}-02$ & 0.0003 & $7.24174 \mathrm{E}-02$ & 0.0002 \\
$500,000,000$ & $5.33494 \mathrm{E}-02$ & 0.0001 & $7.24066 \mathrm{E}-02$ & 0.0000 \\
\hline \multicolumn{5}{c}{ Dose } \\
NPS & Uncollided Radiation & Error & Tolal Radiation & Error \\
\hline 10,000 & $9.30560 \mathrm{E}+00$ & 0.0132 & $1.27954 \mathrm{E}+01$ & 0.0090 \\
$20,000,000$ & $9.41955 \mathrm{E}+00$ & 0.0003 & $1.29102 \mathrm{E}+01$ & 0.0002 \\
$500,000,000$ & $9.41814 \mathrm{E}+00$ & 0.0001 & $1.29085 \mathrm{E}+01$ & 0.0000 \\
\hline \multicolumn{7}{c}{}
\end{tabular}

Shown in the table below is the comparison of the $68 \%$ Confidence Interval $\bar{x}(1 \pm R)$ for the uncollided and total radiation for the different responses based on the number of photons in the MCNPX input deck. 
Table 6.6: $\quad 68 \%$ Confidence Interval for the three MCNPX Input Decks Uncollided and Total Radiation values

\begin{tabular}{|c|c|c|}
\hline \multicolumn{3}{|c|}{ Exit Flux } \\
\hline NPS & Uncollided Radiation Interval & Total Radiation Interval \\
\hline 10,000 & $3.58702 \mathrm{E}-0 \mathrm{I}-3.68298 \mathrm{E}-0 \mathrm{I}$ & $9.36827 \mathrm{E}-0 \mid-9.6 \mathrm{~J} / 2 \mathrm{JE}-0 \mathrm{~J}$ \\
\hline $20,000,000$ & $3.67841 \mathrm{E}-0 \mathrm{l}-3.6806 \mathrm{lE}-01$ & $9.50824 \mathrm{E}-01-9.51394 \mathrm{E}-0]$ \\
\hline $500,000,000$ & $3.67859 \mathrm{E}-0 \mathrm{l}-3.67933 \mathrm{E}-0 \mathrm{~L}$ & $9.5 \mathrm{~L} \mathrm{~L} 60 \mathrm{E}-0 \mathrm{l}-9.5 \mathrm{~J} 350 \mathrm{E}-0 \mathrm{~J}$ \\
\hline \multicolumn{3}{|c|}{ Exposure } \\
\hline 10,000 & $5.2016] \mathrm{E}-02-5.34077 \mathrm{E}-02$ & $7.11133 \mathrm{E}-02-7.24195 \mathrm{E}-02$ \\
\hline $20,000,000$ & $5.33413 \mathrm{E}-02-5.33733 \mathrm{E}-02$ & $7.24029 \mathrm{E}-02-7.243] 9 \mathrm{E}-02$ \\
\hline $500,000,000$ & $5.33441 \mathrm{E}-02-5.33547 \mathrm{E}-02$ & $7.24066 \mathrm{E}-02-7.24066 \mathrm{E}-02$ \\
\hline NPS & & Total Rad \\
\hline 10,000 & $9.18277 \mathrm{E}+00-9.42843 \mathrm{E}+00$ & $1.26802 \mathrm{E}+01-1.29106 \mathrm{E}+0 \mathrm{]}$ \\
\hline $20,000,000$ & $9.41672 \mathrm{E}+00-9.42238 \mathrm{E}+00$ & $1.29076 \mathrm{E}+01-1.29128 \mathrm{E}+01$ \\
\hline $500,000,000$ & $9.41720 \mathrm{E}+00-9.41908 \mathrm{E}+00$ & $1.29085 \mathrm{E}+0 \mathrm{l}-1.29085 \mathrm{E}+0 \mathrm{]}$ \\
\hline
\end{tabular}

Based on the comparisons of the $68 \%$ Confidence Intervals, in theory when similar intervals are compared (total radiation values to total radiation values for a given response), the confidence interval with more particles sampled should be within the confidence interval of a nun with fewer particles sampled. This should be true when normality is assumed and when the relative error decreases as a result of the increased number of particle converging on a more accurate mean value. This was not achieved with the case of dose with its total radiation interval. The one stray result occurred with a confidence interval for the 20 million particle run which was not completely within the 10 thousand particle run, but is almost identical at the upper limit demonstrating that the theoretical results were almost obtained.

The following table is a comparison of the percent different between the mean Monte Carlo buildup factor results with the PARTISN results based on the number of photons in the MCNPX input deck.

Table 6.7: Buildup Factor Percent Difference when varying the MCNPX NPS values.

\begin{tabular}{cccc}
\hline NPS & Exit Flux & Exposure & Dose \\
\hline 10,000 & $\mathbf{3 . 4 1 1 5 5 \%}$ & $-0.94629 \%$ & $-1.04663 \%$ \\
$20,000,000$ & $4.44283 \%$ & $-0.63484 \%$ & $-0.72561 \%$ \\
$500,000,000$ & $4.41119 \%$ & $-0.63473 \%$ & $-0.72739 \%$ \\
\hline
\end{tabular}


The results from varying the number of particles (NPS) in the three different MCNPX runs does not demonstrate a direct relationship between the number of interacting photons and the percent difference of the two computer codes' buildup factor results. In the case of the exit flux response, the best comparison between the two codes occurred at only lo thousand particles. In the case of the exposure response, the best comparison between the two codes occurred at 500 million particles while the best comparison for the dose responses occurred with an MCNPX run of 20 million particles. Furthermore, the percent difference in the four responses as shown above in the 20 million and 500 million particle nuns are fairly identical. This demonstrates that there is no advantage to nu the MCNPX code for 25 times more particles or another 876.90 minutes ( 14.615 hours) to obtain a result that is $0.03164 \%$ better than the 20 million particles run. Lastly, the results from the 10,000 particle run may have better results at the exit flux, but its error statistics are not as good as the other two runs being over $1 \%$, whereas in the other two runs the highest percent error in the MCNPX calculated runs were $0.03 \%$. This therefore concludes that increasing or decreasing the number of particles from 20 million does not substantially affect the MCNPX buildup factor results for all three responses.

Another important issue regarding the Monte Carlo code is its energy cutoff, which is a userdictated energy level where the particles are terminated when their energy falls below this energy cutoff. The user must always be careful when using the energy cutoff to ensure that any low-energy particles that are terminated have either zero or almost zero importance because low-energy particles can often be important to the tally. This is seen in the example of the exposure response where its coefficients increase in orders of magnitude when the photons have an energy level of $10 \mathrm{keV}$ to $\mathrm{l} \mathrm{keV}$. The results from MCNPX will also be biased (low) when the energy cutoff is killing particles that might have otherwise contributed. As a result, based on the MCNPX input code used in this research, the energy cutoff for the particles are at an energy of $1 \mathrm{keV}$.

\subsection{NJOY}

The analysis performed with the two different NJOY output files that supply the PARTISN with the different energy group's total cross section values had two purposes. The first 
purpose was to determine why there was such a large discrepancy between the two versions' exposure and dose buildup factors at photon source energies of 100 and $50 \mathrm{keV}$. The second reason as discussed with the MCNPX energy cutoff, was to detennine if photons with an energy below $10 \mathrm{keV}$ were terminated or just dumped in the NJOY's $10-\mathrm{keV}$ energy group of Wooten's research, which would result in biased buildup factors because the lower energy's response functions coefficients would not have been included in the overall calculations.

The study was arbitrary performed with lead and shown below. The comparison of the total cross section began with an energy group that contained a common higher energy value in both of the NJOY files under investigation. If the results demonstrates that the total cross sections are the same, then it is known that all the lower energies that were incorporated into this NJOY file are dumped in Wooten's NJOY lO-keV group, but if the total cross sections are different, it can be inferred that the NJOY code terminates particles below $10 \mathrm{keV}$ for Wooten's research and $\mathrm{l} \mathrm{keV}$ for this research.

Table 6.8: A comparison of the cross sections for lead with different NJOY files.

\begin{tabular}{|c|c|c|c|c|}
\hline \multirow{3}{*}{$\begin{array}{l}\text { Energy } \\
\text { Group }\end{array}$} & \multirow{3}{*}{$\begin{array}{c}\text { Energy range } \\
(\mathrm{keV})\end{array}$} & \multirow{3}{*}{$\begin{array}{c}\text { 220-group structure } \\
\text { Total Cross Section } \\
\text { (barns) }\end{array}$} & \multirow{2}{*}{\multicolumn{2}{|c|}{ Scattering (barnș) }} \\
\hline & & & & \\
\hline & & & Coheren & Incoherent \\
\hline 220 & $10.367]-10.00$ & $4.26774 \mathrm{E}+04$ & $1.44104 \mathrm{E}+03$ & $1.59369 \mathrm{E}+0 \mathrm{I}$ \\
\hline \multirow{2}{*}{$\begin{array}{l}\text { Energy } \\
\text { GToup }\end{array}$} & \multirow{2}{*}{$\begin{array}{c}\text { Energy range } \\
(\mathrm{keV})\end{array}$} & \multirow{2}{*}{$\begin{array}{c}\text { 244-group structure } \\
\text { Total Cros\$ Section } \\
\text { (bams) }\end{array}$} & \multicolumn{2}{|c|}{ Scattering (barns) } \\
\hline & & & Coherent & Incoherent \\
\hline 237 & $10.367]-10.01$ & $4.26250 \mathrm{E}+04$ & $1.44016 \mathrm{E}+03$ & $1.59422 \mathrm{E}+01$ \\
\hline 238 & $10.01-10.00$ & 4.463 & $1.47373 \mathrm{E}+03$ & $1.57393 \mathrm{E}+01$ \\
\hline 239 & $10.00-6.79412$ & $6.89093 \mathrm{E}+04$ & $1.75466 \mathrm{E}+0.3$ & $1.39341 \mathrm{E}+01$ \\
\hline 240 & $6.79412-4.91881$ & $1.69496 \mathrm{E}$ & $2.38646 \mathrm{E}+03$ & $1.01866 \mathrm{E}+01$ \\
\hline 241 & & & $5 \mathrm{E}+03$ & $4 \mathrm{E}+00$ \\
\hline 242 & 3.5 & & 2.38 & $\mathrm{E}+00$ \\
\hline 243 & $2.55619-$ & $4.20947 \mathrm{E}+05$ & $1.56012 \mathrm{E}+03$ & $3.68769 \mathrm{E}+00$ \\
\hline 244 & $1.71293-1.00$ & $9.64996 \mathrm{E}+05$ & $2.24629 \mathrm{E}+03$ & $2.09749 \mathrm{E}+00$ \\
\hline Total & & $2.74227 \mathrm{E}+06$ & $1.59887 \mathrm{E}+04$ & $7.46366 \mathrm{E}+0 \mathrm{l}$ \\
\hline
\end{tabular}

As depicted in this table, the total cross section consists of more than just the inherent and coherent scattering. Some of the other conditions that contribute to the total cross section are elastic scattering, Compton scattering, pair production, and absorption that were not displayed in the NJOY output file, but discussed earlier in this research. From the analysis of 
the two different group structures, it demonstrates that the total cross section and some of its complements (coherent and incoherent scattering) are larger for the 244-group structure which includes the energy ranges from $10.001 \mathrm{MeV}$ to $1.00 \mathrm{keV}$ when compared to the 220 group stnucture includes the energy range from $10.001 \mathrm{MeV}$ to $10.00 \mathrm{keV}$.

These results conclude that in the 220-group structure the energy cutoff for photons and any other particles in the PARTISN code is an energy of $10 \mathrm{keV}$ because of the cross sections obtained in the NJOY file demonstrate that any particle that may exist below this energy value will be terminated and not accounted for in the final calculations. This same analysis can be applied to the 244-group structure with an energy limit of $1 \mathrm{keV}$. Lastly, this analysis provides evidence for the large percent difference of the exposure and dose buildup factor values between the two PARTISN group structures concerning photons with lower source energies of 100 and $50 \mathrm{keV}$. The reason for this large discrepancy at only the lower source energy photons is because there is a higher probability of down-scatiering in the lowest energy groups where the exposure coefficients increase rapidly in magnitude at photon energy levels below $10 \mathrm{keV}$ than compared to higher source energy photons down-scattering to these same energy groups. This same explanation can be applied to the dose buildup factors where inclusion of these lower energy groups in Wooten's work would have made the results more comparable. 


\section{CONCLUSIONS}

This research demonștrates that improved buildup factors may be determined using up-todate ENDF library cross sections coupled with electron cross sections (imbedded in the CEPXS code) using PARTISN. Despite the differences in the geometries, cross-section data, and the methods that previous authors used to calculate the exposure buildup factors as shown in Appendix C, there is generally good agreement with the buildup factors computed in this study. Results indicate that for the two extreme cases of dose coefficients below 10 keV buildup factors are identical, implying that buildup at such low energies is insensitive to dose coefficients. Major differences between these and Wooten's results are due mainly to the difference in group structure (244-verșs Wooten's 220-groups), which includes more groups and groups with different widths, and new response functions that are based on the new group structure.

Through devising a new group structure, the inclusion of the most recent cross-section data, and the implementation of nine glovebox materials, new buildup factors have been developed to be implemented into Pandemonium. Buildup factors for all 25 incident sources energies and the materials leaded glass and polyethylene, which model a glovebox's windows and gloveports respectively, provide a more realistic composition of glovebox materials and geometries enabling improved dose and exposure calculations, improving estimates of dose levels to the workers.

Pandemonium could be further improved by including buildup factors for glovebox material thicknesses larger than 10 mean free paths and by including buildup factors for multilayered shields. Nonetheless, these slant-path photon buildup factors can be used by the radiation and safety community to model and predict dose rates for increased radiological safety and awareness. 


\section{REFERENCES}

I. Kornreich, D., Dooley, D., "PANDEMONIUM: Bringing Order to Dose in Complicated Glovebox Arrays," LA-UR-99-2765, Los Alamos National Laboratory, 1999.

2. Wooten, H.O., Dudziak, D.J., Hertel, N.E., Kornreich, D.E., “A Time-Dependent Dose Model for Glovebox Processing of Fissile Material," Rad. Prot. Dosim., 115, No.l-4, $350-356,2005$

3. Wooten, H.O., Dudziak, D.J., Kornreich, D.E., Hertel, N.E., "A New Perspective on Angular Buildup Factors for Photons," Transactions of the American Nuclear Society, 92, San Diego, California, 2005.

4. Schimers, F.G., Wooten, H.O., Dudziak, D.J., Yim, M.S., "Buildup Factors for Photons between $10 \mathrm{keV}$ and $10 \mathrm{MeV}$, The American Nuclear Society $14^{\text {th }}$ Biennial Topical Meeting of the Radiation Protection and Shielding Division, Carlsbad, New Mexico, 2006.

5. Waters, L., ed., "MCNPX User's Manual, Verșion 2.3.0," LA-UR-02-067, Los Alamos National Laboratory, 2002.

6. O'Dell, R. et. al., "Revised User's Manual for ONEDANT: A Code Package for OneDimensional, Diffusion Accelerated, Neutral Particle Transport," LA-9 184-M, Rev., Los Alamos National Laboratory, 1989.

7. Wooten, H.O., "Time Dependent Neutron and Photon Dose-Field Analysis," LA-14245-T, Los Alamos National Laboratory, 2005.

8. Hirayama, H., "Calculation of Gamma-ray Exposure Buildup Factors up to $40 \mathrm{mfp}$ Using the EGS4 Monte Carlo Code with a Particle Splitting," J. Nucl. Sci. Tech., 32, 12, 1201-1207, 1995.

9. Chibani, 0., "New Photon Buildup Factors," Nic. Sci. Eng., 137, $215-225,200 \mathrm{~L}$.

10. Shimizu, A., Hirayama, H., "Calculation of Gamma-Ray Buildup Factors up to Depths of $100 \mathrm{mfp}$ by the Method of Invariant Embedding, (II),"J. Ntcl. Sci. Tech., 40, 4, 192-200, 2003 .

11. Faw, R.E., Shultis, J.K., Radiological Assessment: Sources and Doses, American Nuclear Society, La Grange Park, Il., 1999.

12. Alcouffe, R., Baker, R., Tumer, S., Dah1, J., "PARTISN Manual," LA-UR-02-S633, Los Alamos National Laboratory, 2002. 
13. Lamarsh, J.R., Baratta, A.J., Introduction to Nuclear Engineering, Third Edition, Prentice Hall, New Jersey, 2001.

14. Cullen, D., Hubbell, J., Kisssel, L., "EPDL97: The Evaluated Photon Data Library, '97 Version," UCRL-50400 Vol. 6 Rev. 5, University of California, 1997.

15. MacFarlane, R., Muir, D., "The NJOY Nuclear Data Processing System, Version 91," LA-12740-M, Los Alamos National Laboratory, 1994.

16. Daskalov, G., et. al., "Two-Dimensional Discrete-ordinates Photon Transport Calculations for Brachytherapy Dosimetry Applications," Nuc. Sci. Eng. 134, $121-134,2000$.

17. Kitsos, S., et. al., "Improvement of Gamma-Ray $S_{\mathrm{V}}$ Transport Calculations Including Coherent and Incoherent Scatterings and Secondary Sources of Bremsstrahlung and Florescence: Determination of Gamma-Ray Buildup Factors," Nucl. Sci. Eng., 123, 215-217, 1996.

18. Lorence, Jr., L., Morel, J., Valdez, G., "Physics Guide to CEPXS: A Multigroup Coupled Electron-Photon Cross-Section Generating Code, version 1.0," SAND89-1685, Sandia National Laboratories, 1989.

19. Biggs, F., Lighthill, R., "Analytical Approximations for X-ray Cross Sections," SC-RR-452, Sandia Laboratories, 1967.

20. Biggs, F., Lighthill, R. "Analytical Approximations for Total Pair-Production Cross Sections," SC-RR-68-619, Sandia Laboratories, 1968.

21. Halbieb, J., Mehlhom, T., "ITS: The Integrated TIGER Series of Coupled Electron/Photon Monte Carlo Transport Codes," SAND-84-0573, Sandia National Laboratories, 1984.

22. Kim, S., "Gauss-Lobatto F77Code," Department of Mathematics, University of Kentucky," http:/www.ms.uky edu/ $\sim$ skim/GRADE/basic.html, 2004.

23. Berger, M.J., Hubbell, J.H., Seltzer, S.M., Coursey, J.S., Zucker, D.S., "XCYM: Photon Cross Sections Database," http//physics.nist.gov/PhysRefData/Xcom/Text/XCOM.html, 1999.

24. International Commission on Radiological Protection, "Conversion Coefficients for use in Radiological Protection against External Radiation," ICRP Publication 74, Pergamon Press, Oxford, 1997.

25. White, M., "Photoatomic Data Library MCPLIB04: A New Photoatomic Library Based on Data from ENDF/B-VI Release 8," LA-UR-03-1019, Los Alamos National Laboratory, 2003 
26. Foumie, E.M. and Chilton, A.B., "Gamma-Ray Buildup Factors for Concrete Slab Shields Under Slant Incident Conditions," Nwcl. Sci. Eng. 76, 66-69, 1980.

27. American National Standards Institute, "American National Standard for GammaRay Attenuation Coefficients and Buildup Factors for Engineering Materials," Report ANSI/ANS-6.4.3-1991, American Nuclear Society, La Grange Park, Il., l991.

28. Chen, M., "Transmission and Reflection of Gamma and X-rays lncident on Shielding Slabs: Detailed Treatment of Fluorescence and Bremsstrahlung," $\mathrm{Ph.D}$. Dissertation, Kansas State University, 1993.

29. Chen, M.F., and Faw, R.E., "Build-up Factors for Gamma Rays Obliquely Incident on Slab Shields of Concrete, Iron, and Lead," Rod. Prot. Dosim., 51, 27-33, 1994.

30. Kitsos, S., et. al., "Determination of Point Isotropic Buildup Factors of Gamma Rays Including Incoherent and Coherent Scattering for Alumimum, Iron, Lead, and Water by the Discrete-ordinates Method," Nucl. Sci. Fng. 117, 47-66, 1994. 


\title{
9. APPENDICES
}

The following appendices are the compilation of the PARTISN and MCNPX buildup factors for all nine glovebox materials over the energy range of $10 \mathrm{MeV}$ to $10 \mathrm{keV}$ that will be implemented into the Pandemonium 2.0. a code. This section also incorporates the comparison of previous exposure buildup factors by different authors and a sample input file for the four different codes necessary in this research.

\author{
APPENDIX A: PARTISN BUILDUP FACTORS TABLES \\ APPENDIX B: MCNPX BUILDUP FACTORS TABLES \\ APPENDIX C: EXPOSURE BULDUP FACTOR COMPARISONS \\ APPENDIX D: SAMPLE INPUT FILES FOR CODES \\ D. 1 PARTISN sample input file \\ D. 2 MCNPX sample input file \\ D. 3 NJOY sample input file \\ D. 4 CEPXS sample input file
}


This repori has been reproduced diectly from the best avalable copy it is avalabte electroncally on the heb (http itwww doe gow/bndge)

Copaes are avalkable for sale to $U S$ Department

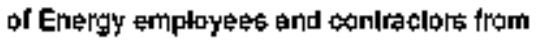
Othoe of Scienilific and Technical Informaton PO Box 62

Oak Rodge, TN 37031

(665) 576-8401

Copoes are ayaltable for galle to the publuc from National Technical Information Service

US Department of Commerce

5285 Porl Royal Road

Springlield, VA 22161

$(800) 553-6847$ 


\section{Los Alamos}

NATIONAL LABORATORY

EST. 1943 